\title{
Techniques for Multivariate Sample Design
}

M. A. Williamson

April 1990

Prepared for the

Energy Information Administration

U.S. Department of Energy under Contract DE-AC06-76RLO 1830

Pacific Northwest Laboratory

Operated for the U.S. Department of Energy

by Battelle Memorial Institute 


\title{
DISCLAIMER
}

This report was prepared as an account of work sponsored by an agency of the United States Government. Neither the United States Government nor any agency thereof, nor Battelle Memorial Institute, nor any of their employees, makes any warranty, expressed or implied, or assumes any legal liabilty or responsibility for the accuracy, completeness, or usefulness of any information, apparatus, product, or process disclosed, or represents that its use would not infringe privateby owned rights. Reference herein to any specific commercial product, process, or service by trade name, trademark, manufacturer, or otherwise, does not necessarily constitute or imply its endorsement, recommendation, or favoring by the United States Government of any agency thereof, or Battelle Memorial Institute. The views and opinions of authors expressed herein do not necessarily state or reflect those of the United States Government or any agency thereof.

\author{
PACIFIC NORTHWEST LABORATORY \\ operated by \\ BATTELLE MEMORIAL INSTITUTE \\ for the \\ UNITED STATES DEPARTMENT OF ENERGY \\ under Contract DE-ACO6-76RLO 1830
}

Printed in the United States of America

Available to DOE and DOE contractors from the

Office of Scientific and Technical Information, P.O. Box 62, Oak Ridge, TN 37831; prices available from (615) 576-8401. FTS 626-8401.

Available to the public from the National Technical Information Service, U.S. Department of Commerce, 5285 Port Royal Rd., Springfieid, vA 22161.

NTIS Price Codes, Microfiche An1

Printed Copy

\begin{tabular}{cr}
\hline Price Code & Page Range \\
\hline A02 & $1-10$ \\
A03 & $11-50$ \\
A04 & $51-75$ \\
A05 & $76-100$ \\
A06 & $101-125$ \\
A07 & $126-150$ \\
A08 & $151-175$ \\
A09 & $176-200$ \\
A10 & $201-225$ \\
A11 & $226-250$ \\
A12 & $251-275$ \\
A73 & $276-300$ \\
A14 & $301-325$
\end{tabular}

\begin{tabular}{cc}
\hline Price Code & Page Range \\
\hline A15 & $326-350$ \\
A16 & $351-375$ \\
A17 & $376-400$ \\
A18 & $401-425$ \\
A19 & $426-450$ \\
A20 & $451-475$ \\
A21 & $476-500$ \\
A22 & $501-525$ \\
A23 & $526-550$ \\
A24 & $551-575$ \\
A25 & $576-600$ \\
A99 & $601-U p$
\end{tabular}


PNL -7338

UC -950

TECHNIQUES FOR MULTIVARIATE SAMPLE DESIGN

M. A. Williamson

Apri1 1990

Prepared for the

Energy Information Administration

U.S. Department of Energy

under Contract DE-ACO6-76RLO 1830

Pacific Northwest Laboratory

Richland, Washington 99352 


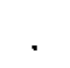




\section{EXECUT IVE SUMMARY}

In this report we consider various techniques for multivariate sample design with potential application to the multiproduct Annual Fuel $0 i 1$ and Kerosene Sales Report (EIA-821) Survey. A review of the current multiproduct sampling (MPS) procedure is presented, and new results useful for Monte Carlo estimation of its company selection probabilities are derived. In addition, an alternative estimator is suggested for use with the MPS technique, and its statistical properties are discussed. Using the alternative estimator, the bias resulting from the use of estimated rather than known company selection probabilities is quantified.

Two new sampling techniques, one based on proportional cell allotment (PCA) and the other on iterative proportional fitting (IPF), are described and their implementation illustrated for bivariate designs. Empirical evidence is cited which indicates that the readily determined selection probabilities for PCA and IPF sampling may be used to approximate the unknown MPS selection probabilities. A comparison of expected sample sizes and sample weights based on the 1989 EIA-821 data is provided. 


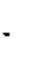




\section{CONTENTS}

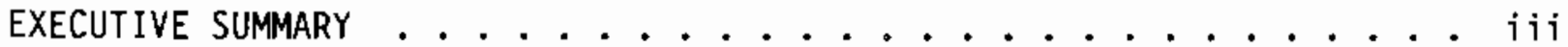

1.0 BACKGROUND . . . . . . . . . . . . . . . . . . . . . . . . 1

1.1 THE ANNUAL FUEL OIL AND KEROSENE SALES REPORT . . . . . . . 1

1.2 DETERMINATION OF SAMPLE QUOTAS . . . . . . . . . . . 1

1.3 Tabular Representation of the SAMPle frame . . . . . . . . 2

1.4 OVERVIEW AND SCOPE ............................. 2

2.0 LiteratuRE REVIEW . . . . . . . . . . . . . . . . . . . 5

2.1 HISTORICAL TECHNIQUES FOR MULTIVARIATE SAMPLE DESIGN . . . . 5

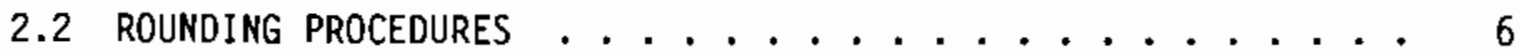

2.3 IPF TECHNIQUES FOR MULTIVARIATE SAMPLE DESIGN $\ldots \ldots$

3.0 MULTIPRODUCT SAMPLING . . . . . . . . . . . . . . . . 11

3.1 LINKED SAMPLE SELECTION . . . . . . . . . . . . . 11

3.1.1 Procedure . . . . . . . . . . . . . . . 11

3.1.2 Properties .................. 11

3.1.3 Inclusion Probability Bounds . . . . . . . . . 12

3.1.4 Adaptive Linked Sample Selection . . . . . . . . 13

3.2 ESTIMATION OF COMPANY INCLUSION PROBABILITIES . . . . . . . 15

3.3 ESTIMATION OF PRODUCT VOLUMES . . . . . . . . . . . . 18

3.3.1 The Adjusted Probability Estimator . . . . . . . 18

3.3.2 A Horvitz-Thompson Type Estimator .......... 20

4.0 PROPORTIONAL CELL ALLOTMENT SAMPLING . . . . . . . . . . . . . 25

4.1 BIVARIATE APPLICATION OF PCA SAMPLING . . . . . . . . 25

4.2 ESTIMATION OF PRODUCT VOLUMES . . . . . . . . . . . . 28

4.3 PCA REDUCTION . . . . . . . . . . . . . . . . 29 
5.0 ITERATIVE PROPORTIONAL FITTING SAMPLING ........... 33

5.1 BIVARIATE APPLICATION OF IPF SAMPLING ......... 33

5.1 .1 Background ................. 33

5.1 .2 Iterative IPF .................. 35

5.1.3 Generalized Iterative Fitting ......... 38

5.2 A PRIORI ADJUSTMENT OF THE INITIAL UNIVARIATE QUOTAS . . . 38

5.2.1 Proportional Adjustment ............ 38

5.2 .2 PCA Adjustment . . . . . . . . . . . 39

5.2 .3 MPS Adjustment ............... 39

5.2 .4 Iterative Quota Adjustment .......... 40

5.2 .5 Recommendations.............. . . 44

5.3 ESTIMATION OF PRODUCT VOLUMES ................. 44

6.0 IMPUTATION FOR CELL NONRESPONSE ............. 45

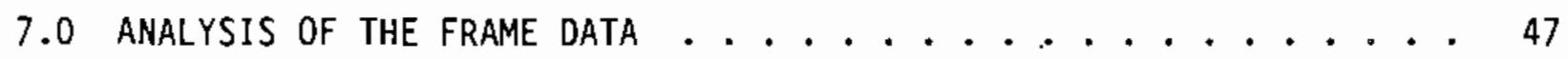

7.1 SUMMARY OF THE METHODS EMPLOYED . . . . . . . . . 47

7.1 .1 MPS Sampling ...................... 47

7.1 .2 PCA Sampling ...................... 48

7.1 .3 IPF Sampling ................. 48

7.1.4 Nonequality of MPS, PCA, and IPF Sample Weights ... 49

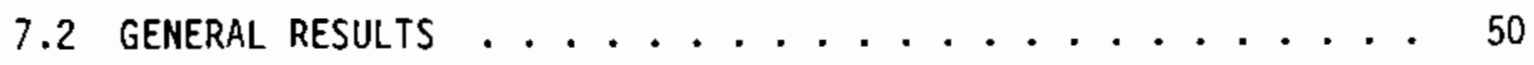

7.2.1 Overview of the Analyses .......... 50

7.2 .2 New York Results ................ 55

7.2 .3 California Results ................ 59

7.2 .4 Pennsylvania Results .............. 64 
7.2 .5 Massachusetts Results ............ 70

7.2 .6 Georgia Results.............. 75

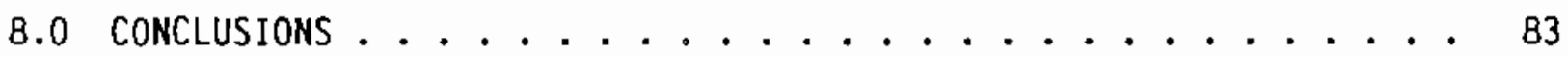

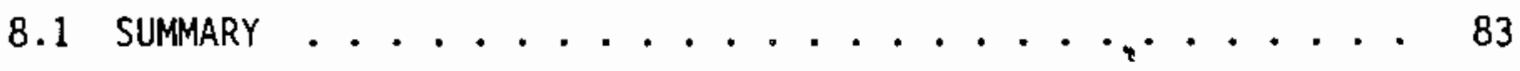

8.2 TOPICS FOR FUTURE STUDY ................... 84

9.0 REFERENCES . . . . . . . . . . . . . . . . 87

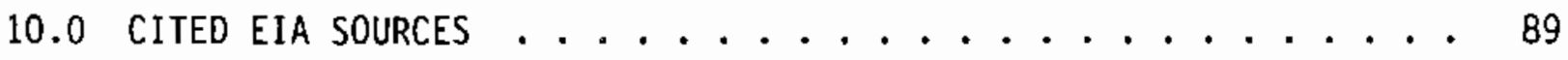




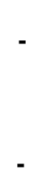




\section{TABLES}

1. New York Frame . . . . . . . . . . . . . . . . 56

2. Reduced NY Frame . . . . . . . . . . . . . . . 59

3. California Frame ....................... 61

4. Reduced CA Frame . . . . . . . . . . . . . . . 64

5. Pennsylvania Frame . . . . . . . . . . . . . . . . . . 66

6. Reduced PA Frame ................... . . 70

7. Massachusetts Frame . . . . . . . . . . . . . 72

8. Reduced MA Frame . . . . . . . . . . . . . . . . . 75

9. Georgia Frame . . . . . . . . . . . . . . . . . . 77

10. Reduced GA Frame . . . . . . . . . . . . . . . 79 


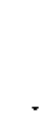




\subsection{BACKGROUND}

\subsection{THE ANNUAL FUEL OIL AND KEROSENE SALES REPORT}

In this report we consider sampling methods applicable to the multiproduct Annual Fuel $0 \mathrm{il}$ and Kerosene Sales Report (Form EIA-821) Survey. For years prior to 1989, the purpose of the survey was to produce state-level estimates of total sales volumes for each of five target variables: residential no. 2 distillate, other retail no. 2 distillate, wholesale no. 2 distillate, retail residual, and wholesale residual. For the year 1989, the other retail no. 2 distillate and wholesale no. 2 distillate variables were replaced by a new variable defined to be the maximum of the two. The strata for this variable (Section 1.2) were crossed with the strata for the residential no. 2 distillate variable, resulting in a single stratified no. 2 distillate variable. Estimation for 1989 focused on the single no. 2 distillate variable and the two residual variables. Sampling accuracy requirements for each product were specified in terms of the coefficients of variation (CVs) for the various estimates based on data taken from recent surveys.

The target population for the Form EIA-821 survey includes companies that deliver or sell fuel oil or kerosene to end-users. The Petroleum Product Sales Identification Survey (Form EIA-863) data base and numerous state and commercial lists provide the basis of the sampling frame, which is updated as new data become available. In addition, company/state-level volumes for distillate fuel oil, residual fuel oil, and motor gasoline are added to aid the design and selection process.

\subsection{DETERMINATION OF SAMPLE QUOTAS}

Certain companies are selected with certainty, including: refiners, companies doing business in four or more states, companies whose market share is more than $5 \%$ for any one of the five target variables, presumed kerosene sellers, supplemental vessel bunkering companies, and petroleum suppliers to electrical utilities. Except for certainty companies and out-of-scope firms, establishments are stratified volumetrically for each of the five target variables. These strata are specific to both product and state, with one to 
three nonzero-volume strata (high, medium, and low) and one zero-volume stratum per product. The boundaries of the nonzero strata are determined empirically using the Dalenius-Hodges minimum variance stratification procedure (see Cochran 1977; Dalenius and Hodges 1959). In addition to the volumetric strata, one additional stratum is created for nonrespondents.

Given the target CVs, the sample allocations, or quotas, for the nonzero strata are generated according to a Neyman (1934) allocation algorithm, using empirically adjusted strata standard deviations based on the volumetric data in the data base. Nominal quotas are set for the zero-volume and nonrespondent strata. Throughout this paper we will refer to the entire set of quotas generated by the process just described as the "initial univariate quotas." It should be noted for later reference that since the quotas for the volumetric strata are determined univariately, they may not be equal for each variable.

\subsection{TABULAR REPRESENTATION OF THE SAMPLE FRAME}

Given either method (i.e., 1989 or pre-1989) for determining sample quotas, it is convenient to represent the EIA-821 sampling frame as a multidimensional contingency table. Letting $J_{j}$ denote the number of strata corresponding to product $i$, we obtain a $\Pi \mathrm{J}_{j}$ table with $\Pi \mathrm{J}_{i}$ cross-strata cells and $\Sigma_{j} J_{j}$ marginal totals. All frame cell sizes are assumed to be known. Note that this table is necessarily incomplete, since the cell corresponding to the intersection of the zero strata is empty. Additional cells may be empty as well.

\subsection{OVERVIEW AND SCOPE}

Given the structure of the EIA-821 sample frame described in Section 1.3 and the quota specification procedure described in Section 1.2, it is not obvious how to construct an efficient sampling mechanism which will meet or exceed the initial univariate quotas, keep the overall sample size small, and exhibit easily described sampling properties. The procedure currently in use, referred to below as multiproduct sampling (MPS), appears to be reasonably efficient and easy to implement, but suffers because its statistical properties are not well understood. Similar techniques, also described below, whose 
statistical properties are more readily inferred, are more difficult to implement - particularly beyond the bivariate case.

In the remainder of this document we consider techniques for multivariate sample design with potential application to the Annual Fuel $0 i 1$ and Kerosene Sales Report (EIA-821) Survey. Section 2 summarizes techniques which have appeared in the literature. Section 3 reviews the multiproduct sampling (MPS) and estimation procedures currently in use and expands the current state of knowledge regarding its statistical properties. In Section 4 the closely related proportional cell allotment (PCA) is introduced. Section 5 contains a description of a technique based on iterative proportional fitting (IPF). In Section 6, imputation for cell nonresponse is discussed. A comparison of the MPS, PCA, and IPF techniques based on analysis of the frame data from the 1989 survey is the subject of Section 7. Finally, in Section 8 , we state some conclusions suggested by this work. 


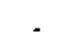

- 


\subsection{LITERATURE REVIEW}

A primary goal of sample survey design is to develop methods of sample selection and estimation which provide estimates of suitable precision at a reasonable cost. Depending on the needs of a particular survey, this may involve minimizing the cost incurred in achieving a specified degree of precision or maximizing precision for a fixed cost. Numerous techniques have been described for balancing precision and cost in the estimation of parameters associated with a single variable. Much less has been written regarding the multivariate case, despite the fact that most surveys are concerned with the estimation of parameters related to two or more variables.

\subsection{HISTORICAL TECHNIQUES FOR MULTIVARIATE SAMPLE DESIGN}

Various authors have considered techniques for stratified random sampling from a two-way cross-stratified frame. Tepping et al. (1943) described a technique called deep stratification, wherein the Latin square principle is applied to reduce the number of sample units. The effectiveness of the designs was greatest when cell sizes were equal. In designs involving unequal cell sizes, which are typical of EIA applications, substantial bias was sometimes observed. Variances of estimates under deep stratification were generally, but not always, less than under simple random sampling.

Goodman and Kish (1950) proposed a scheme they called controlled selection, which increased the probability of selection of "preferred combinations of units." While this is conceptually applicable to a wide range of problems, the technique suffers from its complexity and lack of an internal estimate of sampling error.

Kokan (1963) and Kokan and Kahn (1967) described the determination of cell quotas using nonlinear programming techniques. Variance estimation required the allocation of at least two sampling units per cell; however, this resulted in excessive sample sizes when the number of cells was large.

Bryant et al. (1960) considered design and estimation for a population stratified according to an $r \times c$ contingency table. Population cell sizes 
were assumed to be known and nonzero. A total sample of size $n$ satisfying $\max \{r, c\} \leq n \leq r c$ was allocated to the rows and columns in a manner proportional to $P_{i .}=N_{i} / N$ and $P_{. j}=N_{. j}$, the row and column proportions for the population. A method was then devised for allocating random (nonnegative integer) sample sizes $n_{i j}$ to individual cells satisfying $E\left(n_{i j}\right)=n P_{j} \cdot P_{\cdot j}$. (the expected cell sizes when the rows and columns are independent) and the marginal constraints. Estimation of population means was based on simple random sampling within cells, given the $n_{i j}$.

Since the method of Bryant et al. allocated the $n_{i j}$ without regard to the corresponding population counts. $\mathrm{N}_{i j}$, increased variances were sometimes observed when the $E\left(n_{i j}\right)$ differed markedly from the $N_{i j}$, as may be the case when the rows and columns are not independent. To mitigate this problem, the authors devised a scheme whereby a portion of the sample was assigned with certainty to cells in which the discrepancy between the population and (expected) sample cell proportions was large. The assignment procedure was designed to reduce these discrepancies.

The method of Bryant et al. (1960) suffers from a number of limitations which preclude direct application to EIA surveys. First, the method is not applicable to the incomplete tables which often result from multiway stratifications. Second, no general algorithm was suggested for the rounding of fractional sample sizes. Third, extension beyond the two dimensional case was not considered. Fourth, while the method can accomnodate deviations from independence ( $i . e ., P_{i j}=P_{i} . P . j$ ) using the certainty assignments, Winkler (1987a) has pointed out that this adjustment works well only when the deviations are small. Finally, although Bryant et al. were able to define a number of potential estimators and their variances, sample estimation of these variances was somewhat restrictive in that the within-cell variances were assumed to be constant across cells.

\subsection{ROUNDING PROCEDURES}

As noted in the previous section, the method of Bryant et a1. may result in the specification of noninteger cell quotas. When a large number of cell quotas lie between zero and one, as will often be the case in highly 
stratified designs, a formal rounding procedure may be required. Simple truncation of such quotas may lead to biasing, since nonempty population cells with zero quotas have no chance of being sampled. On the other hand, rounding such quotas to 1 may increase the overall sample size unnecessarily. In such cases, a random rounding procedure with desirable properties may constitute a suitable compromise. Several authors have considered such procedures.

Jessen (1970) described empirical methods for dealing with some of the limitations of the Bryant et al. approach. The portion of a sample of size $n$ allocated to the $i, j$ th cell was $n P_{i j}$, thus forcing $n_{i j}=0$ whenever $P_{i j}=0$. For specific two-way tables with integer marginal quotas and noninteger cell quotas, Jessen described techniques for probabilistically selecting anong "feasible" tables (i.e., integer tables with the desired margins) in order to assure $E\left(n_{i j}\right)=n P_{i j}$. He was unable to meet all constraints in a three-way example, and did not give general algorithms even for the two-way case.

Causey et al. (1985) used a transportation model developed by Cox and Ernst (1982) to address the rounding problem for two-way tables. Given a population partitioned by an $r \times c$ table, a fixed total sample size $n$, and an $r \times c$ array $S=\left(s_{i j}\right)$ denoting the non-rounded sampling quotas in the ijth cell, they recursively defined a sequence $N_{1}, \ldots, N_{s}$ of zero-restricted controlled roundings of $S$ and an associated sequence of probabilities p1, .... $p_{s}$ satisfying $\Sigma_{j} p_{i}=1$ and $\Sigma_{j} p_{j} N_{j}=S$. As defined by Causey et al. (1985), a zero-restricted controlled rounding $R$ for $S$ is an $r \times c$ matrix which preserves the margins of $S$ and for which each $r_{i j}$ is an integer satisfying $\left|r_{i j}-s_{i j}\right|<1$. A rounding $R$ of $S$ is randomly selected so that $P\left(R=N_{j}\right)=$ $P_{i}$, resulting in $E(R)=S$.

The Causey et al. (1985) approach suffers from two primary disadvantages. First, significant computation may be required to produce the required sequences. Second, the algorithm presented is not fully constructive in that the sequence $N_{j}$ is defined recursively, and no algorithm is provided for obtaining $\mathbf{N}_{1}$.

Cox (1987) presented a constructive algorithm for achieving unbiased zerorestricted controlled rounding in two-way tables. Given a two-way table 


$$
A=\begin{array}{c|c}
\left(a_{i j}\right)_{m \times n} & \left(a_{i}, n+1\right)_{m \times 1} \\
\hline\left(a_{m+1}, j\right)_{1 \times n} & \left(a_{m+1, n+1}\right)_{1 \times 1}
\end{array}
$$

with real cell entries $a_{i j}$ and row, column and grand entries $a_{i, n+1}, a_{m+1}, j$, and $a_{m+1}, n+1$, respectively, Cox specified a constructive rounding procedure to produce a rounded table $R(A)$, for which satisfies the following for every a $\in$ A:

1. CONTROLLED ROUNDING: $R(a)=[a]$ or $[a]+1$.

2. ADDITIVITY: $R(A)$ is additive; i.e., the margins of $R(A)$ can be obtained by summing the corresponding entries.

3. ZERO-RESTRICTION: $|R(a)-a|<1$.

4. UNBIASEDNESS: $E(R(a))=a$.

The final rounded array is constructed directly from $A$ rather than from a set of rounded arrays, as is the case in the procedures described by Causey et al. (1985) and Winkler $(1987 a, b)$. Regarding generalization to higher order tables, the author cited an example from Causey et al. to show that extension to three-way tables is not possible.

\subsection{IPF TECHNIQUES FOR MULTIVARIATE SAMPLE DESIGN}

Work by Winkler (1987a,b) focused on three aspects of multivariate sample design: allocation of the marginal quotas among cross-strata cells, rounding of noninteger cell quotas, and development of estimators for quantities of interest. Winkler suggested the use of a form of iterative proportional fitting (IPF) for allocation of the marginal quotas among the cross-strata cells.

IPF was originally introduced by Deming and Stephan (1940) as a method for estimating the cell probabilities $\pi i j$ of an $r \times c$ contingency table for which the population marginal probabilities $P_{i}$. and $P_{. j}$ are known and fixed, given a sample of $n$ observations on the table. The problem arose from situations where sample data required adjustment for consistency with data obtained from 
other sources (e.g., for the 1940 census). Ireland and KuTlback (1968) showed that the IPF procedure is convergent and that the estimates for the $\mathrm{P}_{i j}$ are maximum likelihood (MLE), best asymptotic normal (BAN), and minimize the discrimination information $\Sigma_{j} \Sigma_{j} P_{i j} \ln \left(P_{i j} / \pi_{j j}\right)$ (Kullback 1959), where $\pi_{j j}$ is the cell proportion for the ijth cell in the sample table. Furthermore, it was noted that the technique also applies to multiway tables of dimension greater than two.

In Winkler's $(1987 a, b)$ application of IPF, the roles of population and sample were reversed; that is, the population cell counts ( $N_{i j}$ ) were specified, as were the marginal counts $n_{i}$, and $n_{. j}$ of the sample table, and it was of interest to obtain (typically noninteger) cell entries ( $n_{i j}$ ) satisfying $\Sigma_{j} n_{i j}=n_{i}$. and $\Sigma_{i} n_{i j}=n_{. j}$. IPF represented an attractive method for completing the sample table, since it minimizes the discrimination information and preserves the interaction structure of the population table (Bishop et al. 1975). Because IPF can yield sample allocations which can exceed the population counts, Winkler recommended the use of Dykstra's (1985a,b) generalized iterative fitting procedure (GIFP), which allowed the introduction of convex constraints (in this case $n_{i j} \leq N_{i j}$ ). Winkler was unable to show, however, that Dykstra's procedure guarantees a solution in all cases (Winkler 1986; Dykstra 1986).

An alternative procedure which appears promising involves an iterative application of IPF. If, after any application of IPF, one or more cell sample sizes exceed their corresponding population cell counts, it is assumed that the cells will be sampled in entirety. The row and column quotas corresponding to such a cell are then reduced by an amount equal to the population count for the cell. The population count for the cell is then set to zero, and IPF is applied again using the adjusted quotas. When an application of IPF yields cell sample sizes which do not exceed the population cell counts, the procedure is terminated.

Whether one uses the GIFP approach or the iterative IPF (IIPF) procedure described above, the fitted cell quotas will typically be fractional rather than integer values; thus, some method of rounding must be applied. Winkler (1987a), following the approach of Causey et al. (1985), suggested the 
specification of a sequence of nonnegative integer matrices $M_{j}$ with identical integer margins, together with a sequence of corresponding probabilities $p_{i}$, satisfying $\Sigma_{j} p_{i}=1$ and $\Sigma_{j} p_{j} M_{j}=S$, where $S$ is the fitted sample quota matrix. Winkler did not specify conditions under which such sequences exist, but hypothesized that an iterative integer linear programming procedure could be used to generate the sequences in most cases. His attempts at generating such sequences for specific examples indicated that the process would not be easily mechanized, as heuristic readjustment of margins and other manual intervention was often required.

winkler (1987b) also considered parameter and variance estimation under his IPF sampling scheme. He viewed the procedure as consisting of two stages: (1) selection of a random rounding matrix $R=\left(r_{j}\right)$, indexed here by a single index $j$, such that $P\left(R=M_{i}\right)=p_{i}$, followed by (2) simple random sampling within cells, according to the quotas specified in R. He defined the following unbiased estimator for the population total T:

$$
T^{\star}=\sum_{\substack{r j \neq 0 \\ s j \neq 0}}\left(r_{j} / s_{j}\right) Y_{j}{ }^{\star},
$$

where the $s_{j}$ represent the cell sample quotas obtained from IPF or GIFP, and $Y_{j}{ }^{*}$ is an unbiased estimate of the population cell total (e.g., $Y_{j}^{*}=N_{j} \bar{y}$, where $\bar{y}$ denotes the cell sample average and $N_{j}$ denotes the population count for cell $j$. 


\subsection{MULTIPRODUCT SAMPLING}

\subsection{LINKED SAMPLE SELECTION}

\section{1 .1 Procedure}

We will use the phrase "multiproduct sampling" (MPS) to describe a simplified version of the sampling procedure currently used by the EIA for the EIA-821 survey. Under MPS, a linked sample selection procedure is used to draw the actual sample. The simplification made here is to assume that the procedure is carried out independently for each state. In fact, multistate companies which are not selected with certainty sometimes appear in a state's sample only because they were chosen in another state's sample.

To implement the simplified procedure, all eligible companies are arranged in random order. Companies are then selected sequentially from the list until all initial univariate quotas are filled. Any given company is included in exactly one stratum per product. If, at the time of its selection, at least one of the quotas for a company's strata remains unfilled, the company is placed in the sample. If, on the other hand, all of a company's associated quotas have previously been filled, the company is excluded from the sample.

\section{1 .2 Properties}

As described, the linked sample selection procedure enjoys two important properties. First, given the achieved cell sample size, sampling within cells is simple random. Second, until achieving the initial univariate quota, sampling within a stratum is simple random. These properties give rise to results which will be useful in subsequent analyses. Simple random sampling within cells implies that company inclusion probabilities are constant within cells. Simple random sampling within strata guarantees that the sampling mechanism is appropriate for achievement of the target coefficients of variation (Section 1.1) and that the company inclusion probabilities are bounded as described in Section 3.1.3. 


\subsubsection{Inclusion Probability Bounds}

In this section we establish bounds for the company inclusion probabilities under MPS sampling. These bounds will be useful for determining the number $M$ of Monte Carlo trials required to estimate the company inclusion probabilities (Section 3.3.2) and for motivating an alternative sampling procedure to be described in Section 4. We will also see empirical evidence (Section 7) that these bounds provide good approximations for the MPS inclusion probabilities. For notational convenience, we consider only the two product case, and establish that:

$$
P_{i j} \geq \max \left\{q_{1 i} / N_{i}, q_{2 j} / N_{. j}\right\} \text {. }
$$

where $\quad P_{j j}=$ the inclusion probability for the $i j$ th cell (i.e., the cell corresponding to the intersection of the ith stratum for product 1 and the jth stratum for product 2 .

$N_{i j}=$ the population count for the $i j$ th cell

$q 1 i$ = the initial univariate quota for the ith stratum of product 1

$92 j=$ the initial univariate quota for the $j$ th stratum of product 2

To establish the desired inequality, let $T_{k}, 1 \leq k \leq q 1 i$, denote the draw in which the $k$ th company is selected from stratum $i$ of product 1 . Define $Z_{t}$, $t=1,2,3, \ldots, N_{.}$. to be 1 if a company is selected from stratum $i$ of product 1 and stratum $j$ of product 2 on draw $t$, and 0 otherwise. Then,

$$
\begin{aligned}
N_{i j} P_{i j} & =E\left(\Sigma_{t} Z_{t}\right) \\
& \geq E\left(\Sigma_{k} Z_{T_{k}}\right) \\
& =q_{1}\left(N_{j j} / N_{i} .\right) .
\end{aligned}
$$

The final equality obtains since $\Sigma_{k} Z_{T_{k}}$ follows a hypergeometric distribution with mean $q_{1 i}\left(\mathrm{~N}_{i j} / \mathrm{N}_{i}.\right)$. This establishes $\mathrm{P}_{i j} \geq q_{1 i} / \mathrm{N}_{i}$. . Similarly, $P_{i j} \geq 92 j / N . j$. The same arguments can be applied to each of m products to show 
that each cell inclusion probability is bounded below by the maximum of the initial univariate sampling fractions for its crossed strata.

\subsubsection{Adaptive Linked Sample Selection}

Small selection probabilities for companies in certain cells may be problematic. For example, when achievement of the pre-specified univariate quotas requires near depletion of some cross-strata cells, while other cells remain relatively large, random selection makes it increasingly difficult to choose companies from the shrinking cells. This situation may lead to an unnecessarily large overall sample size. A heuristic procedure which may lead to smaller sample sizes is described below. At its current stage of development, the procedure is presented as a topic for future research. A simulation study would be required to determine the magnitude of any sample size reductions which might be achieved using this approach, as well as to determine the statistical properties of any associated estimators.

At each stage of the selection process, a company is drawn with probability proportional to an adaptive measure summarizing need versus availability.

This procedure can be defined as follows. Let:

$$
\begin{aligned}
& W_{c j}=\text { the number of companies remaining in cell c just prior } \\
& \text { to the jth draw } \\
& Q_{k j}=\text { the number of additional companies required to satisfy } \\
& \text { the kth quota just prior to the jth draw }
\end{aligned}
$$

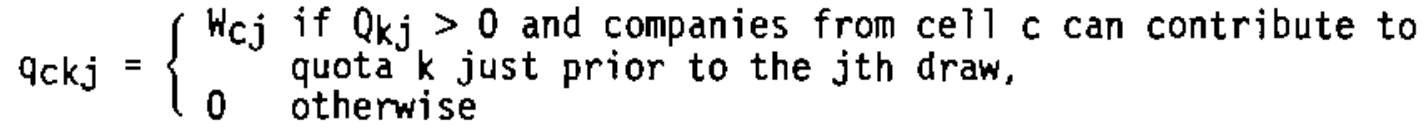

As defined above, $W_{C j}$ represents the total availability of companies in cell c, while qckj represents the availability of companies in cell $c$ for contributing to quota $k$. If quota $k$ has already been filled or cell $c$ does not intersect the stratum to which quota $k$ corresponds, $q c k j=0$. Note that $\Sigma_{c} q_{c k j}$ represents the totality of companies (over all cells) which are available for satisfying quota $k$. Since the quantity $Q_{k j}$ represents the number

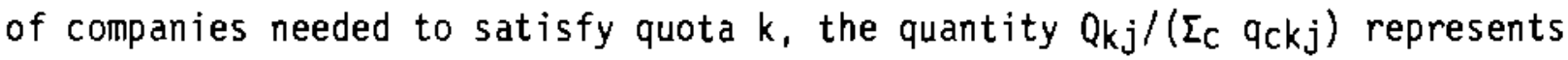


the ratio of total need to total availability for quota $k$, which increases proportional to total need and decreases proportional to total availability. Fixing a cell $c^{\prime}$ and summing over the quotas to which companies in $c^{\prime}$ can contribute ( $i . e .$, quotas $k$ for which that $q_{c}{ }^{\prime} j k>0$ ) yields a measure $S_{C^{\prime}} j$ of the need for companies from cell $c^{\prime}$. This measure is expressed mathematically as:

$$
S_{C^{\prime} j}=\sum_{k: q_{C} k^{\prime} j>0} Q_{k j} /\left(\Sigma_{C} q_{C k j}\right) \text {. }
$$

In the $j$ th draw, a cell $c$ is selected with probability proportional to $S_{c j}$ and a company is then selected at random from cell c.

Example

To illustrate the above procedure, consider the following $2 \times 2$ table of population counts and associated univariate quotas:

$$
\text { POPULATION COUNTS TOTALS QUOTAS }
$$

\begin{tabular}{lrrrr} 
& 2 & 10 & 12 & 3 \\
& 5 & 20 & 25 & 4 \\
\cline { 2 - 5 } TOTALS & 7 & 30 & & \\
QUOTAS & 5 & 6 & &
\end{tabular}

We will number the cells in a clockwise fashion, beginning in the upper lefthand corner of the table. The quota for row $i$ will be referred to as quota $i$ and the quota for column $j$ will be referred to as quota $2+j$. Using these conventions, the following quantities are defined prior to the first draw:

$$
\begin{array}{llllll}
W_{11}=2 & Q_{11}=3 & q 111=2 & q_{121}=0 & q 131=2 & q 141=0 \\
W_{21}=10 & Q_{21}=4 & q 211=10 & q 221=0 & q 231=0 & q 241=10 \\
W_{31}=20 & Q_{31}=5 & q 311=0 & q 321=20 & q 331=0 & q 341=20 \\
W_{41}=5 & Q_{41}=6 & q 411=0 & q 421=5 & q 431=5 & q 441=0 \\
\cline { 3 - 3 } & \Sigma_{c} q_{c k 1} & 12 & 25 & 7 & 30
\end{array}
$$


The above yield the following cell scores:

$$
\begin{aligned}
& \$_{11}=3 / 12+5 / 7=0.9643 \\
& \varsigma_{21}=3 / 12+6 / 30=0.4500 \\
& \$_{31}=4 / 25+6 / 30=0.3600 \\
& S_{41}=4 / 25+5 / 7=0.8743
\end{aligned}
$$

Renormalizing, we choose cells $1,2,3$, and 4 with probabilities 0.3641 , $0.1699,0.1359$, and 0.3301 , respectively. Once a cell has been chosen, a company is selected at random from the cell. The population cell and its corresponding quotas are then reduced by one, and the cell scores recomputed in preparation for selecting a second company. This process is continued until all the initial univariate quotas have been filled.

\subsection{ESTIMATION OF COMPANY INCLUSION PROBABILITIES}

In order to produce estimators of total volume for the products of interest, it is desirable that the company inclusion probabilities be known. Since exact computation of these probabilities is mathematically intractable for MPS sampling, it is necessary to estimate the quantities using Monte Carlo methods. We describe two such methods below.

\section{Method 1}

The first procedure, although described in the 1987 Request for OMB Review of the Petroleum Marketing Program, is no longer used by the EIA. In this scheme, 1001 samples are drawn according to the EIA-821 linked sample selection procedure outlined in Section 3.1.1. If we define

$$
X_{h i j}= \begin{cases}1 & \text { if company } i \text { in stratum } h \text { is drawn in sample } j \\ 0 & \text { otherwise }\end{cases}
$$

then an estimator for the inclusion probability for company $i$ in sratum $h$ is:

$$
\hat{P}_{h i}=(1 / 1001) \Sigma_{j} x_{h i j},
$$


which is binomially distributed with mean $\mathrm{Phi}_{\mathrm{i}}$ and variance

$$
P_{h i}\left(1-P_{h i}\right) / 1001 \text { 。 }
$$

This method has the disadvantage that companies in the same cross-strata cell can have different weights. The current practice is to average the inclusion probabilities of companies within the same cell, which is equivalent to the method described below.

Method 2

The second procedure takes advantage of the fact that each company can be characterized as a member of one, and only one, cross-strata cell, and that for sampling purposes, the companies within a cell are indistinguishable. Consider estimation of the inclusion probability of a company in cell c. Let $\mathrm{N}_{c}$ denote the number of companies in cell c. Assume that $M$ independent samples are to be drawn according to the EIA-821 linked sample selection procedure. Define the random variables:

$$
\begin{aligned}
x_{c i j} & = \begin{cases}1 & \text { if company } i \text { in cell } c \text { is drawn in sample } j \\
0 & \text { otherwise }\end{cases} \\
n_{c j} & =\sum i x_{C i j} \\
& =\text { the number of companies drawn from cell } c \text { in sample } j
\end{aligned}
$$

The inclusion probability $\theta_{c}$ for any company in cell $c$ for sample $j$ is:

$$
\begin{aligned}
\theta_{C} & =P\left(X_{C i 1}=1\right) \\
& =\Sigma_{m} P\left(X_{C i 1}=1 \mid n_{C 1}=m\right) P\left(n_{C 1}=m\right) \\
& =\Sigma_{m}\left(m / N_{C}\right) P\left(n_{C 1}=m\right) \\
& =E\left(n_{C 1}\right) / N_{C} .
\end{aligned}
$$

Using all $M$ independent samples, an unbiased estimator for $\theta_{C}$ is:

$$
\theta_{C}{ }^{\star}=\left(M-1 \Sigma_{j} n_{C j}\right) / N_{C} .
$$


The variance of $B_{C}{ }^{\star}$ is:

$$
\begin{aligned}
V\left(\theta_{C}{ }^{\star}\right) & =\operatorname{Var}\left(n_{C l}\right) /\left[M_{C}^{2}\right] \\
& =\left[E\left(n_{C}{ }^{2}\right)-\left[E\left(n_{C 1}\right)\right]^{2}\right] /\left[M_{C}^{2}\right] \\
& \leq\left[N_{C} E\left(n_{C 1}\right)-\left[E\left(n_{C 1}\right)\right]^{2}\right] /\left[M N_{C}^{2}\right] \\
& =\theta_{C}\left(1-\theta_{C}\right) / M
\end{aligned}
$$

In Section 3.3.2 we will also be interested in the joint inclusion probability $\theta c c$ for two companies $i$ and $i^{\prime}$ ( $i \neq j^{\prime}$ ) in cell $c$; that $i s$, we will require estimates of the probability that companies $i$ and $i$ ' appear in the same sample. Proceeding as above,

$$
\begin{aligned}
\theta_{C C} & =P\left(X_{C i 1} \cdot X_{C i}+1=1\right) \\
& =\Sigma m\left(m^{2}-m\right) /\left(N_{C}^{2}-N_{C}\right) P\left(n_{C}=m\right) \\
& =E\left(n_{C}^{2}-n_{C}\right) /\left(N_{C}^{2}-N_{C}\right),
\end{aligned}
$$

so that an unbiased estimator of $\theta_{C C}$ is:

$$
\theta_{C C}{ }^{\star}=\left[M_{C}\left(N_{C}-1\right)\right]-1 \Sigma_{j} n_{c j}\left(n_{C j}-1\right)
$$

Since $V\left(\theta_{C c}{ }^{*}\right)$ involves third and fourth moments of the random variable ncl, an expression for the quantity would not be particularly useful. A similar analysis shows the joint inclusion probability for company $i$ from cell $c$ and company $i$ ' from cell $c$ ' to be

$$
\theta_{C C^{\prime}}=E\left(n_{C} n_{C}\right) /\left(N_{C} N_{C^{\prime}}\right)
$$

with unbiased estimator:

$$
\theta_{C C^{\prime}}{ }^{*}=\left[M_{C} N_{C^{\prime}}\right]^{-1} \Sigma_{j}\left(n_{C j} n_{C^{\prime}}\right)
$$




\subsection{ESTIMATION OF PRODUCT VOLUMES}

\subsubsection{The Adjusted Probability Estimator}

The adjusted probability estimator $V^{\star}$ (1987 Request for OMB Review of the Petroleum Marketing Program) is the estimator currently used to obtain estimates of total volume for each product. This estimator is defined as:

$$
v^{\star}=\sum_{h} N_{h}\left(\sum_{i=1}^{n h} w_{h i} v_{h i} / \sum_{i=1}^{n h} w_{h i}\right) \text {. }
$$

where $\quad \Sigma_{h}=$ summation over the product strata

$\mathrm{N}_{h}=$ the number of companies in stratum $h$

$n_{h}=$ the number of companies sampled from stratum $h$

$\Sigma_{j}=$ summation over the sampled companies in stratum $h$

Whi $=$ the estimated weight for sampled company $i$ in stratum $h$

$V_{h i}=$ the reported or imputed volume for sampled company $i$ in stratum $h$.

The estimator for $\operatorname{Var}\left(V^{\star}\right)$ currently in use (1989 Petroleum Marketing Annual, p. 417) is:

$$
\hat{\operatorname{Var}}\left(V^{*}\right)=\sum_{h} n_{h}\left(1-\frac{n_{h}}{N_{h}}\right) S h^{2} .
$$

where:

$$
S_{h}^{2}=\frac{\sum_{i=1}^{n h} W_{h i^{2}} V_{h i^{2}}+\bar{V}_{h}^{2} \sum_{i=1}^{n h} W_{h i^{2}}-2 \bar{V}_{h} \sum_{i=1}^{n h} W_{h i^{2}} V_{h}}{\left(n_{h}-1\right)}
$$

and 


$$
\bar{v}_{h}=\frac{\sum_{i=1}^{n h} w_{h i} v_{h i}}{\sum_{i=1}^{n h} w_{h i}}
$$

As defined above, the estimator $V^{*}$ includes both certainty and non-certainty companies. For the sake of simplicity, we will ignore the certainty companies in the remainder of this report, except where specifically noted otherwise.

In the remainder of this section, we will take whi to be $1 / \theta_{c}^{*}$ for the unique cell c containing company $i$ in stratum $h$ (Method 2 of Section 3.2). Because each stratum is partitioned by a finite number of cross-strata cells, $V^{\star}$ may also be written:

$$
V^{*}=\sum_{h}\left\{N_{h}\left[\sum_{c=1}^{C_{h}}\left(\left(1 / \theta h c^{*}\right) \sum_{j=1}^{J h c} t_{h c j} \cdot V_{h c j}\right)\right],\left[\sum_{c=1}^{C_{h}}\left(1 / \theta h c^{*}\right) \sum_{j=1}^{J h c} t_{h c j}\right]\right\},
$$

where

$$
\begin{aligned}
\Sigma_{c}= & \text { summation over cross-strata cells contained in stratum } h \\
C_{h}= & \text { the number of cross-strata cells contained in stratum } h \\
\Sigma_{j}= & \text { summation over companies in cross-stratum } c \text { in stratum } h \\
J_{h c}= & \text { the number of companies in cross-stratum } c \text { in stratum } h \\
\theta_{h c^{*}=} & \text { the estimated selection probability for a company in } \\
& \text { cross-stratum cell } c \text { in stratum } h \\
V_{h c j}= & \text { the reported volume for company } j \text { in cross-stratum } c \text { in } \\
& \text { stratum } h
\end{aligned}
$$

$t_{h c j}=\left\{\begin{array}{l}1 \text { if company } j \text { in cross-stratum cell } c \text { in stratum } h \text { is in the sample, } \\ 0 \text { otherwise. }\end{array}\right.$

From the above expression, it is clear that even if the company selection probabilities were known, exact analysis of the properties of the estimator $V^{*}$ would be difficult. The summand corresponding to a fixed stratum $h$ involves the ratio of two correlated random variables, each of which is 
expressed as a sum of random variables which may also be correlated. Since they may arise due to the necessity of achieving common marginal quotas, correlation of the strata summands is possible as well.

\subsubsection{A Horvitz-Thompson Type Estimator}

Because of the aforementioned difficulties in establishing the statistical properties of the current estimator $V^{*}$, a Horvitz-Thompson like estimator with more easily derived properties is defined as follows:

$$
V_{H T^{*}}=\Sigma_{i}\left(1 / \pi_{i}^{*}\right) t_{i 1} \cdot V_{i}
$$

where:

$\Sigma_{i}=$ summation over all companies in the population

$v_{i}=$ the product volume for company $i$

$t_{i j}= \begin{cases}1 & \text { if company } i \text { is in the } j \text { th Monte Carlo sample } \\ 0 & \text { otherwise }\end{cases}$ $1 / \pi j^{*}=\left\{\begin{array}{l}1 / \theta_{c}{ }^{*} \text { if } \theta_{c}{ }^{\star}>0 \text { for the cross-strata cell } c \text { containing company } i \\ 0 \text { otherwise }\end{array}\right.$

If the company sample upon which the product volume estimates are based is selected independently of the $M$ trial samples generated to produce estimates of the company inclusion probabilities, it is possible that the company sample will contain a company for which $\pi i^{*}=0$. To avoid this difficulty, we assume that the first of the $M$ trial samples used to generate estimates of the company inclusion probabilities is also used to select the company sample.

Note that while $V_{H T^{*}}$ is similar in form to the classical Horvitz-Thompson estimator (Cochran 1977, pp. 259-261), it is not identical. Under the classical definition, the total sample size is fixed, while for $V_{H T}{ }^{*}$ the sample size is random. As a result, not all of the relations and formulae cited by Cochran (1977) hold for $V_{H T^{*}}$ (e.g., relations 9A.36, p. 259). Examination of Cochran's proof of the unbiasedness of the classical estimator reveals that it does not depend upon the fixed sample size property, however. Thus, Cochran's argument shows that $V_{H T} T^{*}$ would be unbiased, if the $\pi_{i}{ }^{*}$ 's were replaced by their true values $\pi i$. In order to determine $E\left(V_{H T} T^{\star}\right)$ using the 
estimates $\pi i^{*}$, we must adapt Cochran's proof appropriately. Following Cochran's lead, we let $t_{i m}$ be a random variable which takes the value 1 if the ith company is chosen in the mth trial, and 0 otherwise. Then:

$$
\begin{aligned}
E\left(V_{H T^{*}}\right) & \left.=\Sigma_{i} E\left\{E\left[\left(1 / \pi_{i}{ }^{*}\right) t_{i 1} \cdot V_{i} \mid t_{i 1}=1\right)\right]\right\} \\
& \left.=\Sigma_{i} E\left\{E\left[\left(1 / x_{j}{ }^{*}\right) t_{i 1} \cdot V_{i} \mid t_{i 1}=1\right)\right]\right\} P\left(t_{i 1}=1\right) .
\end{aligned}
$$

While the above sum is formally over the entire population, use of the random variables $t_{i 1}$ reduces the sum to the specific sample selected. (Recall that the sample chosen on the first simulation trial is used to specify which companies are actually to be in the sample.) Expanding the estimator $\pi_{j}{ }^{*}=$ $\left(t_{i 1}+t_{i 2}+\cdots t_{i M}\right) / M$ and using $P\left(t_{i 1}=1\right)=\pi_{i}$ and $B_{i} \equiv t_{i 2}+\cdots t_{i M} \sim B(M-1, \pi j)$ we have

$$
\begin{aligned}
E\left(V_{H T^{*}}\right) & =\Sigma_{j} E\left\{V_{i} \cdot \pi_{j} \cdot M /\left(1+B_{j}\right)\right\} \\
& =\Sigma_{j} M \pi_{j} V_{j} E\left\{1 /\left(1+B_{j}\right)\right\} .
\end{aligned}
$$

Now

$$
\begin{aligned}
E\{(1 /(1+B i)\} & =\sum_{x=0}^{M-1}\left(\begin{array}{c}
M-1 \\
x
\end{array}\right) \frac{1}{1+x} \pi_{i}^{x}\left(1-\pi_{i}\right)^{M-1-x} \\
& =\frac{1}{M \pi i} \sum_{y=1}^{M}\left(\begin{array}{l}
M \\
y
\end{array}\right) \pi_{i}^{y}\left(1-\pi_{i}\right)^{M-y} \\
& =(M \pi i)^{-1}\left[1-\left(1-\pi_{j}\right)\right]^{M} .
\end{aligned}
$$

Combining the latter two results yields:

$$
E\left(V_{H T}{ }^{*}\right)=\Sigma_{i} V_{i}-\Sigma_{i} V_{i}\left(1-\pi_{j}\right)^{M}
$$

Thus, use of the estimated sampling weights results in a biased estimator with bias $B\left(V_{H T^{*}}\right)=-\Sigma_{j} V_{i}\left(1-\pi_{j}\right) M$. This result can be used as a guide in choosing $M$ in order to reduce the bias to an acceptable level. For example, the bias can be controlled by choosing $M$ to keep the quantities $\left(1-\pi_{j}\right)^{M}$ small, 
and/or by specifying that additional companies be sampled from any cell with a low $\pi i$. Note that using the current value of $M=1000$ appears reasonable for a moderate to large $\pi j$, but is somewhat inadequate for a 5 mall $\pi j$ (e.g., for $\left.\pi_{i}=0.001,(1-\pi j)^{M}=0.37\right)$.

Note that the bounds on the inclusion probabilities developed in Section 2.3 are also useful in the a priori selection of an appropriate value for $M$. If $\left(1-\pi_{i}\right)^{M}<\epsilon$ is desired and the bounds of Section 2.3 show that $\pi_{i} \geq P$, taking $M>\log (\epsilon) / \log (1-P)$ guarantees $(1-\pi j) M<\epsilon$.

Now let $x i j$ denote the joint inclusion probability for companies $i$ and $j$. $\left(\pi_{i j}=\theta_{C C^{\prime}}\right.$ for some $\left.c, c^{\prime}.\right)$ Then the variance of $V_{H} T^{\star}$ can be approximated using (Cochran 1977, p. 260):

$$
V\left(V_{H T^{\star}}\right)=\sum_{i} \frac{\left(1-\pi_{i}^{\star}\right)}{\pi_{i}^{*}} y_{i}{ }^{2}+2 \sum_{i} \sum_{j>i} \frac{\left(\pi_{i j} j^{*}-\pi i^{*} \pi j^{\star}\right)}{\pi i^{*} \pi_{j}^{*}} y_{i} y_{j} .
$$

A sample estimator of $V\left(V_{H T}{ }^{*}\right)$ is:

$\hat{V}\left(V_{H T^{\star}}\right)=\sum_{i} \frac{\left(1-\pi j^{\star}\right)}{\left(\pi i^{\star}\right)^{2}} y_{i} 2 t_{i 1}+2 \sum_{i} \sum_{j>i} \frac{\left(\pi i j^{*}-\pi i^{\star} \pi j^{\star}\right)}{\pi i j^{\star} \pi j^{\star} \pi j^{\star}} y_{i} y_{j} t_{i 1} t_{j 1}$.

The above formulas are only approximations since the $\pi_{i}$ and $\pi_{i j}$ are unknown. Also note that for $V\left(V_{H T}{ }^{*}\right)$, the summation is over the entire population, while for $V\left(V_{H T^{*}}\right)$, the summation is over the sample.

The accuracy requirements for estimated product volumes are expressed in terms of maximum tolerable coefficients of variation (CVs). Because $V_{H T}{ }^{\star}$ is a biased estimator, a more appropriate measure of relative accuracy is the modified $\mathrm{CV}$

$$
C V^{\star}=\left[\operatorname{Var}\left(V_{H T^{\star}}\right)+\mathrm{B}^{2}\left(V_{H T^{*}}\right)\right]^{1 / 2} /\left(\Sigma_{i} V_{i}\right),
$$


where the denominator is summed over both certainty and non-certainty companies. This quantity can be approximated for various values of $M$ using the frame data base volumes and the estimated inclusion probabilities and compared to the target accuracy. Whenever $\mathrm{CV}^{*}$ exceeds the target value, and the difference can be attributed to the bias term in $\mathrm{CV}^{*}$, a larger $\mathrm{M}$ is indicated. This approach should be used with caution, however, since the accuracy of the approximation is unknown and not readily obtained. The recommended approach to detemining an appropriate sample size for $V_{H} T^{*}$ is that based on the inclusion probability bounds detailed earlier in this section. 


.




\subsection{PROPORTIONAL CELL ALLOTMENT SAMPLING}

\subsection{BIVARIATE APPLICATION OF PCA SAMPLING}

The proportional cell allotment (PCA) technique is closely related to MPS in that the company inclusion probabilities are simply defined to be equal to the lower bounds on the MPS inclusion probabilities derived in Section 3.1.3. This provides the bas is for an alternative sampling scheme for bivariate designs. The technique is also useful for approximating the MPS company selection probabilities, as we shall see in Section 7 . Recall that in the two variable case, the expected cell frequencies $E\left(n_{i j}\right)$ under MPS are bounded as follows:

$$
E\left(n_{i j}\right) \geq N_{i j} \max \left\{q_{i .} / N_{i}, q_{. j} / N_{. j}\right\} \text {. }
$$

where $\quad n_{i j}=$ the number of companies sampled from the $i j$ th cell

$$
\begin{aligned}
& N_{i j}=\text { the total number of companies in the } i j \text { th cell } \\
& N_{i}=\Sigma_{j} N_{i j} \\
& N_{. j}=\Sigma_{i} N_{i j} \\
& q_{i .}=\text { the univariate quota for the } i \text { th row } \\
& q_{. j}=\text { the univariate quota for the } j \text { th column }
\end{aligned}
$$

If $P_{i j}$ represents the MPS inciusion probability for a company from the $i j$ th cell, it follows that $P_{i j} \geq \max \left\{q_{i} . / N_{i}, q_{. j} / N_{. j}\right\}$ (Section 3.1.3); hence, the inclusion probabilities for $P C A$ are defined as $P_{i j} \equiv \max \left\{q_{i} . / N_{i}, q, q / N . j\right\}$.

A major distinction between the MPS and PCA techniques is that MPS sampling specifies a sampling mechanism for which the expected cell sample sizes (and hence the sample weights) may not be known. PCA sampling, on the other hand, specifies a table of expected cell sample sizes (and corresponding sample weights) for which an appropriate sampling mechanism may not be readily apparent. In the bivariate case, however, the PCA inclusion probabilities are easily achieved by application of unbiased controlled rounding to the 
table of expected cell sample sizes (Cox 1987). Thus application of PCA sampling involves computing the expected sample table, obtaining an integer sample table using the Cox algorithm, and applying simple random sampling within cells. Unfortunately, Cox's rounding procedure fails beyond two dimensions. In the present application this is not a serious limitation, since the petroleum marketing data analyzed for this report are essentially two dimensional (Section 7).

While implementation of PCA sampling may be difficult or impossible in higher dimensional problems, the technique is still conceptually important in that empirical evidence (Section 7) suggests that the PCA inclusion probabilities often provide useful approximations for their MPS counterparts. For a further discussion of the relative advantages and disadvantages of MPS and PCA sampling, see Section 7.

Example

Consider the following bivariate population with the indicated univariate marginal quotas:

\begin{tabular}{crrrr} 
& \multicolumn{4}{c}{ Population Table } \\
\cline { 3 - 5 } & & $N_{i j}$ & & $q_{j}$. \\
& & 20 & 20 & 10 \\
& 20 & 1 & 1 & 10 \\
& 1 & 1 & 1 & 10 \\
q.j & 10 & 10 & 10 & 30
\end{tabular}

Although the marginal quotas are consistent, the interaction pattern present in the population precludes their (exact) simultaneous achievement. The PCA expected sample table (accurate to two decimal places) is: 


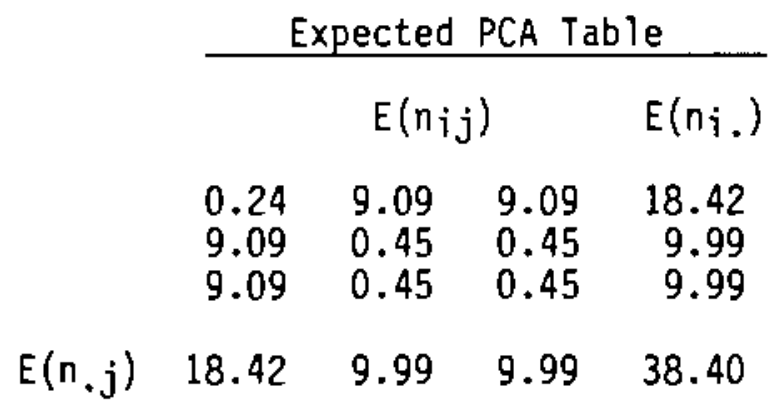

To illustrate the computations involved in the above table, recall that $E\left(n_{i j}\right) \equiv N_{i j} \max \left\{q_{i .} / N_{i}, q_{. j} / N_{. j}\right\}$. Thus $E\left(n_{12}\right)=20 \max \{10 / 41,10 / 22\}=$ $200 / 22=9 . \overline{09}$.

As in this example, the $E\left(n_{i j}\right)$ will generally be fractional and some rounding may be required. Of course it is necessary to round in a manner which ensures that $E\left(n_{i}.\right) \geq q_{i}$. and $E\left(n_{. j}\right) \geq q . j$ for all $i, j$. It is also desirable to round in a manner which guarantees $E\left(n_{i j}\right)>0$ whenever $N_{i j}>0$ and limits further increase of the overall sample size. (In large tables, for example, many of the $E\left(n_{i j}\right)$ 's may be less than 1 , so that rounding to the next larger integer may represent a substantial increase in sample size.) All these goals may be accomplished by rounding "up" at an appropriately chosen decimal place.

The expected PCA table can be used directly as an approximation for the expected MPS table. If PCA is to be used as a sampling method, one must apply Cox's unbiased controlled rounding in order to determine an integer sample table. For example, controlled rounding of the preceding table might result in:

\begin{tabular}{|c|c|c|c|}
\hline \multicolumn{4}{|c|}{ Rounded PCA Table } \\
\hline & $\pi i$ & & $n_{j}$. \\
\hline $\begin{array}{l}1 \\
9 \\
9\end{array}$ & $\begin{array}{l}9 \\
1 \\
0\end{array}$ & $\begin{array}{l}8 \\
0 \\
1\end{array}$ & $\begin{array}{l}18 \\
10 \\
10\end{array}$ \\
\hline 19 & 10 & 9 & 38 \\
\hline
\end{tabular}


Finally, the rounded cell quotas are achieved via simple random sampling within cells.

For the purpose of comparison, the MPS expected sample table was computed using exact methods. The technique used was based on fundamental counting principles and is only available in the form of FORTRAN code. As the program is complex and has not yet been subjected to appropriate quality testing, it will not be described here. The table obtained for this example is in close agreement with one obtained from a Monte Carlo simulation with $M=10,000$ trials, however. Attempts to use the program for the bivariate analysis in Section 7 were unsuccessful due to the excessive computation required. Note the similarity between the PCA and MPS tables, even in the presence of small population cell sizes.

\begin{tabular}{ccccc} 
& \multicolumn{4}{c}{ Expected MPS Table } \\
\cline { 3 - 5 } & & E(nij) & $E\left(n_{i}.\right)$ \\
& & & & \\
& 0.28 & 9.09 & 9.09 & 18.46 \\
& 9.09 & 0.51 & 0.51 & 10.11 \\
& 9.09 & 0.51 & 0.51 & 10.11 \\
$E\left(n_{. j}\right)$ & 18.46 & 10.11 & 10.11 & 38.68
\end{tabular}

Inclusion probabilities under either method are simply $E\left(n_{i j}\right) / N_{i j}$.

\subsection{ESTIMATION OF PRODUCT VOLUMES}

A Horvitz-Thompson type estimator $V_{H T}{ }^{\prime}$ analogous to $V_{H T}{ }^{\star}$ of Section 3.3 .2 can be used for estimation of product volumes under PCA sampling. In this case, the company inclusion probabilities $\pi i$ are known, so that formula 3.3.2.1 is modified by replacing each estimated inclusion probability $\pi i^{\star}$ by $\pi j$. This gives

$$
V_{H T^{\prime}}=\Sigma_{i}\left(1 / \pi_{j}\right) t_{i} \cdot V_{i}
$$


Note we have removed the second subscript from the random variable $t_{i}$ since only one sample is generated under PCA sampling. The proofs given by Cochran (1977. pp. 259-261) show that $V_{H T^{\prime}}$ is unbiased with variance

$$
V\left(V_{H T^{\prime}}\right)=\sum_{i} \frac{(1-\pi j)}{\pi i} y_{j} 2+2 \sum_{i} \sum_{j>i} \frac{(\pi i j-\pi j \pi j)}{\pi i \pi j} y_{i} y_{j}
$$

An unbiased sample estimator for $V\left(V_{H T}{ }^{\prime}\right)$ is

$$
\hat{V}\left(V_{H T^{\prime}}\right)=\sum_{i} \frac{\left(1-\pi_{j}\right)}{\left(\pi_{j}\right)^{2}} y_{i} t_{i}+2 \sum_{i} \sum_{j>i} \frac{\left(\pi i j-\pi i \pi_{j}\right)}{\pi_{i j} \pi_{i} \pi_{j}} y_{i} y_{j} t_{j} t_{j}
$$

It is easily verified that $V_{H T}{ }^{\prime}$ is equivalent to the estimator $(2.3 .1)$ suggested by Winkler (1987b).

\subsection{PCA REDUCTION}

In certain cases, the PCA expected sample table may be used to generate a new expected sample table which satisfies the initial univariate quotas, but which exhibits smaller expected sample sizes than either PCA (and hence MPS, since PCA expected sample sizes do not exceed their MPS counterparts). We refer to this technique as $P C A$ reduction. At the current stage of development, PCA reduction is presented only as a technique for reducing the overall sample size. Further study is required to determine its impact on the precision of estimation.

Some reduction in overall sample size may be achieved by fixing $i$ and $j$ and comparing the quantities $\left[n_{j}{ }^{\star}\right]_{p}, n_{j} .^{\star}-n_{i}$, and $n_{. j} j^{\star}-n_{. j}$, where $[x]_{p}$ is defined by $[x]_{p}=\max \{n p: n$ is a nonnegative integer and $p n<x\}$ for a fixed $0<p \leq 1$. If

$$
m^{\star} \equiv \min \left\{\left[n_{i j}\right]_{p}, n_{i}{ }^{\star}-n_{i}, n_{. j}-n_{. j}\right\}>0,
$$


the quantities $n_{i j}{ }^{\star}, n_{i} .^{*}$, and $n . j^{*}$ can be decreased by $m^{*}$, thus reducing the adjusted sample size by $\mathrm{m}^{*}$. This procedure can be applied sequentially to each $i, j$ combination.

After reduction, Cox's controlled rounding procedure can be applied to produce an integer sample table. Simple random sampling is performed within cells as before.

\section{Example}

To illustrate PCA reduction, we consider the following population table from Winkler (1987a) with the indicated initial univariate quotas:

Population Table

$$
\begin{array}{rrrrrrrrr}
\multicolumn{1}{c}{N_{i j}} \\
0 & 2 & 2 & 2 & 0 & 1 & 0 & 1 & 3 \\
1 & 1 & 4 & 0 & 3 & 0 & 1 & 12 & 3 \\
1 & 0 & 4 & 3 & 4 & 8 & 1 & 19 & 3 \\
0 & 2 & 2 & 3 & 6 & 14 & 11 & 35 & 3 \\
0 & 1 & 5 & 2 & 15 & 26 & 25 & 51 & 3 \\
0 & 0 & 1 & 2 & 9 & 28 & 47 & 118 & 3 \\
1 & 0 & 2 & 3 & 12 & 22 & 93 & 222 & 3 \\
1 & 3 & 3 & 12 & 16 & 16 & 52 & 442 & 3
\end{array}
$$

$\begin{array}{llllllllll}\mathrm{q} . \mathrm{j} & 3 & 3 & 3 & 3 & 3 & 3 & 3 & 3 & 24\end{array}$

Application of proportional cell allocation yields (approximately):

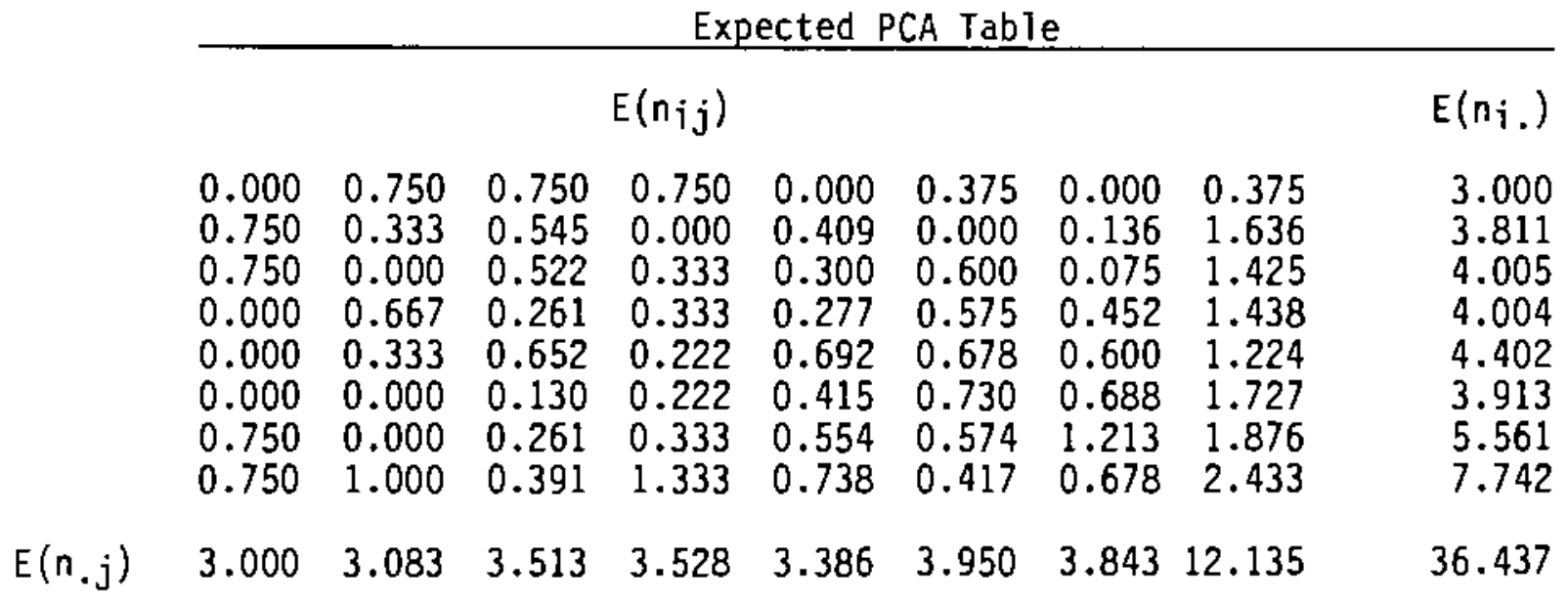


It is apparent from the above table that the adjusted marginal quotas represent a $50 \%$ increase over the initial univariate quotas. Applying PCA reduction with $p=0.001$ (because the tables are rounded to the third decimal place) yields the following reduced table:

\begin{tabular}{|c|c|c|c|c|c|c|c|c|}
\hline \multicolumn{9}{|c|}{ Reduced PCA Table } \\
\hline \multicolumn{8}{|c|}{$E\left(n_{i j}\right)$} & \multirow[b]{2}{*}{$\begin{array}{r}E\left(n_{i .}\right) \\
3.000 \\
3.000 \\
3.000 \\
3.000 \\
3.000 \\
3.000 \\
3.000 \\
3.000\end{array}$} \\
\hline $\begin{array}{l}0.000 \\
0.750 \\
0.750 \\
0.000 \\
0.000 \\
0.000 \\
0.750 \\
0.750\end{array}$ & $\begin{array}{l}0.750 \\
0.250 \\
0.000 \\
0.667 \\
0.333 \\
0.000 \\
0.000 \\
1.000\end{array}$ & $\begin{array}{l}0.750 \\
0.520 \\
0.522 \\
0.261 \\
0.486 \\
0.130 \\
0.261 \\
0.087\end{array}$ & $\begin{array}{l}0.750 \\
0.000 \\
0.333 \\
0.333 \\
0.222 \\
0.222 \\
0.333 \\
0.807\end{array}$ & $\begin{array}{l}0.000 \\
0.409 \\
0.300 \\
0.277 \\
0.692 \\
0.415 \\
0.554 \\
0.353\end{array}$ & $\begin{array}{l}0.375 \\
0.000 \\
0.600 \\
0.575 \\
0.666 \\
0.730 \\
0.053 \\
0.001\end{array}$ & $\begin{array}{l}0.000 \\
0.136 \\
0.075 \\
0.452 \\
0.600 \\
0.688 \\
1.048 \\
0.001\end{array}$ & $\begin{array}{l}0.375 \\
0.952 \\
0.420 \\
0.435 \\
0.001 \\
0.815 \\
0.001 \\
0.001\end{array}$ & \\
\hline 3.000 & 3.000 & 3.000 & 3.000 & 3.000 & 3.000 & 3.000 & 3.000 & 24.000 \\
\hline
\end{tabular}

To illustrate the computations which resulted in the above table, we begin with the entry in the lower right hand corner of the original PCA table. Since $p=0.001$, the entry cannot be reduced below 0.001 , so the cell has a potential reduction of 2.432 . The associated row total exceeds the initial univariate quota of 3 by 4.742 and the associated column total exceeds 3 by 9.135. Thus, we reduce the entry and its corresponding row and column totals by $m^{*}=\min \{2.432,4.742,9.135\}$. We then move on to the cell in the 8 th row and 7 th column and repeat the process. This process is continued until the entire table is covered. In general, the final table obtained will depend upon the sequence in which the cells are reduced.

Application of Cox's algorithm is required to determine integer sample quotas. For the present example, this would result in a table such as: 
Final Sample Table

\begin{tabular}{|c|c|c|c|c|c|c|c|c|}
\hline \multicolumn{8}{|c|}{$n_{i j}$} & \\
\hline $\begin{array}{l}0 \\
1 \\
1 \\
0 \\
0 \\
0 \\
0 \\
1\end{array}$ & $\begin{array}{l}1 \\
0 \\
0 \\
1 \\
0 \\
0 \\
0 \\
1\end{array}$ & $\begin{array}{l}1 \\
1 \\
0 \\
0 \\
1 \\
0 \\
0 \\
0\end{array}$ & $\begin{array}{l}1 \\
0 \\
0 \\
1 \\
0 \\
0 \\
1 \\
0\end{array}$ & $\begin{array}{l}0 \\
0 \\
0 \\
1 \\
0 \\
0 \\
1 \\
1\end{array}$ & $\begin{array}{l}0 \\
0 \\
1 \\
0 \\
1 \\
1 \\
0 \\
0\end{array}$ & $\begin{array}{l}0 \\
0 \\
0 \\
0 \\
1 \\
1 \\
1 \\
0\end{array}$ & $\begin{array}{l}0 \\
1 \\
1 \\
0 \\
0 \\
1 \\
0 \\
0\end{array}$ & \\
\hline 3 & 3 & 3 & 3 & 3 & 3 & 3 & 3 & \\
\hline
\end{tabular}




\subsection{ITERATIVE PROPORTIONAL FITTING SAMPLING}

\subsection{BIVARIATE APPLICATION OF IPF SAMPLING}

\subsubsection{Background}

The final technique to be considered is based on the method of iterative proportional fitting (IPF). As noted earlier, IPF was originally introduced by Deming and Stephan (1940) as a method for estimating the cell probabilities $P_{i j}$ of an $r \times c$ contingency table for which the population marginal probabilities $P_{i}$. and $P_{. j}$ are known and fixed, given a sample of $n$ observations on the table. For bivariate tables, Ireland and Kullback (1968) showed that the IPF procedure is convergent and that the estimates for the $P_{i j}$ are maximum likelihood (MLE), best asymptotic normal (BAN), and minimize the discrimination information (Kullback 1959) $\Sigma_{i} \Sigma_{j} P_{i j} \ln \left(P_{i j} / \pi_{i j}\right)$, where $\pi_{i j}$ is the cell proportion for the $i j$ th cell in the sample table. It was noted that the technique extends to multiway tables of dimension greater than two.

In applying IPF to multivariate sampling, the roles of population and sample are reversed; that is, the population cell counts $\left(N_{i j}\right)$ are known, as are the marginal counts $n_{j}$. and $n_{. j}$ of the sample table, and it is of interest to obtain (typically noninteger) cell entries $\left(n_{i j}\right)$ satisfying $\Sigma_{j} n_{i j}=n_{i}$. and $\Sigma_{j} n_{i j}=n_{. j}$. IPF represents an attractive method for completing the sample table, since it minimizes the discrimination information and preserves the interaction structure of the population table in some cases (Bishop et al. 1975).

When used as a sampling scheme, IPF sampling suffers from the same problem as does PCA sampling: that of constructing a suitable rounding of the expected sample table. In the bivariate problem, Cox's algorithm can be used, but no suitable algorithm exists beyond the two-dimensional case.

In addition to the rounding problem, IPF requires an a priori adjustment of the initial univariate quotas in order to compute the expected sample table. obtaining a suitable adjustment is nontrivial and may preclude exact reproduction of the population interaction pattern, as we shall see in Section 5.2. Ideally, what is needed is an algorithm for determining suitable 
quotas which will allow IPF allocation of the adjusted marginals among cells, but which does not greatly increase the overall sample size required. In general, suitably adjusted quotas should exhibit the following properties:

(a) The sums of quotas agree across variables.

(b) The adjusted quotas do not increase the overall sample size unnecessarily.

(c) Given a nonempty cell $(i, j)$, there is at least one (integer) allocation of the adjusted marginal quotas among the cells which achieves the adjusted marginal quotas and for which the allocation to cell $(i, j)$ is greater than zero.

The desirability of properties (a) and (b) is obvious. Property (c) is included to guarantee that the adjusted quotas are achievable and to avoid any bias which may result from the specification of marginal quotas which prevent sampling from one or more cells. In addition to these properties, it is also desirable that the adjusted quotas be such that the initial application of IPF results in an expected sample table which does not exceed the population count in any cell. This may not be possible for some populations, however. In such cases, iterative application of IPF (IIPF) (Section 5.1.2) or the Generalized Iterative Fitting Procedure (GIFP) (Section 5.1.3) may produce an appropriate expected sample table.

Example

This example illustrates that it is not always possible to simultaneously satisfy univariate quotas, even when $\Sigma_{i} q_{i}=\Sigma_{j} q_{. j}$. Consider again the twoway population with the following cell counts and initial univariate quotas:

Population Table

$\begin{array}{rrrr} & N_{i j} & & q i . \\ 1 & 20 & 20 & 10 \\ 20 & 1 & 1 & 10 \\ 20 & 1 & 1 & 10\end{array}$

q.j $\quad \begin{array}{llll}10 & 10 & 10 & 30\end{array}$ 
While it is clear that the indicated quotas are achievable univariately, it is not possible to sample a total of $n=30$ companies and satisfy the quotas for both variables simultaneously.

The difficulties in the above table are easily illustrated. Since the quota for row 1 is 10 companies, the total companies sampled from cells $(1,2)$ and/or $(1,3)$ cannot exceed 10 . But this prevents achievement of the quotas for columns 2 and 3 . Similarly, the quota for column 1 prevents achievement of the quotas for rows 2 and 3 . If the univariate quotas are taken as minimal, the only solution is to raise the quotas for row 1 and column 1 . Row 1 and column 1 quotas of 16 represent minimal increases, but may be unacceptable for unbiased estimation in that cell $(1,1)$ cannot be sampled. Raising the row 1 and column 1 quotas to 17 allows sampling of cell $(1,1)$.

Application of IPF with the adjusted quotas yieids the following expected sample table:

\begin{tabular}{lrrrr} 
& \multicolumn{4}{c}{ Expected IPF Table } \\
\cline { 3 - 5 } & \multicolumn{3}{c}{$E\left(n_{i j}\right)$} & $E\left(n_{i}\right)$ \\
& 0.219 & 8.391 & 8.391 & 17.001 \\
& 8.391 & 0.805 & 0.805 & 10.001 \\
& 8.391 & 0.805 & 0.805 & 10.001 \\
$E\left(n_{. j}\right)$ & 17.001 & 10.001 & 10.001 & 37.003
\end{tabular}

The adjustment described above clearly satisfies properties (a), (b), and (c). For more complex tables an appropriate adjustment may not be as apparent. What are needed are more generally applicable techniques for determining appropriate quota adjustments. Some suggested algorithms are described in the remainder of this section.

\section{1 .2 Iterative IPF}

Assuming one can find a suitable a priori adjustment with which to begin the process (see Sections 5.2.1 - 5.2.4), iterative application of IPF (IIPF) may yield a smaller expected total sample size than the proportional adjustment techniques. If, after any application of IPF, one or more expected 
cell sample sizes exceed their corresponding population cell counts, it is assumed that the cells will be sampled in entirety. The quotas corresponding to such a cell are then reduced by an amount equal to the population count for the cell. The population count for the cell is then set to zero, and IPF is applied again using the adjusted quotas. When an application of IPF yields cell sample sizes which do not exceed the population cell counts, the procedure is teminated.

In addition to requiring an a priori adjustment of the initial univariate quotas, a second disadvantage of IIPF is that the multiple iterations may result in an expected sample table whose interaction structure differs substantialiy from that of the original population.

Example

We return to the population table from the preceding example to show that iterative application of IPF may fail for consistent quotas which are not realizable. Note that the initial univariate quotas for the example were consistent. Applying IPF with the initial univariate margins yields (approximately):

$$
\begin{aligned}
& \text { Expected IPF Table } \\
& \text { (Initial Univariate Margins) } \\
& E\left(n_{i j}\right) \quad E\left(n_{i .}\right) \\
& \begin{array}{llll}
0.025 & 4.988 & 4.988 & 10.001
\end{array} \\
& \begin{array}{llll}
4.988 & 2.506 & 2.506 & 10.000
\end{array} \\
& \begin{array}{llll}
4.988 & 2.506 & 2.506 & 10.000
\end{array} \\
& E\left(n_{. j}\right) \quad 10.001 \quad 10.000 \quad 10.000 \quad 30.001
\end{aligned}
$$

Since the lower right hand quotas exceed their corresponding population counts, the cells are taken with certainty, yielding the revised table: 


$$
\begin{aligned}
& \mathrm{N}_{i j} \quad \mathrm{qi} \text {. } \\
& \begin{array}{rrrrr}
1 & 20 & 20 & 10 \\
20 & 0(+1) & 0(+1) & 8(+2) \\
20 & 0(+1) & 0(+1) & 8(+2)
\end{array} \\
& \text { q.j } 10 \quad 8(+2) \quad 8(+2) \quad 30
\end{aligned}
$$

Because of the simplicity of the above table, it is clear that the only possible sample design is which will meet the initial univariate quotas is:

$\begin{array}{rcccc} & & n_{i j} & & n_{i} \\ & & & & \\ & 0 & 8 & 8 & 16 \\ & 8 & 1 & 1 & 10 \\ & 8 & 1 & 1 & 10 \\ n_{. j} \quad 16 & 10 & 10 & 36\end{array}$

A major objection to the above table is that the upper left-hand cell is assigned a sample size of 0 , which may result in biased estimates. In addition, it is clear that the table does not maintain the interaction pattern of the population table, again due to the empty cell.

In general, identification of the possible designs will not be obvious and it will be necessary to apply IPF to the reduced table. In the above case, we attempt to apply IPF to:

$\begin{array}{rrrrr} & & N_{i j} & & \\ & & & & \\ 1 & 20 & 20 & 10 \\ 20 & 0 & 0 & 8 \\ 20 & 0 & 0 & 8 \\ 9 . j & 10 & 8 & 8 & 36\end{array}$

This results in a table which does not meet the initial quotas: 


\begin{tabular}{rrcrr} 
& \multicolumn{4}{c}{ Final Sample Table } \\
\cline { 2 - 5 } & & $E\left(n_{i j}\right)$ & & $E\left(n_{i}\right)$ \\
& 0 & 8 & 8 & 16 \\
5 & 1 & 1 & 7 \\
5 & 1 & 1 & 7 \\
$E\left(n_{. j}\right)$ & 10 & 10 & 10 & 30
\end{tabular}

As in the case of proportional adjustment, it may be advantageous to remove strata associated with high extreme quota fractions prior to the application of iterative IPF. Iterative IPF is then applied to the remaining table.

\subsubsection{Generalized Iterative Fitting}

A technique which can replace IIPF in some applications is to use Dykstra's $(1985 a, b)$ generalized iterative fitting procedure (GIFP) in place of IIPF. Because GIFP allows the constraints $E\left(n_{i j}\right) \leq N_{i j}$, it need only be applied once. A major disadvantage of GIFP is that it is computationally intensive. In addition, the limits of its applicability in the present context are not well understood (Dykstra 1986).

\subsection{A PRIORI ADJUSTMENT OF THE INITIAL UNIVARIATE QUOTAS}

Sections 5.2.1 - 5.2.4 detail a priori adjustments of the initial univariate quotas to which the IIPF or GIFP techniques can be applied.

\subsubsection{Proportional Adjustment}

The simplest approach is specify marginal quotas which are proportional to the population margins and which meet or exceed the initial univariate quotas. In the bivariate case, this is easily accomplished by defining revised quotas $q i .{ }^{\star}$ and $q . j^{*}$ by:

$$
\begin{aligned}
& q_{i}{ }^{\star}=N_{i} . \max \left\{q_{1} . / N_{1}, q_{2} . / N_{2} ., \ldots, q .1 / N_{.1}, q_{.2} / N_{.2}, \ldots\right\} \\
& q_{. j}{ }^{\star}=N_{. j} \max \left\{q_{1} . / N_{1} ., q_{2} . / N_{2} ., \ldots, q .1 / N_{.1}, q_{.2} / N_{.}, \ldots\right\}
\end{aligned}
$$


This approach will generally be useful when there are no high extremes among the "quota fractions" (i.e., the quantities in brackets). If, for example, $q_{i,} / \mathrm{Ni}_{.}=1$ for some $i$, this procedure will require sampling of the entire population. Even in less extreme cases, the technique may result in an unnecessarily large overall sample size. An advantage of proportional adjustment is that the IPF expected sample table is simply:

$$
\left(N_{i j}\right) \max \left\{q_{1} . / N_{1}, q_{2} . / N_{2}, \ldots, q_{.1} / N_{1}, q .2 / N_{.2}, \ldots\right\} .
$$

The generalization of the technique to higher dimensional tables is straightforward.

Proportional adjustment is easily modified in the presence of a small number of extreme quota fractions. In this case, one can simply sample the extreme strata with certainty, and apply proportional adjustment to the remainder of the table.

\subsubsection{PCA Adjustment}

PCA adjustment simply involves computing margins appropriate for PCA sampling and using these margins as revised quotas for the application of IPF. There is, of course, no guarantee that the initial application of IPF will produce expected sample sizes which do not exceed their corresponding population counts. In general, PCA adjustment must be used in conjunction with one of the processes described in Section 5.1 .

\subsubsection{MPS Adjustment}

Under MPS adjustment, either the expected MPS margins or the margins from a particular MPS sample are used as revised quotas for the application of IPF. As for PCA adjustment, the initial application of IPF may produce some expected sample sizes which exceed their corresponding population counts, so that use of one of the processes described in Section 5.1 may be necessary as well. 


\subsubsection{Iterative Quota Adjustment}

In this section we describe by example a new iterative technique which produces an initial adjustment of the univariate quotas for a bivariate table. The technique is applied to the table considered above and is shown to yield consistent, realizable margins. Iterative proportional fitting is applied to the adjusted margins to obtain expected sample sizes for the cross-strata cells. The unbiased zero-restricted controlled rounding procedure described by Cox (1987) (See Section 3.1) can then be applied to obtain integer sample sizes in a manner which is consistent with the desired expected cell sizes. It should be noted that at its present stage of development, the technique is applicable only in the bivariate case. Extension to higher dimensional tables has not been considered.

In the example below, application of the iterative adjustment technique produces realizable margins and facilitates the application of IPF. The technique may not produce realizable margins for all tables, however, since the conditions upon which it is based, while necessary, have not been shown to be sufficient. In addition, IPF may produce cell sample sizes larger than the corresponding population cell counts, even though a table has realizable margins (cf., Winkler 1987a, Tables 3.1-3.3).

It should be remarked that constraints similar to (1) below involving multiple cells may not be satisfied. Separability and the complementary constraints $n_{. j}+n_{i},-n \leq N_{i j}$ may impose adjustments other than those produced by the algorithm to be described.

Despite the numerous caveats noted above, the iterative process should be useful for producing an initial justification of the row and column quotas which will set a lower bound on the joint sample size required to achieve the original univariate quotas.

The technique is based on a set of easily derived conditions which are necessary (but which have not been shown to be sufficient) for the attainment of properties (a) $-(c)$ of Section 5.2. Let $n_{i j}$ denote the number of companies to be sampled from cell $(i, j)$ and let $N_{i j}$ denote the population count for the same cell. Clearly we must have $n_{i j} \leq N_{i j}$. The population count for the 
union of row $i$ and column $j$ is $N_{i}+N_{. j}-N_{i j}$, and the number of companies to be sampled from that portion of the table is $n_{i} .+n_{. j}-n_{i j}$. If the total sample size is to be $n$, and the total population size is denoted by $N$, it follows that

$$
\begin{gathered}
n-n_{i}-n_{. j}+n_{i j} \leq N-N_{i}-N_{. j}+N_{j j} ; i_{. e .} \\
n_{i j} \leq N-N_{i}-N_{. j}+N_{i j}+n_{i .}+n_{. j}-n_{.}
\end{gathered}
$$

The conditions (5.2.4.1) assume an additive table. We now describe an iterative procedure which begins with marginal quotas $n_{i}$. and $n_{.} j$ which may be inconsistent with $(5.2 .4 .1)$ or for which $R=\Sigma_{i} n_{i}$. and $C=\Sigma_{j} n_{. j}$ may differ. The procedure performs nonnegative integer adjustments to obtain new quotas which agree and are consistent with (5.2.4.1) (if possible).

Transposing if necessary, we may assume that $R \leq C$. Let $s_{i j}=$

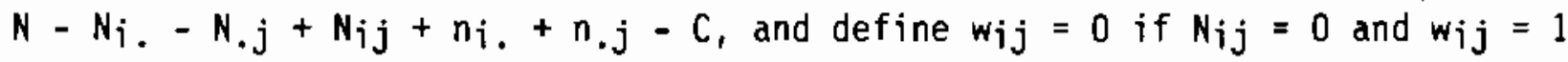
if $\mathrm{N}_{i j}>0$. Because of property $(c)$, we require $s_{i j} \geq w_{i j}$. For each $i$, the quantity $A_{j}:=\max _{j}\left(w_{i j}-s_{i j}\right)+$ represents the amount by which $n_{i}$. must be increased in order that $s_{i j} \geq w_{i j}$ for all $j$. If $\Sigma_{i}\left(n_{i}\right.$. + $\left.A_{j}\right) \leq C_{\text {, we may }}$ define adjusted row quotas $n_{i} .^{*}=n_{i} .+A_{j}$ and assign the remaining $C-\Sigma_{j}\left(n_{i}+A_{j}\right)$ companies to the row quotas arbitrarily, as long as no row quota exceeds its corresponding population row total. If $\Sigma_{j}\left(n_{i} .+A_{j}\right)>C_{\text {, }}$ define $n_{j} .^{*}=n_{i}+A_{i}$ for all $i$ and repeat the process using the revised row totals $n_{i} .{ }^{*}$.

Example

We illustrate the algorithm by applying it to the population table of the example from Section 5.2.1. Since $w_{i j}$ simply indicates whether or not $N_{i j}>0$, we have $w_{i j}=1$ for all $i$ and $j$. Using

$$
s_{i j}=N-N_{j} .-N_{. j}+N_{i j}+n_{i}+n_{. j}-C_{1}
$$

we obtain $s_{11}=85-41-41+1+10+10-30=-6$. Similarly, $s_{i j}=32$ all other $i, j$ pairs. Thus we have shown that 


$$
W=\left(w_{i j}\right)=\left[\begin{array}{lll}
1 & 1 & 1 \\
1 & 1 & 1 \\
1 & 1 & 1
\end{array}\right] \text { and } S=\left(s_{i j}\right)=\left[\begin{array}{lll}
-6 & 32 & 32 \\
32 & 32 & 32 \\
32 & 32 & 32
\end{array}\right] \text {. }
$$

so the only quota adjustment is $n_{1} .^{*}=n_{1}+A_{1}=17$, resulting in the table

$$
\begin{array}{ccccc} 
& & N_{i j} & & n_{i} . \\
& 1 & 20 & 20 & 17 \\
& 20 & 1 & 1 & 10 \\
& 20 & 1 & 1 & 10 \\
n . j & 10 & 10 & 10 & 30 / 37
\end{array}
$$

Transposing the adjusted matrix to ensure $R \leq C$ gives:

$$
\begin{aligned}
& \mathrm{Nij}_{\mathrm{ij}} \mathrm{ni} \\
& \begin{array}{rrrr}
1 & 20 & 20 & 10 \\
20 & 1 & 1 & 10 \\
20 & 1 & 1 & 10
\end{array} \\
& \begin{array}{lllll}
n . j & 17 & 10 & 10 & 37 / 30
\end{array}
\end{aligned}
$$

Now

$$
S=\left[\begin{array}{rrr}
-6 & 32 & 32 \\
25 & 25 & 25 \\
5 & 25 & 25
\end{array}\right]
$$

and the adjustment $n_{1} .^{*}=n_{1}++7=17$ is indicated, yielding the table

$$
\begin{array}{rrrrc} 
& \multicolumn{5}{c}{\mathrm{Nij}} & & \mathrm{ni} . \\
& 1 & 20 & 20 & 17 \\
& 20 & 1 & 1 & 10 \\
& 20 & 1 & 1 & 10 \\
n . j & 17 & 10 & 10 & 37 / 37
\end{array}
$$


Since $R=C$, transposition is not necessary. Again computing $S$ yields

$$
S=\left[\begin{array}{rrr}
1 & 32 & 32 \\
32 & 25 & 25 \\
32 & 25 & 25
\end{array}\right] \geq w .
$$

Since $S \geq W$ and $\Sigma_{i} n_{j}=\Sigma n_{. j}$, the adjustment process is completed. Note that the process has produced the same adjustments described in Section 2.1.1. We now have the following population cell counts with marginal quotas $n_{i}$, and $n \cdot j:$

\begin{tabular}{rrrrr} 
& \multicolumn{5}{c}{$\boldsymbol{N}_{\mathbf{i j}}$} & $\boldsymbol{n}_{\mathbf{i}}$ \\
& 1 & 20 & 20 & 17 \\
20 & 1 & 1 & 10 \\
20 & 1 & 1 & 10 \\
$n_{. j}$ & 17 & 10 & 10 & 37
\end{tabular}

To complete the sampling process, IPF is applied, resulting in the expected sample table:

$$
\begin{aligned}
& E\left(n_{i j}\right) \quad E\left(n_{i}\right) \\
& \begin{array}{llll}
0.2 & 8.4 & 8.4 & 17.0
\end{array} \\
& \begin{array}{llll}
8.4 & 0.8 & 0.8 & 10.0
\end{array} \\
& \begin{array}{llll}
8.4 & 0.8 & 0.8 & 10.0
\end{array} \\
& E(n . j) \quad 17.0 \quad 10.0 \quad 10.0 \quad 37.0
\end{aligned}
$$

Unbiased zero-restricted controlled rounding is used to select a random rounding of the above table; e.g., 


$$
\begin{array}{rrrrr} 
& & n_{\mathbf{i j}} & & n_{\mathbf{i}} \\
& 1 & 8 & 8 & 17 \\
& 8 & 1 & 1 & 10 \\
& 8 & 1 & 1 & 10 \\
n . j & 17 & 10 & 10 & 37
\end{array}
$$

Finally, simple random sampling is carried out within cells.

\subsubsection{Recommendations}

Because of its simplicity, the proportional adjustment technique of Section 5.2.1 is recommended whenever the resulting sample size is not excessive; however, such applications are likely to be limited, since the existence of a single high row or column sampling fraction can inflate the overall sample size necessarily.

In analyzing the 1989 frame data for selected states (Section 7). iterative IPF using expected MPS margins as the a priori adjustment of the initial was found to be a useful technique for generating an expected IIPF table. The MPS margins were used (Section 5.2.3) in order to compare expected sample sizes and sample weights for the three sampling techniques. In practice, since a primary reason for using IPF sampling is to avoid the Monte Carlo simulation required in MPS sampling, one would not have expected MPS margins available. Given the close relationship between MPS and PCA margins noted in Section 7, use of the readily computed PCA margins (Section 5.2.2) should be satisfactory.

The iterative adjustment technique described in Section 5.2.4 requires further evaluation. In addition, it is unknown whether the technique can be extended beyond the bivariate case.

\subsection{ESTIMATION OF PRODUCT VOLUMES}

Estimates of product volumes under IPF sampling can be obtained exactly as described for PCA sampling in Section 4.2. 


\subsection{IMPUTATION FOR CELL NONRESPONSE}

One indicator of the success of any multivariate approach to sampling from an $n$-dimensional table is an overall sample size $n$ which is small relative to the total number of cells in the table. This may be problematic from the standpoint of implementation, however, since nonresponse may have greater impact when cell quotas are small.

The primary danger in nonresponse is the bias which may occur when the nonresponse tendency is in some way correlated with the variable or variables of interest. This bias is probably best minimized by an increased effort to elicit responses via call-backs or by appropriate (matched) substitution of prior non respondents for current nonrespondents. When the above approaches are impossible or impractical, some form of imputation is indicated. In a survey of nonresponse imputation techniques, Chapman (1976) described several common imputation procedures, most of which involve some form of substitution or reweighting.

Kish (1965) has argued that substitution "... generally is of little help and may actually make matters worse", since [the substitutes] "merely replace the nonrespondents with more elements that resemble the respondents already in the sample." This argument is somewhat weakened here, due to the fact that no elements from the cell are already in the sample. Furthermore, the definition of cell membership implies a certain degree of similarity to other members of the cell. It may be possible to increase the likelihood of obtaining replacements which resemble the nonrespondents by choosing replacements exhibiting closely matched frame data volumetric profiles.

Since reweighting generally involves the revision of weights for responding companies, most reweighting schemes are subject to Kish's criticism of replacement techniques. In addition, the total absence of companies in a particular cell makes some forms of reweighting impossible without collapsing cells. Because of these disadvantages, reweighting is not recommended in conjunction with the sampling schemes described here. 
If the matched substitution described above is not practical, a regression-based form of imputation is recommended. Assuming surrounding cells are not too sparsely sampled, a parallelepiped consisting of the nonresponse cell and neighboring cells with responses would form the bas is for $\mathrm{N}$-way analysis of covariance models which could be used to estimate responses for the nonresponse cell. Use of frame data volumes or data from prior months as covariates could improve the predictive power of such a model. A separate model would be required for each product. 


\subsection{ANALYSIS OF THE FRAME DATA}

\subsection{SUMMARY OF THE METHODS EMPLOYED}

Analysis of the petroleum marketing frame data is based on three sample designs defined earlier: the current multiproduct sampling (MPS) technique, the proportional cell allotment (PCA) technique, and the iterative proportional fitting (IPF) approach. Before discussing the data, we review the relative advantages and disadvantages of the three schemes.

\subsubsection{MPS Sampling}

We recall that the MPS technique is applied directly to the initial univariate quotas. The sampling method may be described as a random number of trials. During each trial a company is selected at random (without replacement) from the sampling frame. If, at the time of its selection, a company is able to contribute to at least one of its associated quotas, the company is placed in the sample. If all such quotas have already been met or exceeded, the company is discarded. The trials continue until all quotas have been met or exceeded, resulting in a random total sample size.

The MPS technique has several advantages over the PCA and IPF approaches. First, it can be applied directly to the initial univariate quotas, even thought these quotas may be inconsistent. Second, the technique is applicable for any number of variables. Finally, MPS produces integer samples for each cell.

The major disadvantage of the MPS approach is the incomplete knowledge of its sampling properties. At the present time, it is only possible to compute exact selection probabilities for small bivariate populations. For applications involving more than two variables, company selection probabilities must be estimated, resulting in biased total volume estimates whose variances can only be approximated. 


\subsubsection{PCA Sampling}

Proportional cell allotment (PCA) is closely related to MPS in that the company selection probabilities are simply defined to be equal to the lower bounds on the MPS selection probabilities derived in Section 3.1.3.

Advantages of the PCA technique include the ease of calculating the expected sample sizes and company selection probabilities and the fact that the expected sample sizes will generally be less than for MPS. Disadvantages include the need to apply unbiased controlled rounding and the difficulty in extending PCA beyond two dimensions. Despite the latter disadvantage, empirical evidence suggests that the PCA sampling weights provide good approximations for the corresponding MPS sampling weights; thus PCA sampling may be conceptually useful in deriving MPS estimates. That MPS and PCA weights need not be identical is demonstrated by the example in Section 4.1 .

\subsubsection{IPF Sampling}

In this technique, IPF is applied to appropriately adjusted marginal quotas in order to determine expected cell sample sizes $E\left(n_{i j}\right)$. Upon obtaining a suitable expected sample table, unbiased controlled rounding is applied to determine integer cell quotas. These quotas are then satisfied by simple random sampling from their corresponding cells.

The major advantage of the IPF approach lies in its ability to preserve the interaction pattern of the population table (which should reduce the variance of estimation for a given expected sample size in certain problems).

The IPF approach suffers from the same disadvantages as PCA sampling; that is, the need to apply unbiased controlled rounding and the resulting difficulty in extending the technique beyond two dimensions. IPF sampling entails the additional disadvantage of requiring preadjustment of the initial univariate marginal quotas. As was indicated in Section 5.2, determination of an appropriate adjustment is nontrivial, unless one is willing to forego preservation of the population interactions to some extent. As was the case for PCA, empirical evidence indicates that IPF expected sample sizes and sample weights are highly correlated with their MPS counterparts, al though the relationship is not as strong as for PCA. 


\subsubsection{Nonequality of MPS, PCA, and IPF Sample Weights}

In this section we show by example that MPS, PCA, and IPF sample weights need not coincide. Since the sample weights for a bivariate table are in each case defined by $W_{i j}=N_{i j} / E\left(n_{i j}\right)$, it suffices to show differences among the expected sample tables generated by the three methods for the same population. We consider again the following population with the specified initial univariate quotas of $q i$. and $q . j$ :

$$
\begin{aligned}
& \text { Population Table } \\
& \begin{array}{rrrr} 
& \mathrm{N}_{i j} & & q_{i} . \\
1 & 20 & 20 & 10 \\
20 & 1 & 1 & 10 \\
20 & 1 & 1 & 10
\end{array} \\
& \begin{array}{lllll}
q . j & 10 & 10 & 10 & 30
\end{array}
\end{aligned}
$$

The exact (up to rounding) PCA and MPS expected sample tables were given in the

\begin{tabular}{|c|c|c|c|c|}
\hline & \multicolumn{3}{|c|}{$E\left(n_{i j}\right)$} & \multirow{2}{*}{$\begin{array}{r}E\left(n_{i} .\right) \\
18.42 \\
9.99 \\
9.99\end{array}$} \\
\hline & $\begin{array}{l}0.24 \\
9.09 \\
9.09\end{array}$ & $\begin{array}{l}9.09 \\
0.45 \\
0.45\end{array}$ & $\begin{array}{l}9.09 \\
0.45 \\
0.45\end{array}$ & \\
\hline \multirow[t]{4}{*}{$E(n, j)$} & 18.42 & 9.99 & 9.99 & 38.40 \\
\hline & \multicolumn{4}{|c|}{ Expected MPS Table } \\
\hline & & \multicolumn{2}{|c|}{$E\left(n_{i j}\right)$} & $E\left(n_{j}.\right)$ \\
\hline & $\begin{array}{l}0.28 \\
9.09 \\
9.09\end{array}$ & $\begin{array}{l}9.09 \\
0.51 \\
0.51\end{array}$ & $\begin{array}{l}9.09 \\
0.51 \\
0.51\end{array}$ & $\begin{array}{l}18.46 \\
10.11 \\
10.11\end{array}$ \\
\hline$E(n . j)$ & 18.46 & 10.11 & 10.11 & 38.68 \\
\hline
\end{tabular}
example of Section 4.1:

Expected PCA Table 
If the $E\left(n_{i j}\right)$ obtained via IPF are to agree with the expected cell frequencies from either of the other methods, then the margins will agree as well; thus, we apply IPF using the adjusted margins from the preceding tables. Using the PCA margins generates the following exact (up to rounding) IPF expected sample table:

\begin{tabular}{|c|c|c|c|c|}
\hline & \multicolumn{4}{|c|}{$\begin{array}{c}\text { Expected IPF Table } \\
\text { (PCA Adjustment) }\end{array}$} \\
\hline & \multicolumn{3}{|c|}{$E\left(n_{i j}\right)$} & $E\left(n_{i}\right)$ \\
\hline & $\begin{array}{l}0.41 \\
9.00 \\
9.00\end{array}$ & $\begin{array}{l}9.00 \\
0.49 \\
0.49\end{array}$ & $\begin{array}{l}9.00 \\
0.49 \\
0.49\end{array}$ & $\begin{array}{r}18.41 \\
9.98 \\
9.98\end{array}$ \\
\hline$E(n, j)$ & 18.41 & 9.98 & 9.98 & 38.37 \\
\hline
\end{tabular}

Using the MPS margins generates the following exact (up to rounding) IPF expected sample table:

\begin{tabular}{|c|c|c|c|c|}
\hline & \multicolumn{4}{|c|}{$\begin{array}{l}\text { Expected IPF Table } \\
\text { (MPS Adjustment) }\end{array}$} \\
\hline & \multicolumn{3}{|c|}{$E\left(n_{i j}\right)$} & $E\left(n_{i}\right)$ \\
\hline & $\begin{array}{l}0.38 \\
9.04 \\
9.04\end{array}$ & $\begin{array}{l}9.04 \\
0.53 \\
0.53\end{array}$ & $\begin{array}{l}9.04 \\
0.53 \\
0.53\end{array}$ & $\begin{array}{l}18.46 \\
10.10 \\
10.10\end{array}$ \\
\hline$E(n, j)$ & 18.46 & 10.10 & 10.10 & 38.40 \\
\hline
\end{tabular}

Note that no two of the preceding four tables are exactly the same.

\subsection{GENERAL RESULTS}

\subsubsection{Overview of the Analyses}

The data analyzed were for the year 1989 and differed from data for prior years in that the three no. 2 distillate variables were treated as a single variable with up to twenty-five strata, while the residual fuel oil variables were treated as separate variables with up to five strata each. For the latter 
two variables, the strata were numbered from 1 to 5 , with 1 representing a nonrespondent category, 2 representing a zero volume stratum, and 3 through 5 representing low, medium, and high volume strata, respectively.

The single no. 2 distillate variable was created in three steps. First, the other retail and wholesale no. 2 distillate variables were replaced by a single (nonresidential) variable defined to be the maximum of the two. Both the residential and nonresidential no. 2 distillate variables were then stratified in the same way as were the residual variables. Finally, the two variables were cross stratified to create a single distillate variable. This resulted in a three-dimensional problem, rather than the five-dimensional problem associated with prior years.

To illustrate the application of MPS, PCA, and IPF sampling to these data, results for the States of New York, California, Pennsylvania, Massachusetts, and Georgia are described below (Sections 7.2.2 - 7.2.6). A five variable analysis was not possible, since no quotas were determined for that case.

In studying the data for the states mentioned above, many commonalities were found. Accordingly, a generic description is provided here which will not be repeated for the individual states. Where illustration is required, we will often refer to the New York results.

For each of the states considered, the sampling frame can be represented as a $\mathrm{J}_{1} \times \mathrm{J}_{2} \times \mathrm{J}_{3}$ table of cross-strata cells, where $\mathrm{J}_{1} \leq 25, \mathrm{~J}_{2} \leq 5$, and $J_{3} \leq 5$ denote the number of strata for the no. 2 distillate, retail residual, and wholesale residual variables, respectively. Slicing the table into the $J_{3}$ sections corresponding to the wholesale residual strata results in $\mathrm{J}_{3}$ bivariate tables. Table 1, for example, indicates that the New York frame can be represented as three bivariate tables. Similar tables are provided for each of the states considered. Note that in each case, the row and column totals are summed over the bivariate table, while the initial univariate quotas are for the population as a whole.

Upon examining the bivariate tables for any given state, one finds the first table (corresponding to stratum 1 of the wholesale residual variable) contains an isolated cell representing the intersection of the first stratum 
for each of the three variables. The cell's isolation is a result of the fact that the first stratum for each of the three variables represents the nonrespondent stratum. The impact of its isolation is that the cell is sampled in an essentially independent manner under any of the three sampling schemes. As a result, the maximum specified initial univariate quota for nonrespondents is attained exactly under each of the schemes. In the case of the New York frame (Table 1), this cell contains 612 companies, of which 35 are sampled.

It was also found that the majority of the sample frame for each state was contained in the union of the isolated cell described above and the bivariate slice corresponding to the second (zero volume) stratum of the wholesale residual variable. In the case of New York (Table 1), the union of this slice and the isolated cell accounted for approximately $99.6 \%$ of the total company population, with only six companies represented by the remaining slices. Three Variable Analyses

For each state, we first examine the results typical of a full three variable application of MPS, PCA, and IPF in order to compare the expected sample sizes and sample weights generated by the techniques. Comparisons have been made for estimated MPS expected sample sizes generated by the Petroleum Marketing Division (based on 1000 Monte Carlo trials), exact PCA expected sample sizes, and exact IPF expected sample sizes. Similar comparisons were made for the sample weights under the three schemes. One additional comparison was made between the MPS sample weights $\hat{W}_{i j k}=N_{i j k} / \hat{E}\left(n_{i j k}\right)$ and their smoothed versions $A_{i j k} \equiv\left(\hat{W}_{i} . . \hat{W} . j . \hat{W} . . k\right) / \hat{W}^{2} \ldots$.

As discussed earlier (Sections 5.1, 5.2), preadjustment of the initial univariate strata quotas was required prior to the application of IPF. In order to make the IPF comparisons as equitable as possible, the estimated MPS expected marginal sample sizes were used as the margins for the initial application of IPF. This approach was motivated by the fact that the theoretical sample weights under each procedure are given by $W_{i j k}=$ $\mathrm{N}_{i j k} / \mathrm{E}\left(\mathrm{n}_{i j k}\right)$; hence, if the sample weights are to be comparable, the expected sample sizes and expected margins must be comparable as well. As indicated in Section 5.2, however, the specification of consistent, realizable margins 
does not guarantee that the expected sample table produced by IPF will satisfy $E\left(n_{i j k}\right) \leq N_{i j k}$. Indeed, in most cases it was necessary to apply IPF iteratively (Section 5.1.2) in order to obtain a table in which none of the expected sample sizes exceeded their corresponding population cell sizes. The cells removed during the application of IIPF are indicated in the frame tables (Tables 1-10) by triangles placed around their corresponding cell counts.

In general, a close correspondence is noted when comparing the PCA and MPS weights. The expected sample sizes and sample weights are nearly identical under the two methods, and hence closely follow the identity line when plotted as ordered pairs (see, e.g., Figures 1 and 2). The MPS sample weights and their smoothed versions also appear to follow the identity line, but with somewhat more scatter (Figure 5).

The expected sample sizes and sample weights for IPF and MPS also fall about the identity line, as illustrated in Figures 3 and 4 , although not as tightly as for PCA and MPS. The outliers in the plots comparing MPS weights to IPF weights (e.g., New York Figures 4 and 9) arise from two sources: differences in expected cell sample sizes under the MPS and IPF techniques and differences resulting from the iterative application of IPF. The impact of the first source is most clearly seen if the initial application of IPF produces a usable expected sample table (i.e., one satisfying $E\left(n_{i j}\right) \leq N_{i j}$ ). This was the case in Section 7.1.4, where IPF was applied to a population using expected MPS margins as adjusted marginal quotas. Comparison of the resulting IPF expected sample table to the (exact) MPS expected sample table shows that the two sampling techniques are not equivalent. When more than one application of IPF is required (as was the case for the State of New York) to obtain an expected sample table satisfying $E\left(n_{i j}\right) \leq N_{i j}$, it becomes difficult to assess the impact of the first source. It is clear, however, that multiple applications of IPF will force some cells to be selected with certainty, resulting in sample weights $W_{i j k}=1$. If these companies are not selected with certainty under MPS, their MPS sample weights will necessarily exceed 1. Iterative IPF does not appear to be the cause of the major outliers 
in the IPF vs MPS sample weight plots, however, since most of the outliers are associated with IPF sample weights not equal to 1 .

For each of the IPF vS MPS sample weight plots, the major outliers are circled and numbered. Corresponding cells in the appropriate frame table are marked in the same way so that the outliers can be attributed to their proper cells. The outliers for figure 4, for example, correspond to two cells in Table 1. Outliers on the MPS vs smoothed MPS sample weight plots are identified in a similar fashion, using squares rather than circles; thus, the boxed outliers in figure 5 correspond to the boxed cells in Table 1.

No satisfactory explanation has been found to indicate why some cells correspond to outliers on the sample weight graphs and others do not. In comparing IPF and MPS weights (e.g., Figure 4), one might expect the remaining cells in strata which have had cells removed under IIPF to be more prone to produce outliers. This does not appear to be the case, however. The only obvious observation is that outliers seem to be more frequent within small strata. On the other hand, a comparison of MPS weights with their smoothed counterparts (e.g., Figure 5) indicates that most of these outliers correspond to large strata. Again, no obvious explanation presents itself.

\section{Bivariate Analyses}

We noted above that a large majority of the sampling frame for each state is included in the union of the isolated nonrespondent cell and the bivariate slice corresponding to stratum 2 (the zero volume stratum) of the wholesale residual variable. A simplification of the sampling problem can be effected by sampling the isolated cell separately and sampling the small number of companies in strata 3-5 of the wholesale residual variable with certainty. Removal of these components reduces the sampling frame to a bivariate table to which any of the three techniques described earlier can be successfully applied. The reduced bivariate table for New York is displayed in Table 2.

In the bivariate analyses, many of the initial univariate quotas have been retained, even though some may have been partially satisfied as a result of the certainty sampling of the remaining wholesale residual strata. This partial filling of certain row and column quotas is indicated by the 
"previously filled" counts provided in the margins of the reduced bivariate tables. In certain cases it may be appropriate to adjust the initial univariate quotas to account for such partial filling (e.g., to reduce the overall sample size). Of course, adjustment will be required if the initial univariate quota for a given column exceeds the population total for that column in the reduced table. For the State of New York, this occurred for stratum 10 of the no. 2 distillate variable. The initial univariate quota was 19 for this stratum, but only 17 companies were included in the second slice of Table 1. In fact, the population count for the stratum was exactly 19, requiring that the stratum be sampled in its entirety. For this reason, the stratum was removed from the reduced table. Only mandatory adjustments, such as the one just described for New York, were made in the analyses described below.

The comparisons of expected sample sizes and sample weights for cells in the reduced bivariate tables are analogous to the comparisons made for the three-dimensional tables. The general conclusions made (i.e., that PCA quotas and weights provide the best approximations of their MPS counterparts) are also the same.

\subsubsection{New York Results}

For the State of New York, thirteen of the no. 2 distillate strata were nonempty, as were four of the retail residual and three of the wholesale residual strata. Crossing the three variables results in a $13 \times 4 \times 3$ table. slicing the table into sections corresponding to the three wholesale residual strata results in the three bivariate tables shown in Table 1.

Three Variable Analysis

In the three variable analysis for the State of New York, the initial application of IPF generated expected sample sizes which sometimes exceeded their corresponding frame counts. Since all such cells were in either stratum 10 or stratum 25 (both of which must be sampled with certainty in order to fulfil their respective sample quotas), these strata were removed from the frame and IPF reapplied. The second application of IPF resulted in two additional cells whose expected sample sizes were larger than the corresponding 
TABLE 1. New York Frame

WHOLESALE RESIDUAL STRATUM $=1$, QUOTA $=4$ RETAIL RESIDUAL STRATA

$\begin{array}{lrrrrrrr}\text { NO. } 2 & 1 & 612 & 0 & 0 & 0 & 612 & 35 \\ \text { DISTILLATE } & 8 & 0 & 0 & 0 & 0 & 0 & 4 \\ \text { STRATA } & 9 & 0 & 0 & 0 & 0 & 0 & 4 \\ & 10 & 0 & 0 & 0 & 0 & 0 & 19 \\ & 13 & 0 & 0 & 0 & 0 & 0 & 13 \\ & 14 & 0 & 0 & 0 & 0 & 0 & 4 \\ & 15 & 0 & 0 & 0 & 0 & 0 & 6 \\ & 18 & 0 & 0 & 0 & 0 & 0 & 12 \\ & 19 & 0 & 0 & 0 & 0 & 0 & 4 \\ & 20 & 0 & 0 & 0 & 0 & 0 & 13 \\ & 23 & 0 & 0 & 0 & 0 & 0 & 12 \\ & 24 & 0 & 0 & 0 & 0 & 0 & 7 \\ & 25 & 0 & 0 & 0 & 0 & 0 & 23 \\ \text { TOTAL } & & 612 & 0 & 0 & 0 & 612 & \\ \text { QUOTA } & & 5 & 4 & 4 & 6 & & \end{array}$

WHOLESALE RESIDUAL STRATUM=2, QUOTA $=4$ RETAIL RESIDUAL STRATA

$\begin{array}{lrrrrrrr}\text { NO. } 2 & 1 & 0 & 0^{2} & 0 & 0 & 0 & 35 \\ \text { DISTILLATE } & 8 & 0 & \frac{109}{19}^{2} & 8^{2} & 1 & 118 & 4 \\ \text { STRATA } & 9 & 0 & 19 & 0 & 19 & 4 \\ & 10 & 0 & 15 & 2 & 0 & 17 & 19 \\ & 13 & 0 & \frac{451}{41} & (13)^{1} & 1 & 465 & 13 \\ & 14 & 0 & 41 & 1 & 0 & 42 & 4 \\ & 15 & 0 & 10 & 1 & 4 & 12 & 6 \\ & 18 & 0 & 186 & 6 & 3 & 195 & 12 \\ & 19 & 0 & 49 & 2 & 8 & 51 & 4 \\ & 20 & 0 & 15 & 1 & 4 & 17 & 13 \\ & 23 & 0 & 39 & 6 & 0 & 45 & 12 \\ & 24 & 0 & 26 & 7 & 2 & 35 & 7 \\ & 25 & 0 & 15 & 4 & 3 & 22 & 23 \\ \text { TOTAL } & & 0 & 975 & 51 & 12 & 1038 & \\ \text { QUOTA } & & 5 & 4 & 4 & 6 & & \end{array}$


TABLE 1. New York Frame (Cont.)

WHOLESALE RESIDUAL STRATUM $=3$, QUOTA $=4$

RETAIL RESIDUAL STRATA

$\begin{array}{lrrrrrrr}\text { NO. } 2 & 1 & 0 & 0 & 0 & 0 & 0 & 35 \\ \text { DISTILLATE } & 8 & 0 & 3 & 0 & 0 & 3 & 4 \\ \text { STRATA } & 9 & 0 & 0 & 0 & 0 & 0 & 4 \\ & 10 & 0 & 1 & 0 & ]^{3} & 2 & 19 \\ & 13 & 0 & 0 & 0 & 0 & 0 & 13 \\ & 14 & 0 & 0 & 0 & 0 & 0 & 4 \\ & 15 & 0 & 0 & 0 & 0 & 0 & 6 \\ & 18 & 0 & 0 & 0 & 0 & 0 & 12 \\ & 19 & 0 & 0 & 0 & 0 & 0 & 4 \\ & 20 & 0 & 0 & 0 & 0 & 0 & 13 \\ & 23 & 0 & 0 & 0 & 0 & 0 & 12 \\ & 24 & 0 & 0 & 0 & 0 & 0 & 7 \\ & 25 & 0 & 0 & 0 & 1 & 1 & 23 \\ \text { TOTAL } & & 0 & 4 & 0 & 2 & 6 & \\ \text { QUOTA } & & 5 & 4 & 4 & 6 & & \end{array}$

frame counts. These cells were removed, the marginal totals adjusted, and IPF was applied a third, and final, time. This yielded an expected sample table with cell entries less than or equal to their corresponding frame counts.

Two Variable Analysis

As indicated above, the sampling problem for the New York data can be reduced to two dimensions by separate sampling of the 35 company quota from the isolated cell formed by the intersection of the first strata of the three variables, and certainty sampling of strata 10 and 25 of the no. 2 Distillate variable and the remainder of stratum 3 of the Wholesale Residual variable. Removing these three components from the population table yields a new bivariate population shown in Table 2 . 


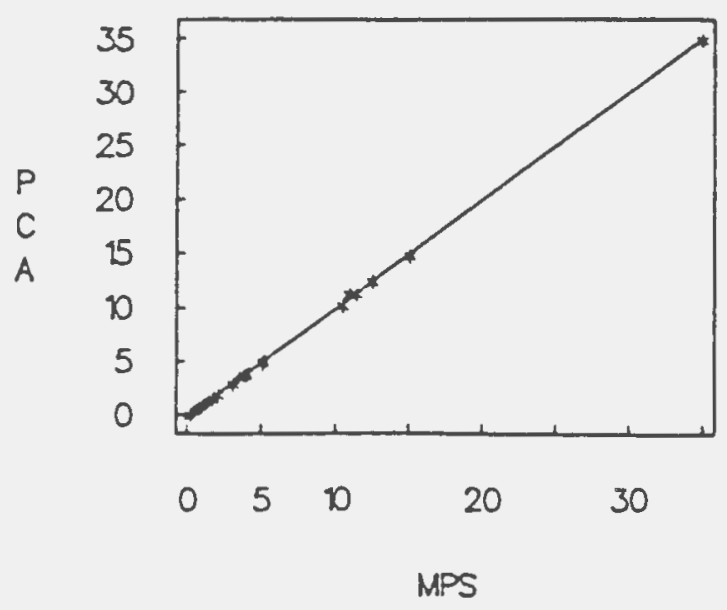

FIG I NY SAMPLE SIZES

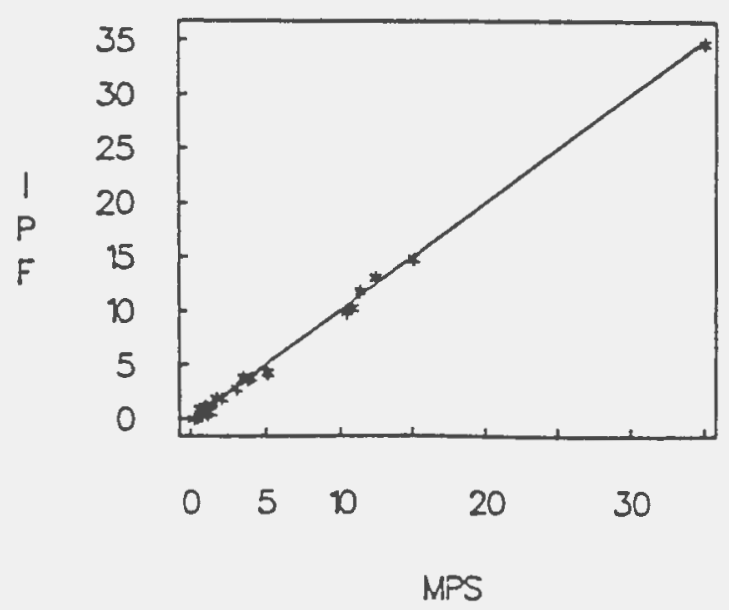

FK 3. NY SAMPLE SIZES

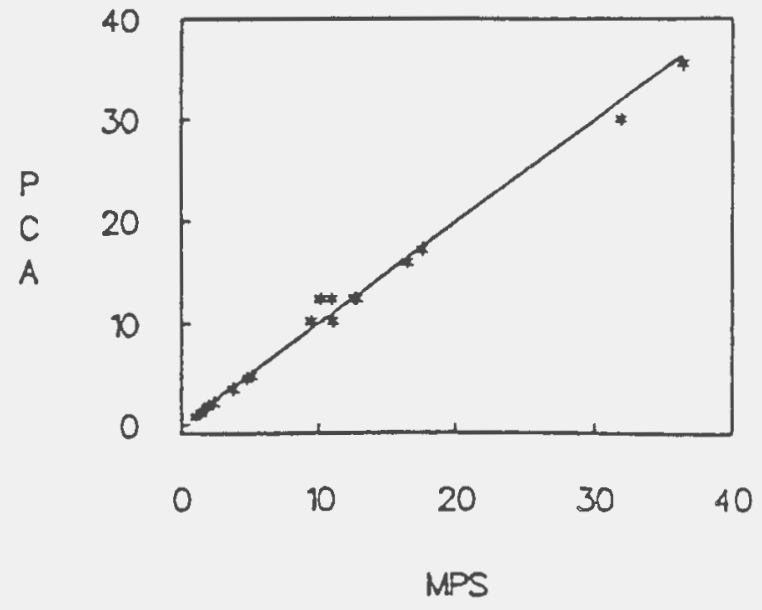

FIG 2. NY SAMPLE WEIGHTS

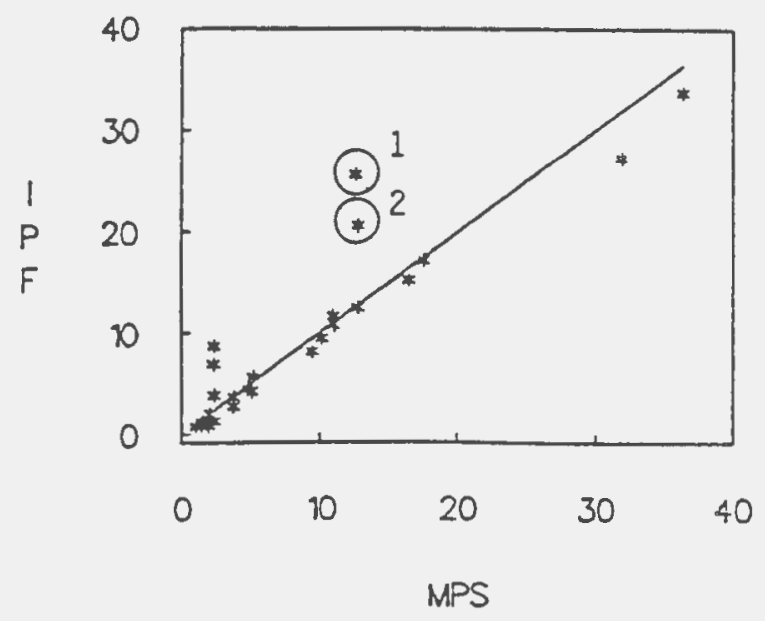

FIG 4. NT SAMPLE WEIGHTS

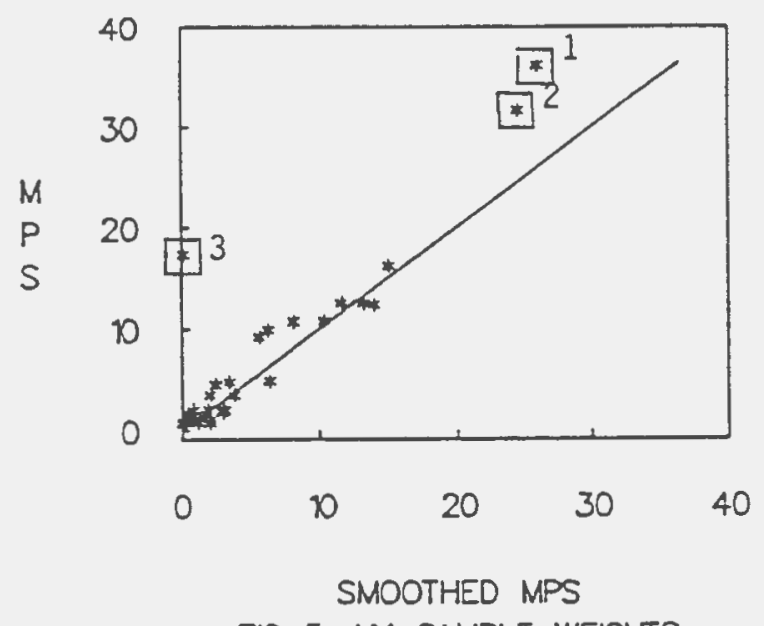

FIG 5. NY SAMPLE WEIGHTS 


\section{TABLE 2. Reduced NY Frame}

$$
\begin{gathered}
\text { WHOLESALE RESIDUAL STRATUM }=2 \text {, QUOTA }=4 \\
\text { RETAIL RESIDUAL STRATA }
\end{gathered}
$$

$$
\begin{array}{llll}
2 & 3 & 4 & \text { TOTAL QUOTA PREVIOUSLY }
\end{array}
$$

$\begin{array}{lrrrrr}\text { N0. } 2 & 8 & { }_{109}^{2} & (8)^{2} & 1 & 118 \\ \text { DISTILLATE } & 9 & 19 & 0 & 0 & 19 \\ \text { STRATA } & 13 & {[45]^{1}} & (13)^{1} & 1 & 465 \\ & 14 & 41 & 1 & 0 & 42 \\ & 15 & 10 & 1 & \AA & 12 \\ & 18 & 186 & 6 & 3 & 195 \\ & 19 & 49 & 2 & 0 & 51 \\ & 20 & 15 & 1 & 1 & 17 \\ & 23 & 39 & 6 & 0 & 45 \\ & 24 & 26 & 7 & 2 & 35 \\ & & & & & \\ \text { TOTAL } & & 945 & 45 & 9 & 1038 \\ \text { QUOTA } & 4 & 4 & 6 & \\ \text { PREVIOUSLY FILLED } & 34 & 6 & 5 & \end{array}$

IPF was applied twice before yielding a table with sample quotas less than or equal to the corresponding frame entries. Expected cell sample sizes and sample weights for the three methods were compared exactly as in the three variable analysis. Examination of Figures 6-10 shows that the conclusions of these comparisons are generally the same.

\subsubsection{California Results}

For the State of California, ten of the no. 2 distillate strata were nonempty, as were three of the retail residual and three of the wholesale residual strata. Slicing the $10 \times 3 \times 3$ table into sections corresponding to its wholesale residual strata yields the bivariate tables shown in Table 3 . 


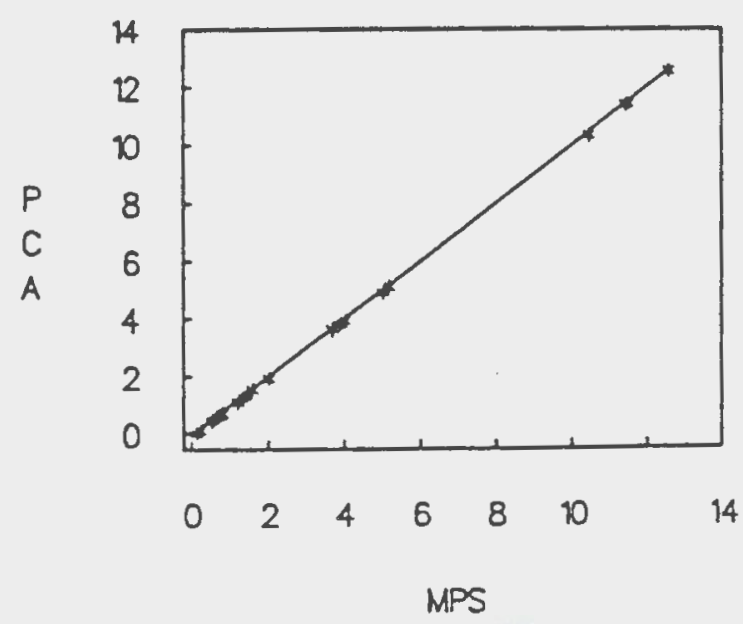

FK 6. NY SAMPLE SIZES

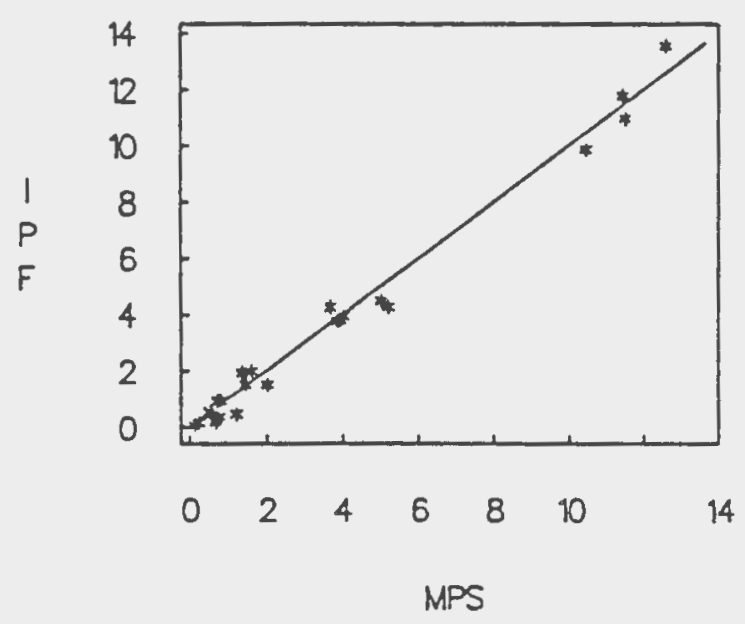

FIG 8. NY SAMPLE SIZES

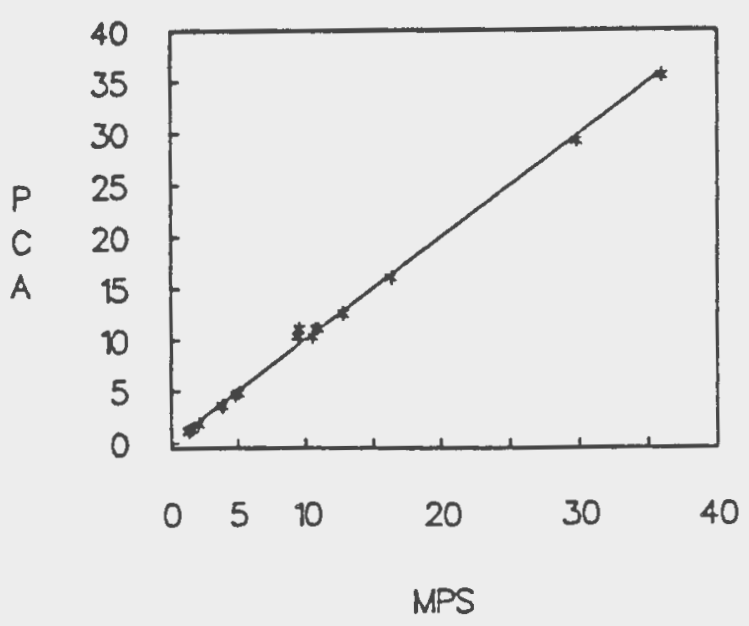

FIG 7. NY SAMPLE WEIGHTS

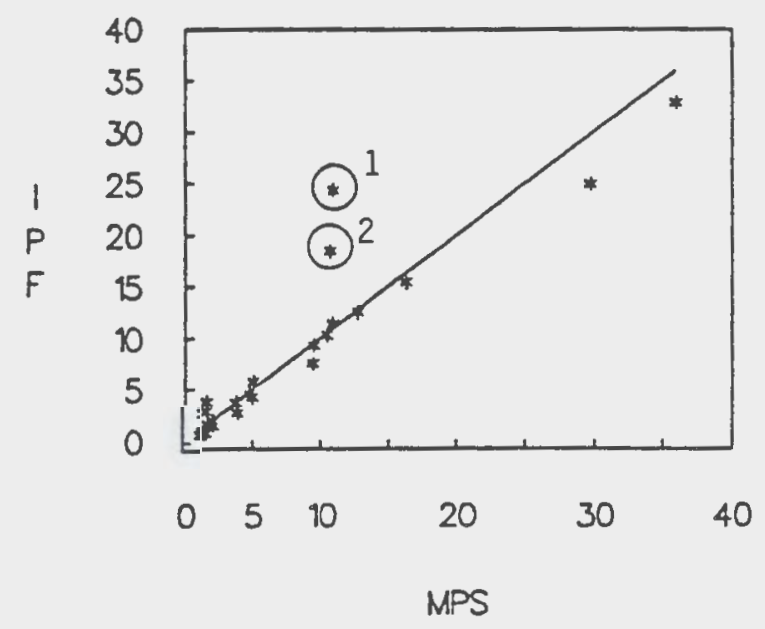

FIG 9. NY SAMPLE WEIGHTS

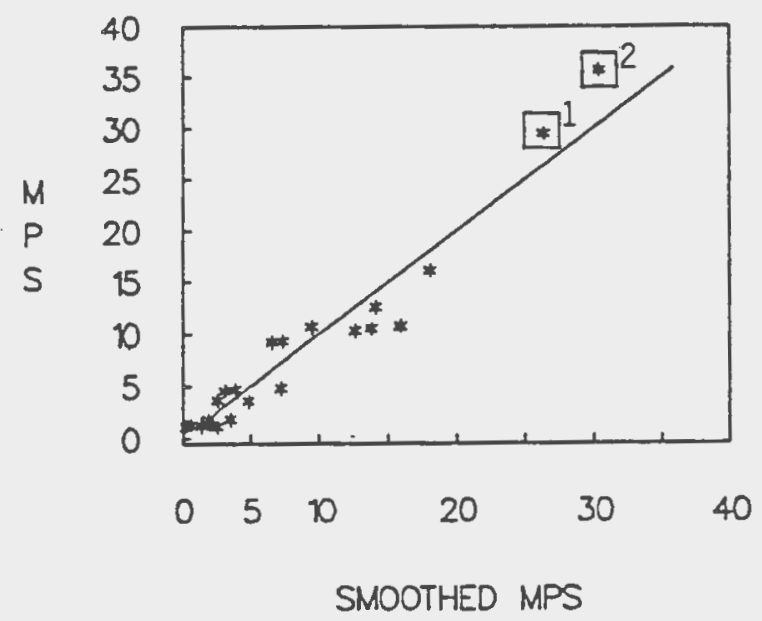

FIG 10. NY SAMPLE WEIGHTS 


\section{TABLE 3. California Frame}
WHOLESALE RESIDUAL STRATUM $=1$, QUOTA $=4$ RETAIL RESIDUAL STRATA

$\begin{array}{lr}\text { NO. } 2 & 1 \\ \text { DISTILLATE } & 8 \\ \text { STRATA } & 9 \\ & 10 \\ & 13 \\ & 14 \\ & 15 \\ & 18 \\ & 19 \\ & 20\end{array}$

TOTAL

QUOTA

23 TOTAL QUOTA

$\begin{array}{lllll}185 & 0 & 0 & 185 & 20\end{array}$

$\begin{array}{rrrrr}0 & 0 & 0 & 0 & 6\end{array}$

$\begin{array}{lllll}0 & 0 & 0 & 0 & 6\end{array}$

$\begin{array}{lllll}0 & 0 & 0 & 0 & 40\end{array}$

$\begin{array}{lllll}0 & 0 & 0 & 0 & 5\end{array}$

$\begin{array}{lllll}0 & 0 & 0 & 0 & 4\end{array}$

$\begin{array}{lllll}0 & 0 & 0 & 0 & 4\end{array}$

$\begin{array}{lllll}0 & 0 & 0 & 0 & 12\end{array}$

$\begin{array}{rrrrr}0 & 0 & 0 & 0 & 10 \\ 0 & 0 & 0 & 0 & 3\end{array}$

$\begin{array}{rlll}185 & 0 & 0 & 185 \\ 4 & 4 & 5 & \end{array}$

WHOLESALE RESIDUAL STRATUM $=2$, QUOTA $=4$ RETAIL RESIDUAL STRATA

NO. 2

DISTILLATE 8

STRATA 9

10

13

14

15

18

19

20

TOTAL

QUOTA

1
8
9
10
13
14
15
18
19
20

1

2

3 TOTAL QUOTA

${ }_{0}^{0}$

$0 \quad 60$

$0 \quad 36$

$0 \quad 25$

$0 \quad 6$

$0 \quad 13$

$0 \begin{array}{ll}0 & 13 \\ 0 & 3\end{array}$

$\begin{array}{rr}0 & 0 \\ (4) & 164 \\ (1)^{5} & 75 \\ 6 & 66 \\ 0 & 36 \\ 0 & 25 \\ 0 & 6 \\ 0 & 13 \\ 1 & 14 \\ 0 & 3\end{array}$

$\begin{array}{rr}0 & 20 \\ 164 & 6\end{array}$

$\begin{array}{rr}75 & 6 \\ 66 & 40\end{array}$

$36 \quad 5$

64

$13 \quad 12$

$3 \quad 3$

$\begin{array}{rrrrr}0 & 390 & 12 & 402 & 1038 \\ 4 & 4 & 5 & & \end{array}$ 


\section{TABLE 3. California Frame (Cont.) \\ WHOLESALE RESIDUAL STRATUM $=3$, QUOTA $=4$ \\ RETAIL RESIDUAL STRATA}

$\begin{array}{lrrrrrr}\text { NO. } 2 & 1 & 0 & 0 & 0 & 0 & 20 \\ \text { DISTILLATE } & 8 & 0 & 33 & & \\ \text { STRATA } & 9 & 0 & 0 & 0 & 4 & 6 \\ & 10 & 0 & 1 & 3 & 4 & 6 \\ & 13 & 0 & 0 & 0 & 0 & 5 \\ & 14 & 0 & 0 & 0 & 0 & 4 \\ & 15 & 0 & 0 & 0 & 0 & 4 \\ & 18 & 0 & 0 & 0 & 0 & 12 \\ & 19 & 0 & 0 & 0 & 0 & 10 \\ & 20 & 0 & 0 & 0 & 0 & 3 \\ \text { TOTAL } & & 0 & 4 & 4 & 8 & 6 \\ \text { QUOTA } & & 4 & 4 & 5 & & \end{array}$

For the California data, the initial application of IPF generated a table of expected sample sizes consistent with (i.e., not exceeding) their corresponding frame counts. Comparisons of the resulting expected sample sizes and sample weights are given in Figures 11-15.

Two Variable Analysis

The sampling problem for the California data was reduced to two dimensions by separate sampling of the 25 company quota from the isolated cell formed by the intersection of the first strata of the three variables and certainty sampling of stratum 20 of the no. 2 Distillate variable. Removing these components from the population table yields a new bivariate population shown in Table 4. 


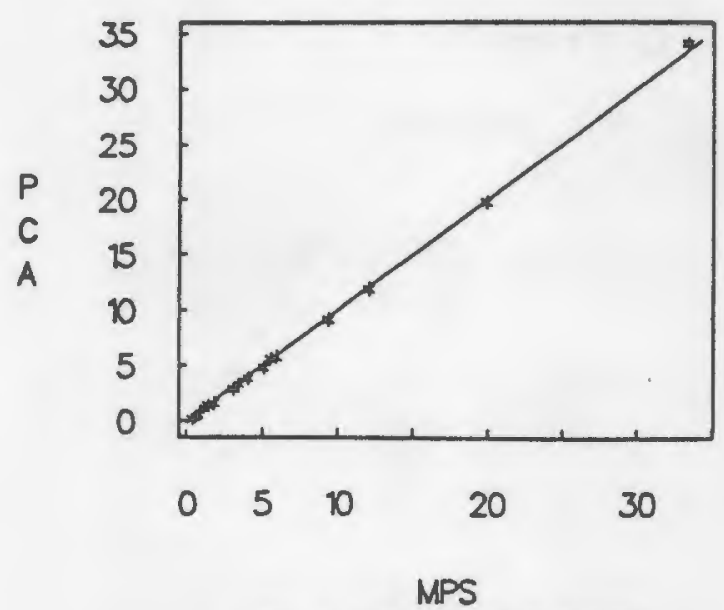

FIG IL CA SAMPLE SRES

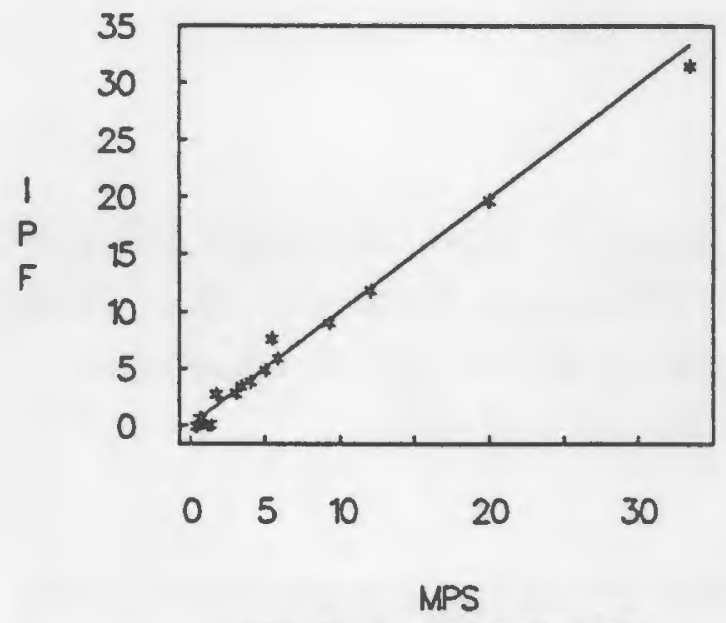

FIG 13. CA SAMPLE SIEES

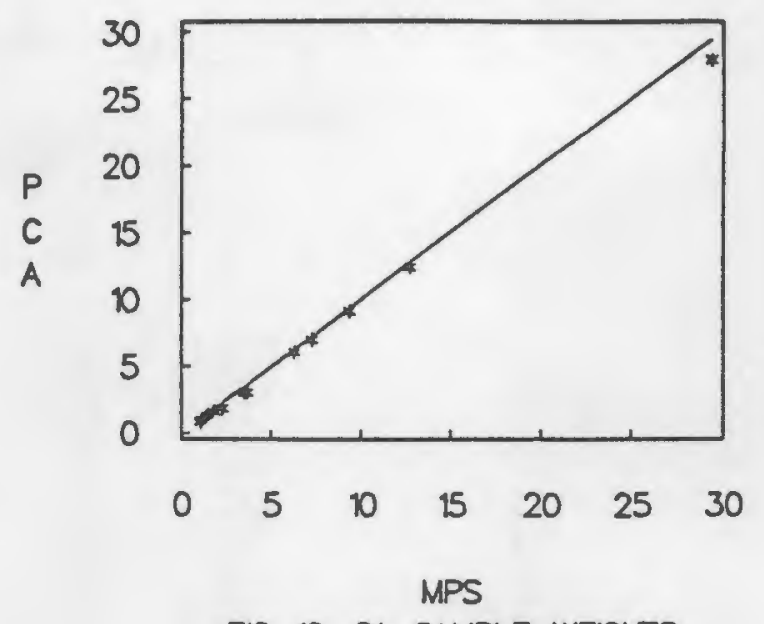

FIG 12. CA SAMPLE WEIGHTS

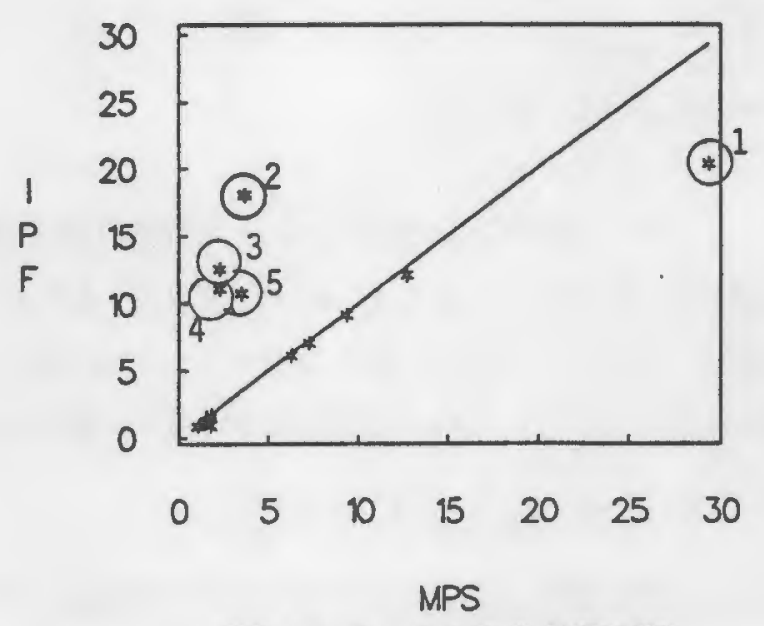

FIG 14. CA SAMPLE WEIGHTS

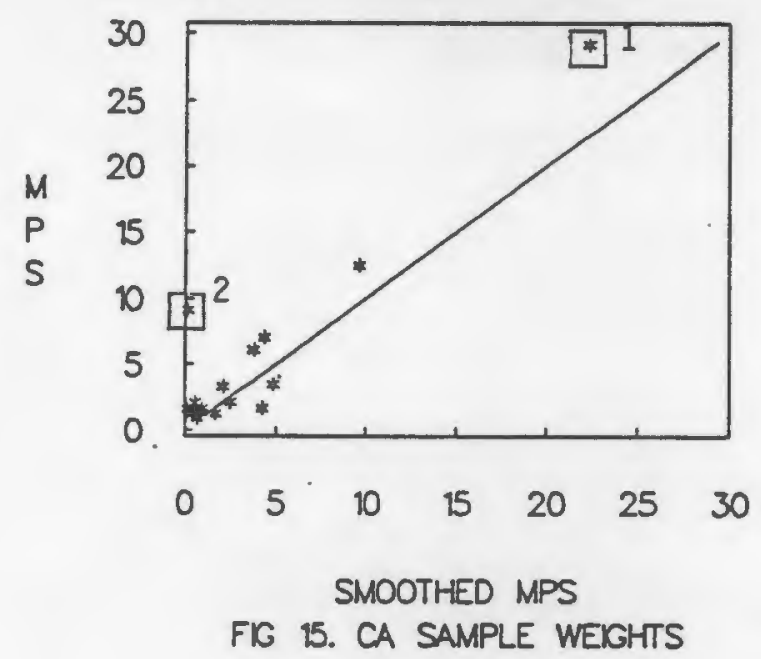


TABLE 4. Reduced CA Frame

(WHOLESALE RESIDUAL STRATUM=2, QUOTA=4)

RETAIL RESIDUAL STRATA

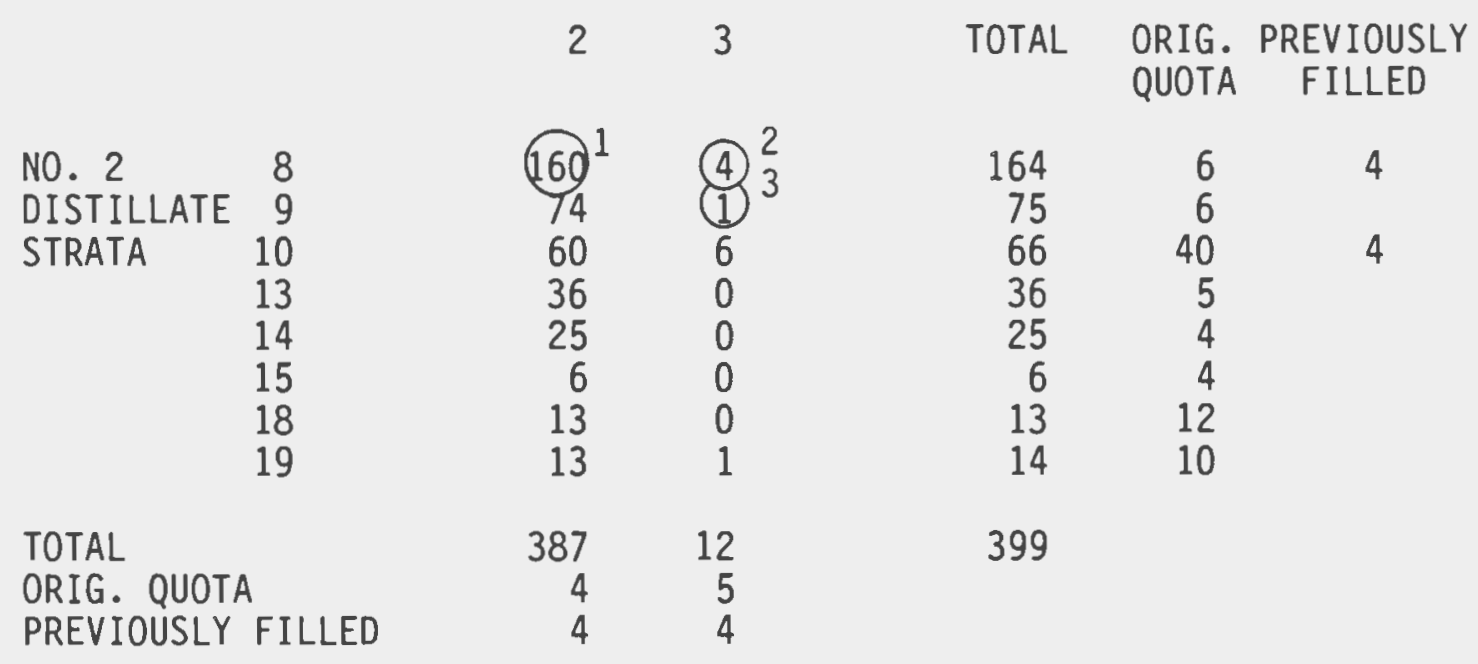

The initial application of IPF resulted in an expected sample table with sample quotas less than or equal to the corresponding frame entries. Expected cell sample sizes and sample weights for the three methods were compared exactly as in the three variable analysis (Figures 16-20).

\subsubsection{Pennsylvania Results}

For the State of Pennsylvania, thirteen of the no. 2 distillate strata were nonempty, as were four of the retail residual and all of the wholesale residual strata. Slicing along the wholesale residual strata produced the five two-way tables shown in Table 5. 


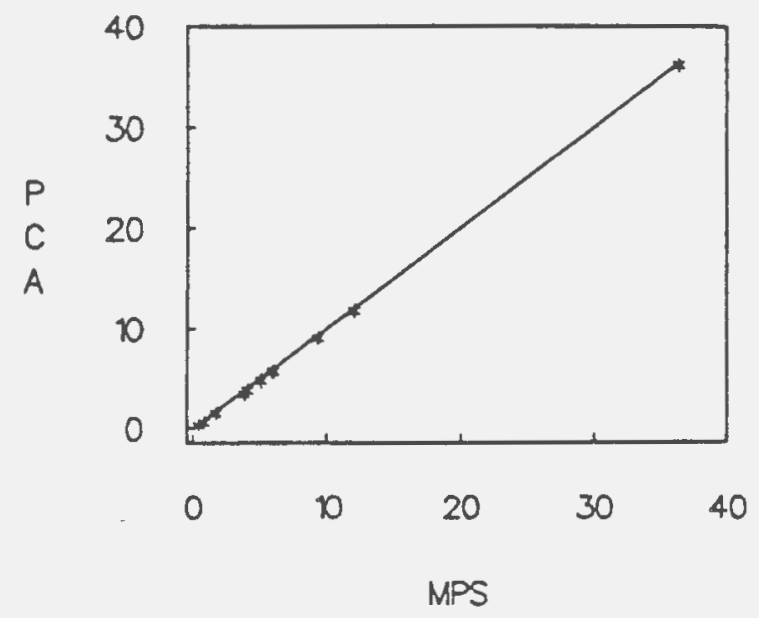

FK 16. CA SAMPLE SRES

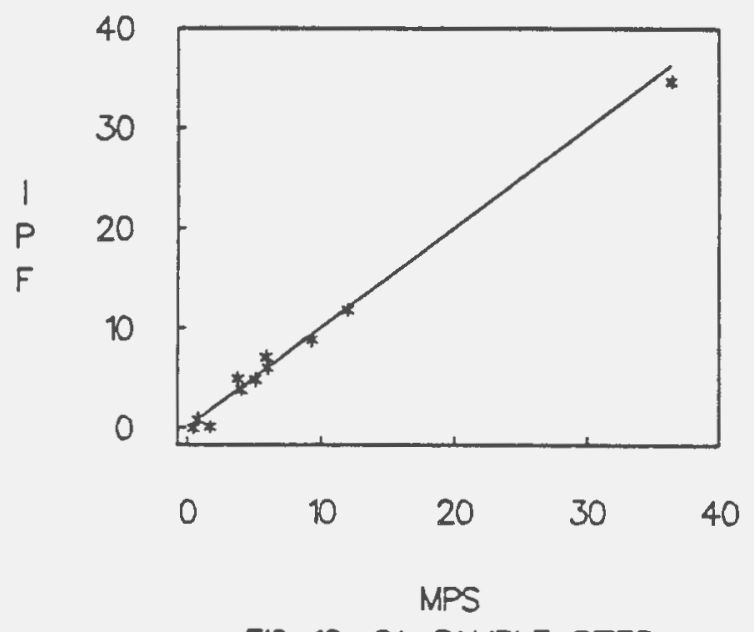

FIG 18. CA SAMPLE SZES

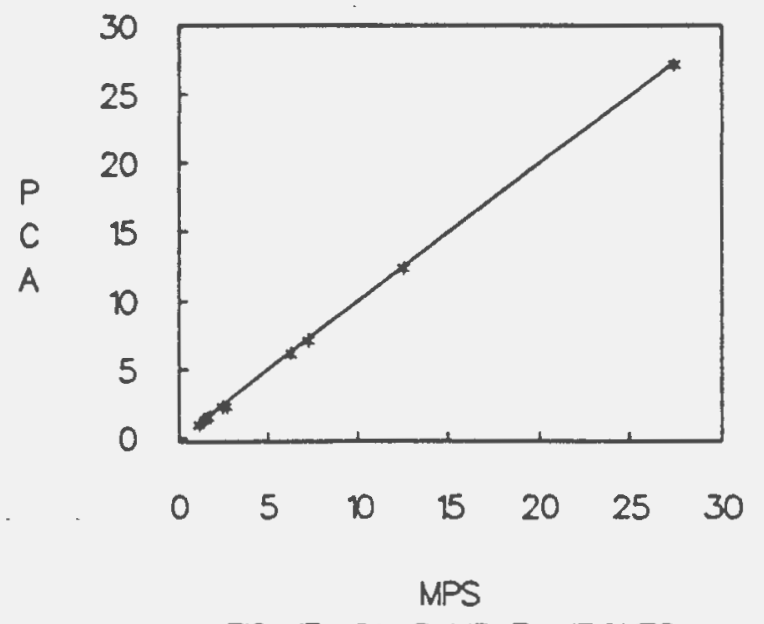

FIG 17. CA SAMPLE WEKHTS

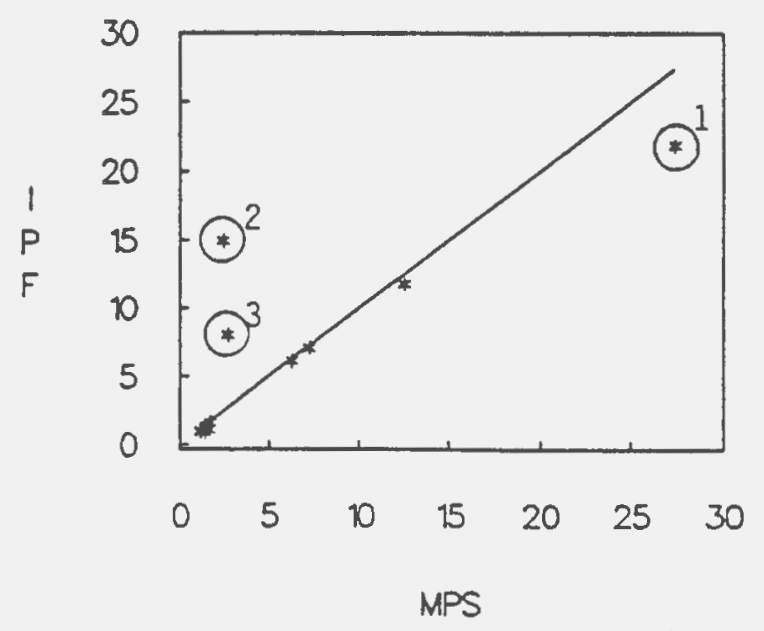

FIG 19. CA SAMPLE WEIGHTS

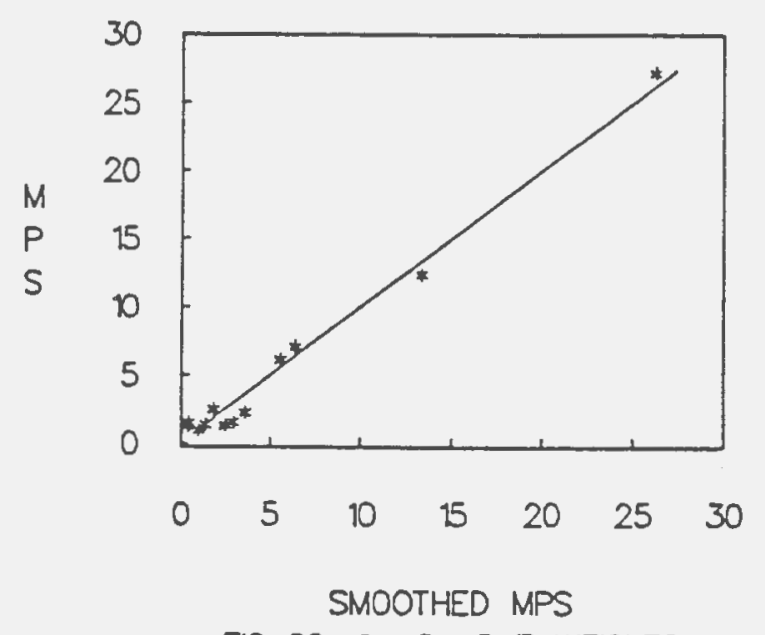

FIG 20. CA SAMPLE WEIGHTS 
TABLE 5. Pennsylvania Frame

WHOLESALE RESIDUAL STRATUM $=1$, QUOTA $=4$ RETAIL RESIDUAL STRATA

$\begin{array}{lr}\text { NO. } 2 & 1 \\ \text { DISTILLATE } & 7 \\ \text { STRATA } & 8 \\ & 9 \\ & 12 \\ 13 \\ 14 \\ 17 \\ 18 \\ 19 \\ 22 \\ 23 \\ 24\end{array}$

TOTAL

QUOTA

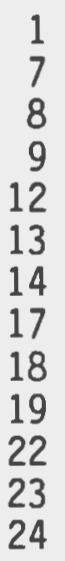

2

3

4 TOTAL QUOTA

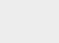

$\begin{array}{rlllrr}274 & 0 & 0 & 0 & 274 & 20 \\ 0 & 0 & 0 & 0 & 0 & 4 \\ 0 & 0 & 0 & 0 & 0 & 4 \\ 0 & 0 & 0 & 0 & 0 & 12 \\ 0 & 0 & 0 & 0 & 0 & 7 \\ 0 & 0 & 0 & 0 & 0 & 9 \\ 0 & 0 & 0 & 0 & 0 & 4 \\ 0 & 0 & 0 & 0 & 0 & 6 \\ 0 & 0 & 0 & 0 & 0 & 13 \\ 0 & 0 & 0 & 0 & 0 & 8 \\ 0 & 0 & 0 & 0 & 0 & 7 \\ 0 & 0 & 0 & 0 & 0 & 12 \\ 0 & 0 & 0 & 0 & 0 & 46\end{array}$

$\begin{array}{rllll}274 & 0 & 0 & 0 & 274 \\ 4 & 4 & 4 & 4 & \end{array}$

WHOLESALE RESIDUAL STRATUM $=2$, QUOTA $=4$ RETAIL RESIDUAL STRATA

$\begin{array}{lr}\text { NO. } 2 & 1 \\ \text { DISTILLATE } & 7 \\ \text { STRATA } & 8 \\ & 9 \\ & 12 \\ 13 \\ 14 \\ 17 \\ 18 \\ 19 \\ 22 \\ 23 \\ 24\end{array}$

TOTAL

QUOTA

1
7
8
9
12
13
14
17
18
19
22
23
24

2

3

4 TOTAL QUOTA

$\begin{array}{lll}0 & \\ 0 & 22 & \\ 0 & 25\end{array}$

0

0

0

0

0

0

$0 \quad \frac{173}{36}$

020

$\begin{array}{ll}0 & 30 \\ 0 & 45\end{array}$

0
3
1
1
0
$(2)^{1}$
0
$(1)^{2}$
$(2)^{3}$
3
0
1
1

$\begin{array}{rrr}0 & 0 & 20 \\ 0 & 25 & 4 \\ 0 & 26 & 4 \\ 2 & 21 & 12 \\ 0 & 177 & 7 \\ 0 & 210 & 9 \\ 1 & 26 & 4 \\ 0 & 84 & 6 \\ 0 & 175 & 13 \\ 1 & 40 & 8 \\ 1 & 21 & 7 \\ 8 & 31 & 12 \\ 3 & 49 & 46\end{array}$

$\begin{array}{rrrrr}0 & 862 & 15 & 8 & 885 \\ 4 & 4 & 4 & 4 & \end{array}$ 
TABLE 5. Pennsylvania Frame (Cont.)

WHOLESALE RESIDUAL STRATUM $=3$, QUOTA $=2$ RETAIL RESIDUAL STRATA

NO. 2 ISTILLATE $\frac{1}{7}$

STRATA 8

9

13

14

17

18

19

22

23

TOTAL

QUOTA

23

0

0

0

4

0

0

0

0

0

0
0
0

$\begin{array}{ll}0 & 1 \\ 4 & 4\end{array}$
4 TOTAL QUOTA

$\begin{array}{ll}0 & 0 \\ 0 & 0 \\ 1 & 0 \\ 0 & 0 \\ 0 & 0 \\ 0 & 0 \\ 0 & 0 \\ 0 & 0 \\ 0 & 0 \\ 0 & 0 \\ 0 & 0 \\ 0 & 0 \\ 0 & 0\end{array}$

$\begin{array}{ll}1 & 0 \\ 4 & 4\end{array}$ $\begin{array}{rr}0 & 20 \\ 0 & 4 \\ 1 & 4 \\ 1 & 12 \\ 0 & 7 \\ 0 & 9 \\ 0 & 4 \\ 0 & 6 \\ 0 & 13 \\ 0 & 8 \\ 0 & 7 \\ 0 & 12 \\ 0 & 46\end{array}$

2

WHOLESALE RESIDUAL STRATUM $=4$, QUOTA $=1$ RETAIL RESIDUAL STRATA

NO. 2 DISTILLATE 7 STRATA

TOTAL QUOTA

$\begin{array}{llll}2 & 3 & 4 & \text { TOTAL QUOTA }\end{array}$

1

0

0

0

0
0

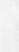

(1)

(1)

0
0

$\begin{array}{ll}0 & 0 \\ 4 & 4\end{array}$

$\begin{array}{lll}0 & 0 & 0 \\ 0 & 0 & 0 \\ 0 & 0 & 0 \\ 0 & 0 & 0 \\ 0 & 0 & 0 \\ 0 & 0 & 0 \\ 0 & 0 & 0 \\ 0 & 0 & 0 \\ 0 & 0 & 0 \\ 0 & 0 & 0 \\ 0 & 0 & 0 \\ 0 & 0 & 0 \\ 0 & 1 & 0\end{array}$

$\begin{array}{ll}0 & 1 \\ 4 & 4\end{array}$ $\begin{array}{lll}0 & 0 \\ 0 & 0\end{array}$

0

0

$0 \quad 0$

0

0

$\begin{array}{rrr}0 & 0 & 8 \\ 0 & 0 & 7\end{array}$

$\begin{array}{lll}0 & 0 & 12 \\ 0 & 1 & 46\end{array}$

$\begin{array}{ll}0 & 1 \\ 4 & \end{array}$ 


\section{TABLE 5. Pennsylvania Frame (Cont.) \\ WHOLESALE RESIDUAL STRATUM $=5$, QUOTA $=1$ RETAIL RESIDUAL STRATA}

$\begin{array}{lrrrrrrr} & & 1 & 2 & 3 & 4 & \text { TOTAL } & \text { QUOTA } \\ \text { N0. 2 } & 1 & 0 & 0 & 0 & 0 & 0 & 20 \\ \text { DISTILLATE } & 7 & 0 & 0 & 0 & 0 & 0 & 4 \\ \text { STRATA } & 8 & 0 & 0 & 0 & 0 & 0 & 4 \\ & 9 & 0 & 0 & 0 & 0 & 0 & 12 \\ & 12 & 0 & 0 & 0 & 0 & 0 & 7 \\ & 13 & 0 & 0 & 0 & 0 & 0 & 9 \\ & 14 & 0 & 0 & 0 & 0 & 0 & 4 \\ & 17 & 0 & 0 & 0 & 0 & 0 & 6 \\ & 18 & 0 & 0 & 0 & 0 & 0 & 13 \\ & 19 & 0 & 0 & 0 & 0 & 0 & 8 \\ & 22 & 0 & 0 & 0 & 0 & 0 & 7 \\ \text { TOTAL } & 23 & 0 & 0 & 0 & 0 & 0 & 12 \\ \text { QUOTA } & 24 & 0 & 0 & 0 & 1 & 1 & 46 \\ & & 0 & 0 & 0 & 1 & 1 & \end{array}$

Three Variable Analysis

Iterative application of IPF resulted in certainty sampling of three additional cells representing five companies. Expected sample sizes and sampling weights under the three procedures are compared in Figures 21-25 and show trends similar to those found for the other states analyzed.

Two Variable Analysis

The sampling problem for the Pennsylvania data can be reduced to two dimensions by separate sampling of the isolated cell in the slice corresponding to stratum 1 of the wholesale residual variable and certainty sampling of strata 3-5 of the same variable. Removing these components from the population table yields a new bivariate population shown in Table 6 . 


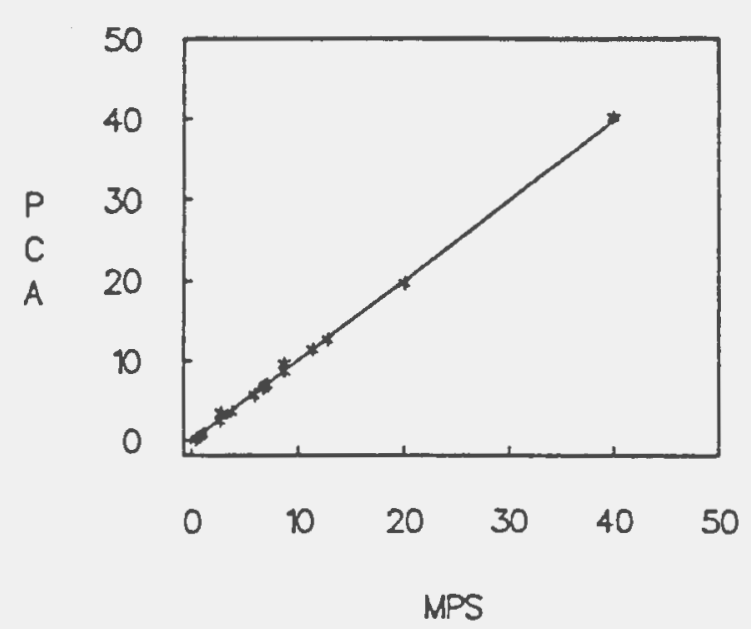

FIG 2L PA SAMPLE SIZES

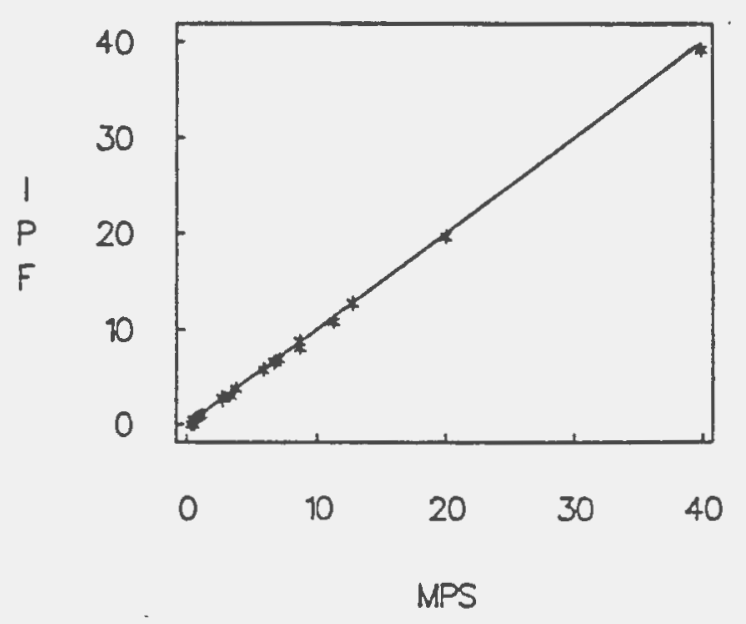

FIG 23. PA SAMPLE SEES

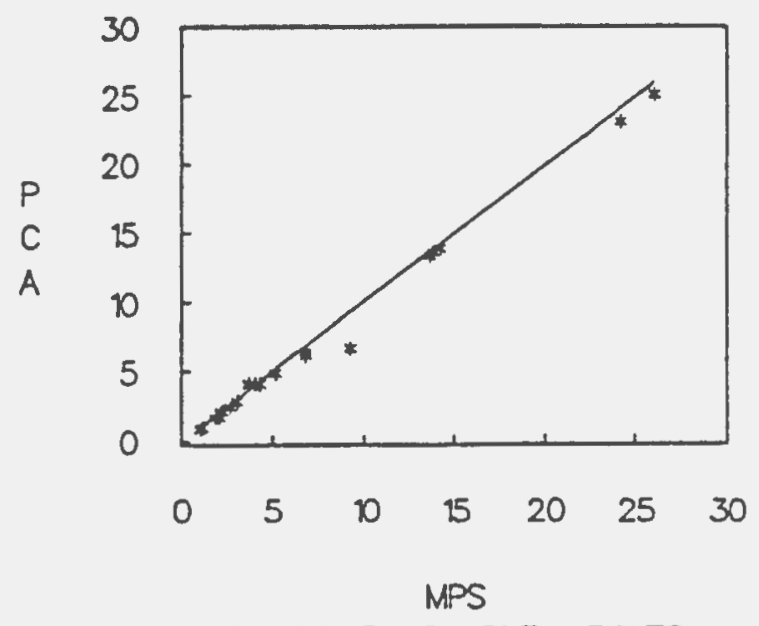

FIG 22. PA SAMPLE WEIGHTS

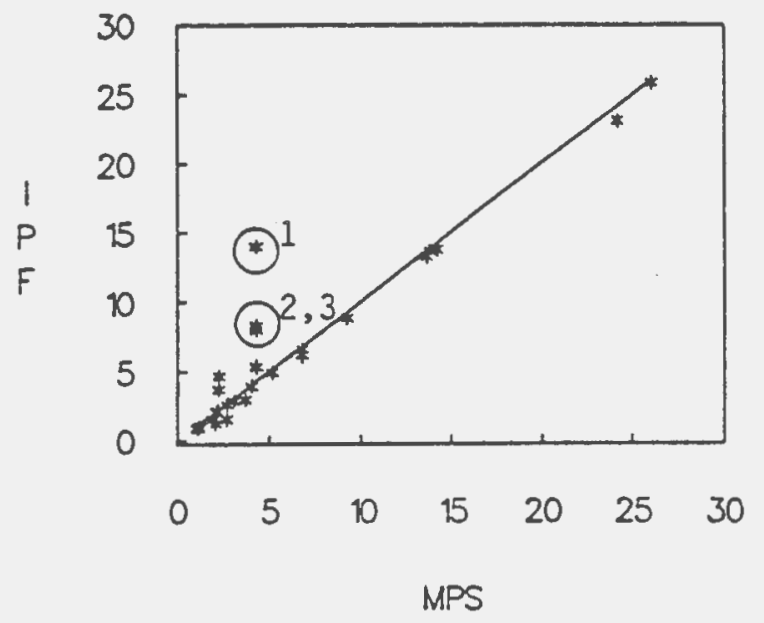

FIG 24. PA SAMPLE WEIGHTS

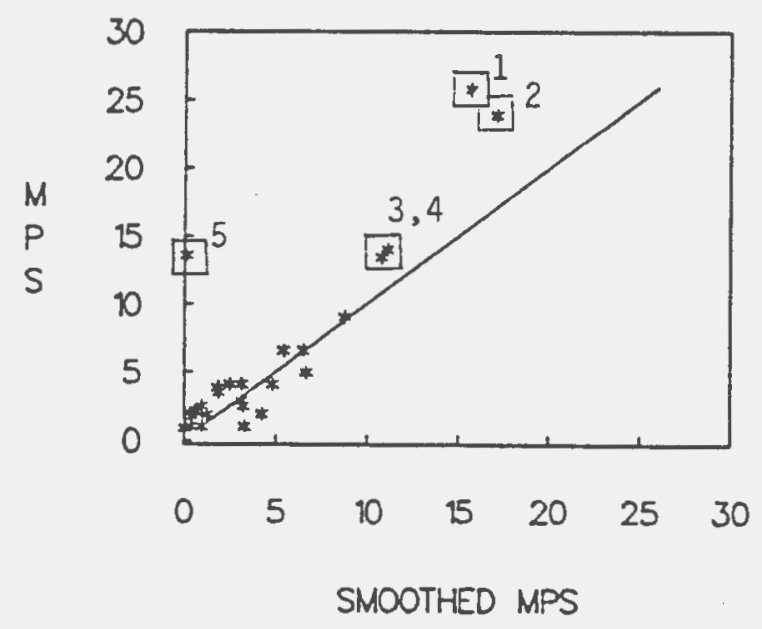

FIG 25. PA SAMPLE WEIGHTS 
TABLE 6. Reduced PA Frame

WHOLESALE RESIDUAL STRATUM $=2$, QUOTA $=4$

RETAIL RESIDUAL STRATA

NO. $2 \quad 7$

DISTILLATE 8

STRATA

TOTAL

QUOTA

PREVIOUSLY FILLED

9

12

14

17

18

19

22

23

24

\begin{tabular}{r}
2 \\
22 \\
25 \\
18 \\
$1_{177}^{1}$ \\
\hline 208 \\
25 \\
83 \\
173 \\
36 \\
20 \\
30 \\
45
\end{tabular}

862

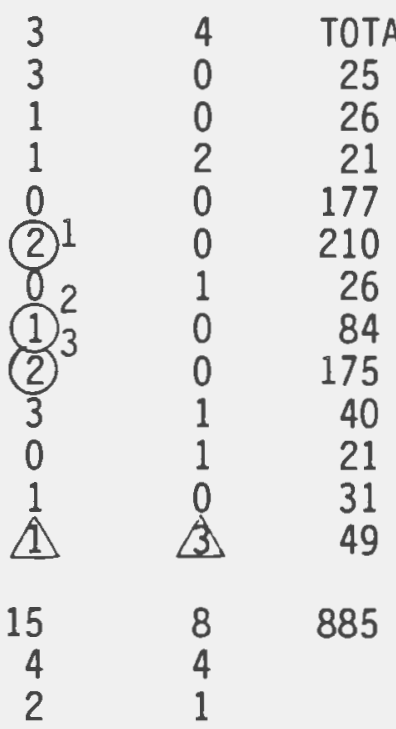

4

PREVIOUSLY

FILLED

$\begin{array}{cc} & \text { PREVIOUSLY } \\ \text { QUOTA } & \text { FILLED } \\ 4 & \\ 4 & 1 \\ 12 & 1 \\ 7 & \\ 9 & \\ 4 & \\ 6 & \\ 13 & \\ 8 & \\ 7 & \\ 12 & \\ 46 & 2\end{array}$

The initial application of IPF resulted in the removal of two cells representing four companies. With these components removed from the table, IPF yielded an expected sample table with sample quotas less than or equal to the corresponding frame entries. Expected cell sample sizes and sample weights for the three methods were compared (Figures 26-30) exactly as in the three variable analysis.

\subsubsection{Massachusetts Results}

For the State of Massachusetts, eight of the no. 2 distillate strata were nonempty, as were one of the retail residual and two of the wholesale residual strata. Crossing the three variables results in a $17 \times 4 \times 3$ table. Slicing the table into sections corresponding to the three wholesale residual strata results in three bivariate tables results in Table 7 . 


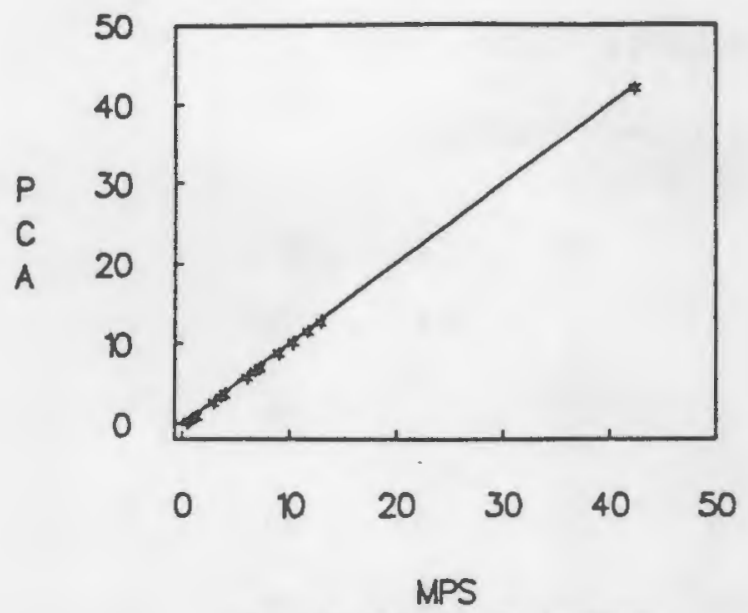

FIG 26. PA SAMPLE SZES

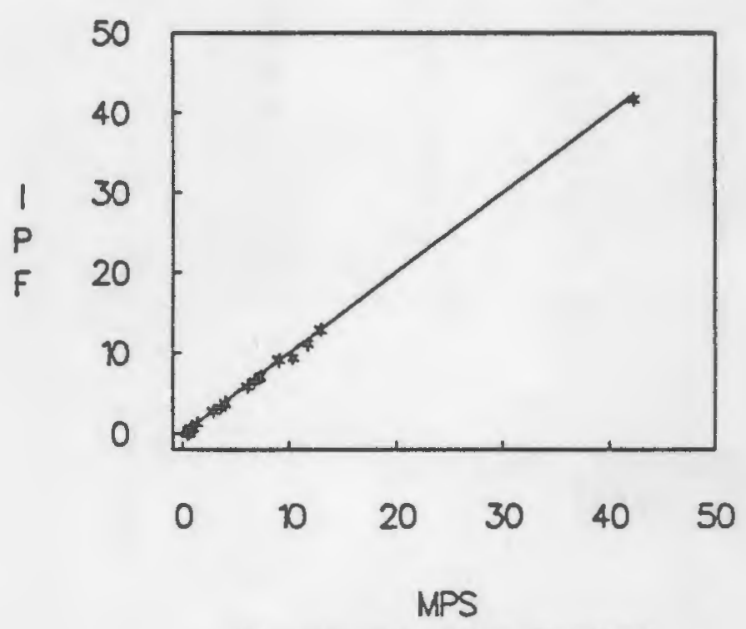

FIG 28. PA SAMPLE SIZES

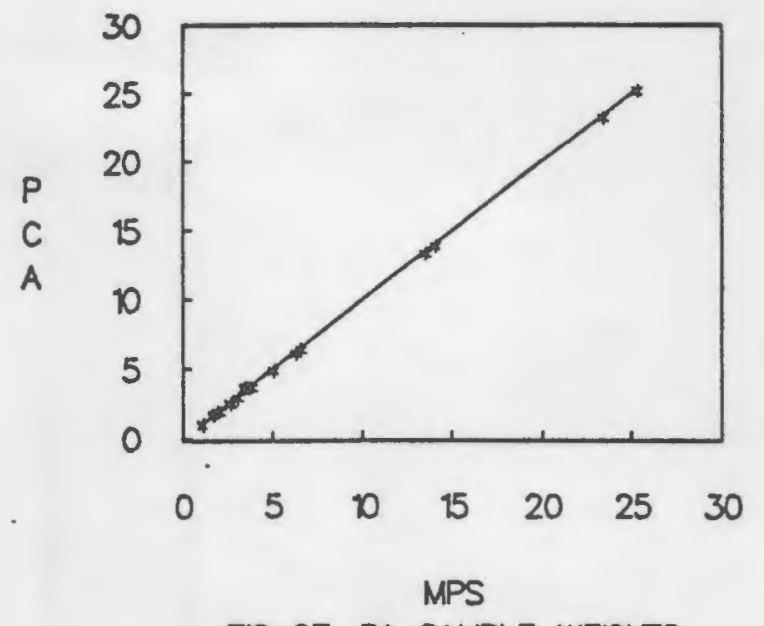

FIG 27. PA SAMPLE WEIGHTS

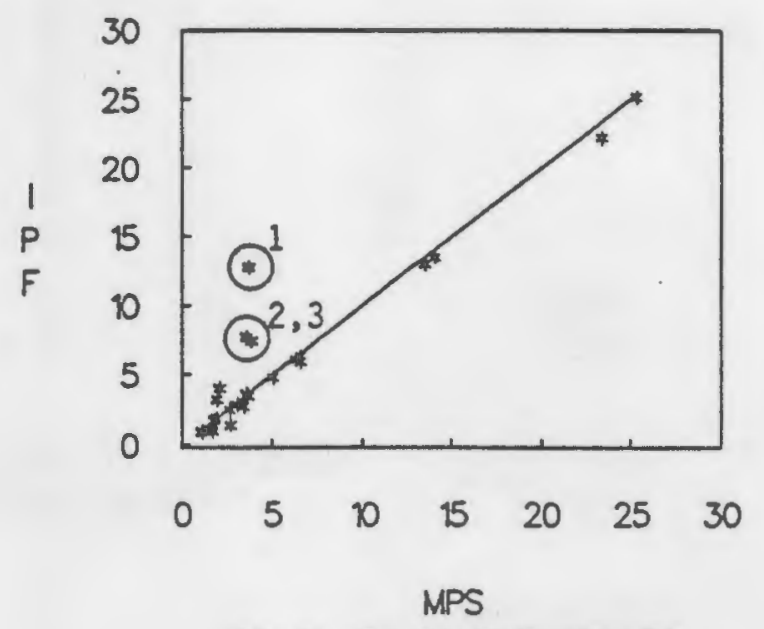

FIG 29. PA SAMPLE WEIGHTS

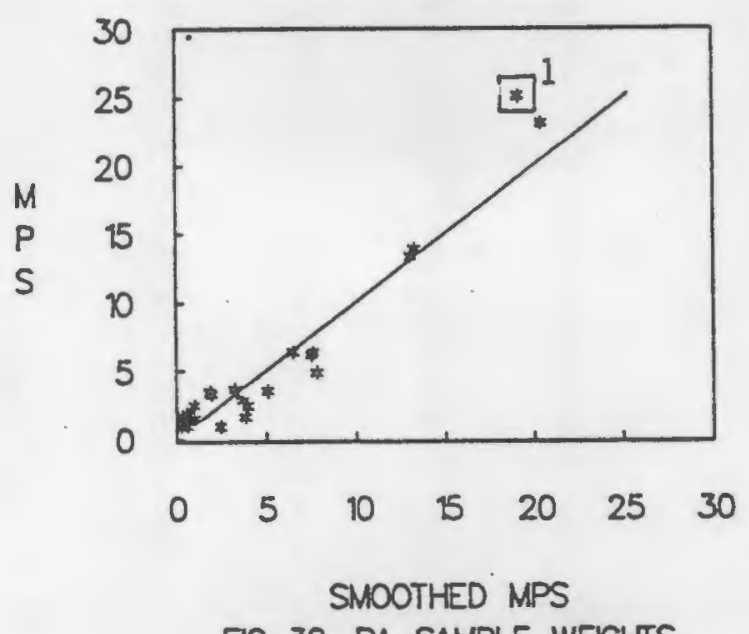

FIG 30. PA SAMPLE WEIGHTS 


\section{TABLE 7. Massachusetts Frame}

WHOLESALE RESIDUAL STRATUM $=1$, QUOTA $=4$ RETAIL RESIDUAL STRATA

$\begin{array}{lrrrrrrr} & & 1 & 2 & 3 & 4 & \text { TOTAL } & \text { QUOTA } \\ \text { N0. } 2 & 1 & 391 & 0 & 0 & 0 & 391 & 26 \\ \text { DISTILLATE } & 7 & 0 & 0 & 0 & 0 & 0 & 4 \\ \text { STRATA } & 8 & 0 & 0 & 0 & 0 & 0 & 4 \\ & 9 & 0 & 0 & 0 & 0 & 0 & 4 \\ & 10 & 0 & 0 & 0 & 0 & 0 & 9 \\ & 12 & 0 & 0 & 0 & 0 & 0 & 11 \\ & 13 & 0 & 0 & 0 & 0 & 0 & 5 \\ & 14 & 0 & 0 & 0 & 0 & 0 & 4 \\ & 15 & 0 & 0 & 0 & 0 & 0 & 4 \\ & 17 & 0 & 0 & 0 & 0 & 0 & 11 \\ & 18 & 0 & 0 & 0 & 0 & 0 & 5 \\ & 19 & 0 & 0 & 0 & 0 & 0 & 4 \\ & 20 & 0 & 0 & 0 & 0 & 0 & 4 \\ & 22 & 0 & 0 & 0 & 0 & 0 & 6 \\ & 23 & 0 & 0 & 0 & 0 & 0 & 6 \\ & 24 & 0 & 0 & 0 & 0 & 0 & 11 \\ & 25 & 0 & 0 & 0 & 0 & 0 & 21 \\ \text { TOTAL } & & 391 & 0 & 0 & 0 & 391 & \\ \text { QUOTA } & & 26 & 4 & 4 & 4 & & \end{array}$

WHOLESALE RESIDUAL STRATUM $=2$, QUOTA $=4$ RETAIL RESIDUAL STRATA

$\begin{array}{lllll}1 & 2 & 3 & 4 & \text { TOTAL QUOTA }\end{array}$

NO. 2
DISTILLATE
STRATA

TOTAL

QUOTA

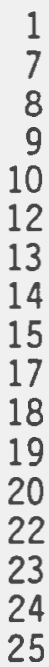

25

10

12

13

15

17

18

19

20

22

23

0
0

0

4

$$
\text { (1) }
$$


TABLE 7. Massachusetts Frame (Cont.)

WHOLESALE RESIDUAL STRATUM $=4$, QUOTA $=1$

RETAIL RESIDUAL STRATA

$\begin{array}{lrlllllr}\text { NO. } 2 & 1 & 0 & 0 & 0 & 0 & 0 & 26 \\ \text { DISTILLATE } & 7 & 0 & 0 & 0 & 0 & 0 & 4 \\ \text { STRATA } & 8 & 0 & 0 & 0 & 0 & 0 & 4 \\ & 9 & 0 & 0 & 0 & 0 & 0 & 4 \\ & 10 & 0 & 0 & 0 & 0 & 0 & 9 \\ 12 & 0 & 0 & 0 & 0 & 0 & 11 \\ & 13 & 0 & 0 & 0 & 0 & 0 & 5 \\ & 14 & 0 & 0 & 0 & 0 & 0 & 4 \\ 15 & 0 & 0 & 0 & 0 & 0 & 4 \\ 17 & 0 & 0 & 0 & 0 & 0 & 11 \\ & 18 & 0 & 0 & 0 & 0 & 0 & 5 \\ 19 & 0 & 0 & 0 & 0 & 0 & 4 \\ & 20 & 0 & 0 & 0 & 0 & 0 & 4 \\ 22 & 0 & 0 & 0 & 0 & 0 & 6 \\ & 23 & 0 & 0 & 0 & 0 & 0 & 6 \\ 24 & 0 & 0 & 0 & 0 & 0 & 11 \\ 25 & 0 & 0 & 1]^{5} & 0 & 1 & 21\end{array}$

TOTAL

QUOTA

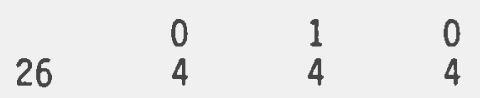

1

Three Variable Analysis

In the three variable analysis for the State of Massachusetts, the first application of IPF generated two expected sample sizes which exceeded their corresponding frame counts. These cells were sampled with certainty, and IPF was applied to the remaining table. This second application resulted in expected sample sizes satisfying $E\left(n_{i j k}\right) \leq N_{i j k}$ for all cells. Expected sample sizes and sampling weights under all three sampling procedures are compared in Figures 31-35 and show trends similar to those found for the other states analyzed.

Two Variable Analysis

As is evident from Table 7, removal of the isolated nonrespondent cell and certainty sampling of a single company in the fourth stratum of the wholesale residual variable (which is required to meet the stratum quota), reduces the Massachusetts frame to a bivariate table (Table 8 ). 


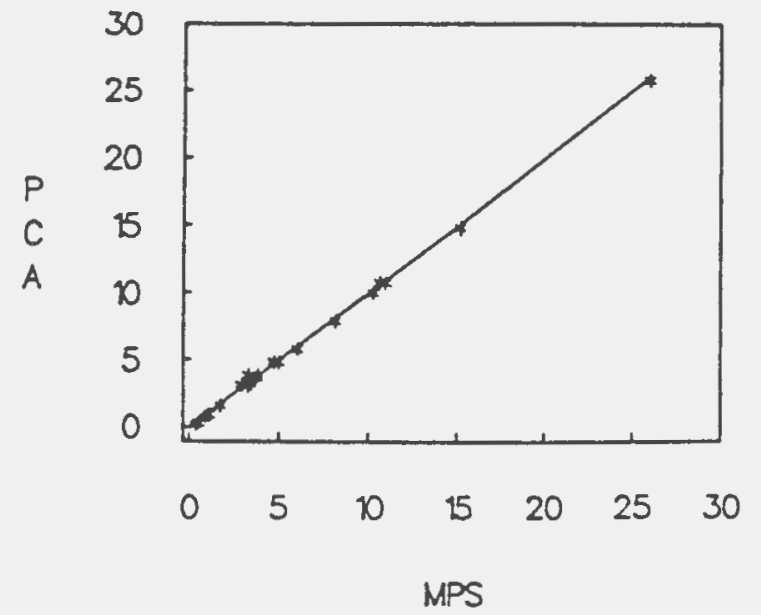

FIG 31. MA SAMPLE SEES

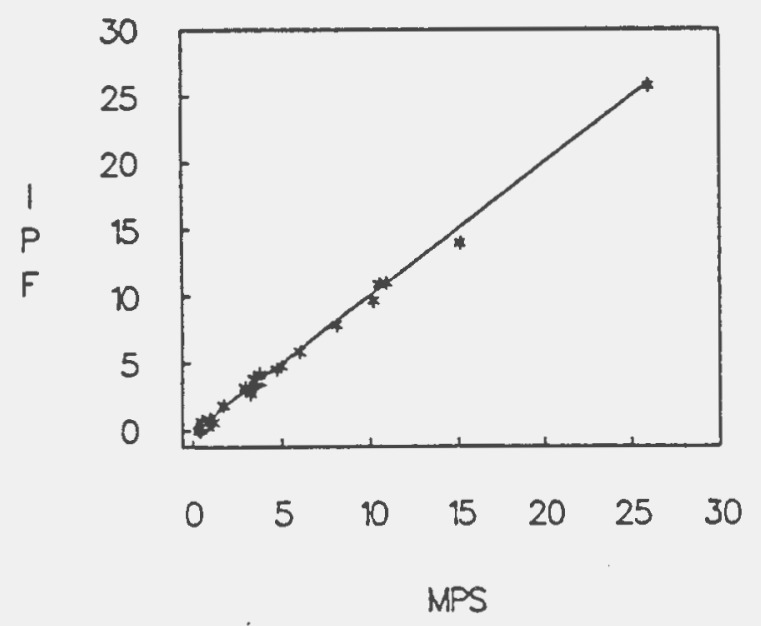

FIG 33. MA SAMPLE SIZES

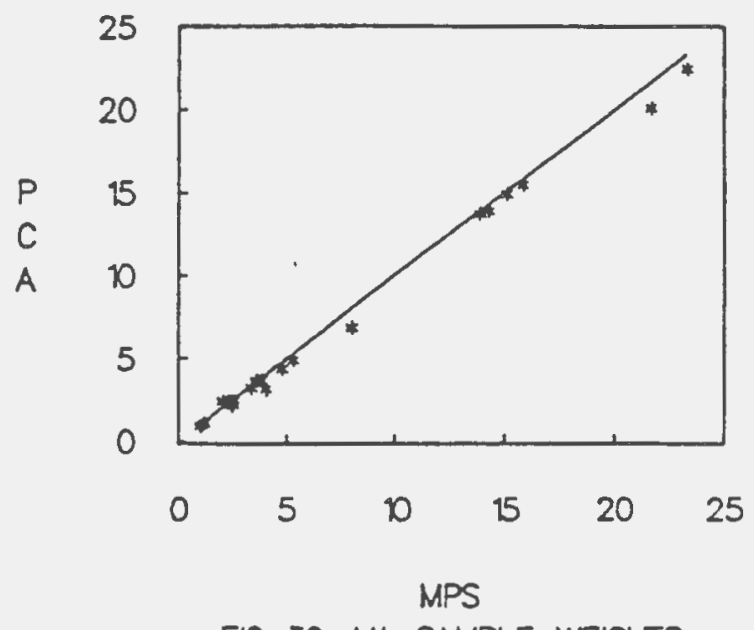

FIG 32. MA SAMPLE WEIGHTS

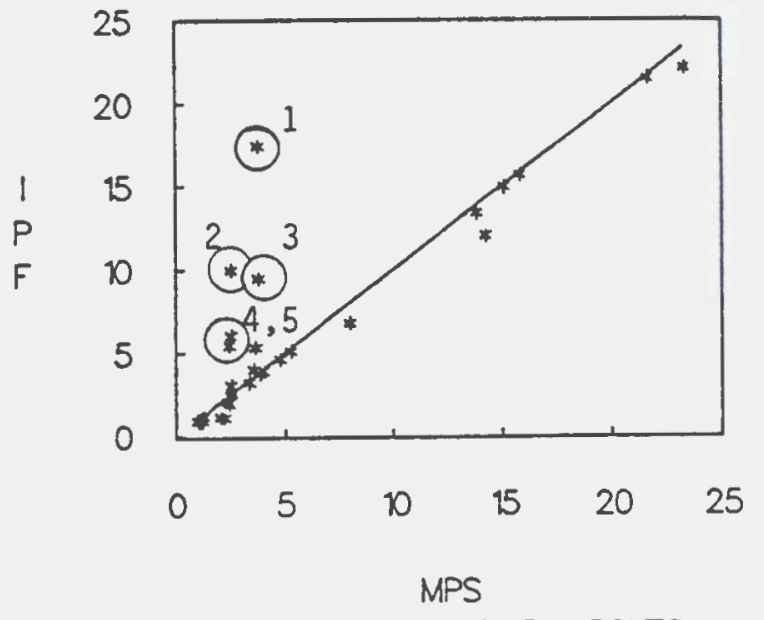

FIG 34. MA SAMPLE WEIGHTS

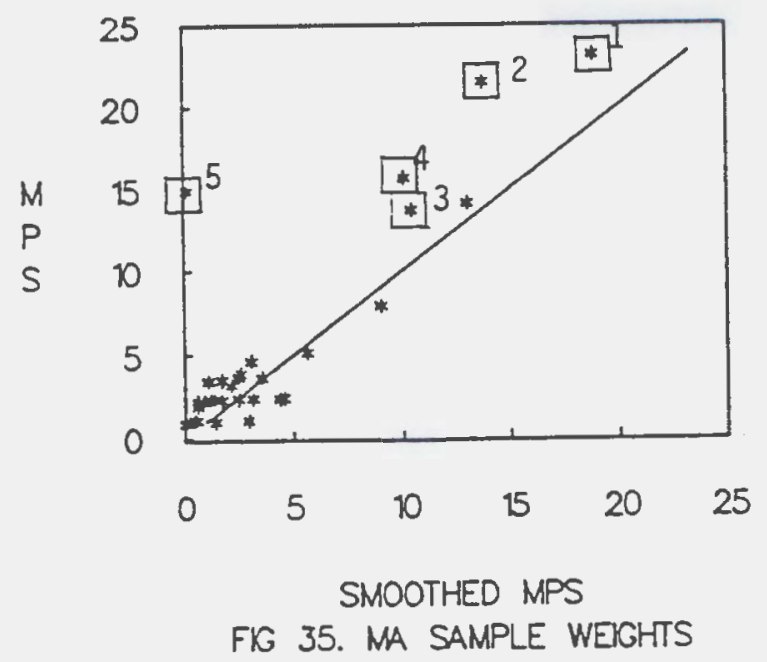


TABLE 8. Reduced MA Frame

(WHOLESALE RESIDUAL STRATUM=2, QUOTA=4)

RETAIL RESIDUAL STRATA

$\begin{array}{llll}2 & 3 & 4 & \text { TOTAL QUOTA PREVIOUSLY }\end{array}$

FILLED

\begin{tabular}{|c|c|c|c|c|c|c|}
\hline $\begin{array}{l}\text { NO. } 2 \\
\text { DISTILLATE } \\
\text { STRATA }\end{array}$ & $\begin{array}{r}7 \\
8 \\
9 \\
10 \\
12 \\
13 \\
14 \\
15 \\
17 \\
18 \\
19 \\
20 \\
22 \\
23 \\
24 \\
25\end{array}$ & 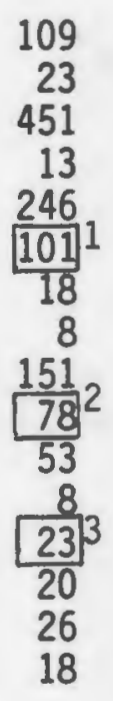 & $\begin{array}{r}8 \\
4 \\
13 \\
8 \\
1 \\
8 \\
0 \\
1 \\
0 \\
0 \\
1 \\
1 \\
0 \\
0 \\
1 \\
4\end{array}$ & $\begin{array}{l}1 \\
1 \\
1 \\
\&^{2} \\
\frac{1}{0} \\
0 \\
1 \\
1 \\
1)^{4} \\
0 \\
(2)^{5} \\
0 \\
0 \\
1 \\
8\end{array}$ & $\begin{array}{r}118 \\
28 \\
465 \\
13 \\
248 \\
101 \\
18 \\
10 \\
152 \\
78 \\
56 \\
9 \\
23 \\
20 \\
28 \\
24\end{array}$ & $\begin{array}{r}4 \\
4 \\
4 \\
9 \\
11 \\
5 \\
4 \\
4 \\
11 \\
5 \\
4 \\
4 \\
6 \\
6 \\
11 \\
21\end{array}$ \\
\hline $\begin{array}{l}\text { TOTAL } \\
\text { QUOTA } \\
\text { PREVIOUSLY }\end{array}$ & FILLED & $\begin{array}{r}814 \\
4\end{array}$ & $\begin{array}{r}14 \\
4 \\
1\end{array}$ & $\begin{array}{r}10 \\
4\end{array}$ & 838 & \\
\hline
\end{tabular}

IPF was applied twice before yielding a table with sample quotas less than or equal to the corresponding frame entries. Expected cell sample sizes and sample weights for the three methods were compared exactly as in the three variable analysis. Examination of Figures 36-40 shows that the conclusions of these comparisons are generally the same.

\subsubsection{Georgia Results}

For the State of Georgia, thirteen of the no. 2 distillate strata were nonempty, as were three of the retail residual and four of the wholesale residual strata. Crossing the three variables results in the four bivariate tables given in Table 9. 


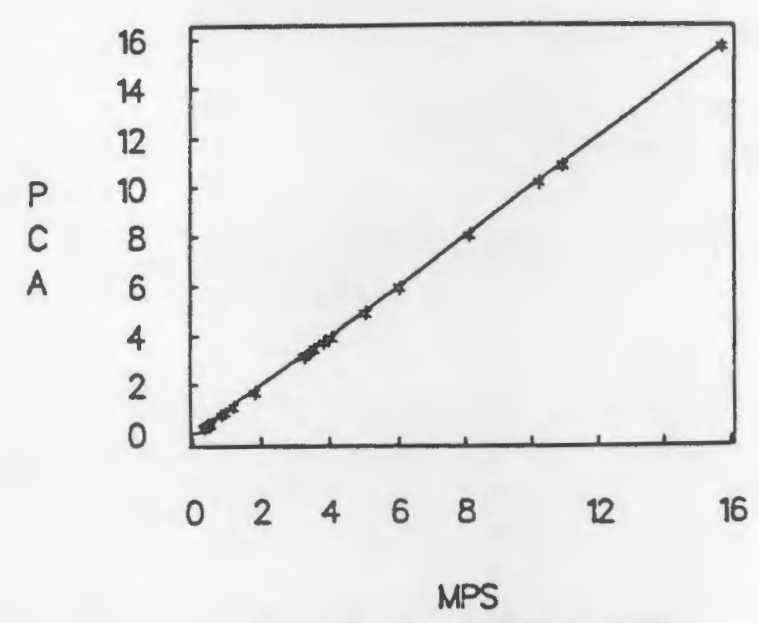

FIG 36. MA SAMPLE SIZES

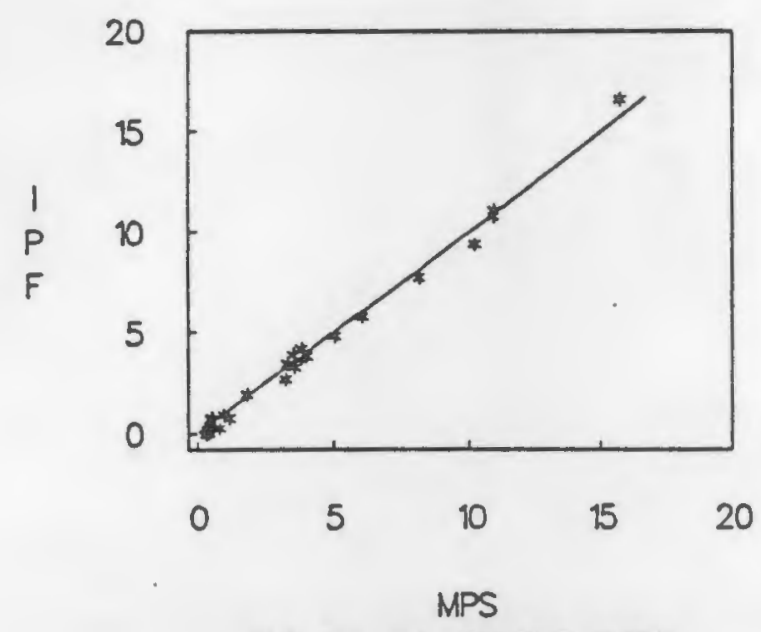

FIG 38. MA SAMPLE SIZES

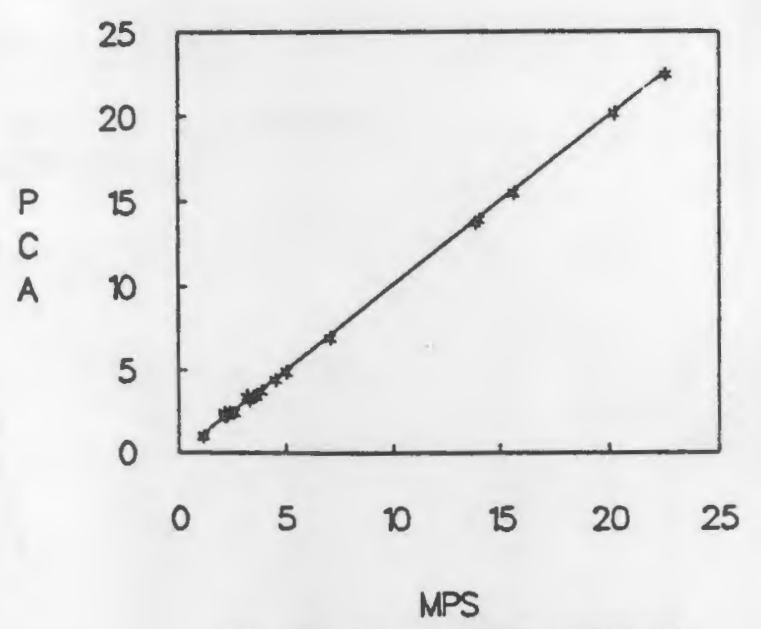

FIG 37. MA SAMPLE WEKGHTS

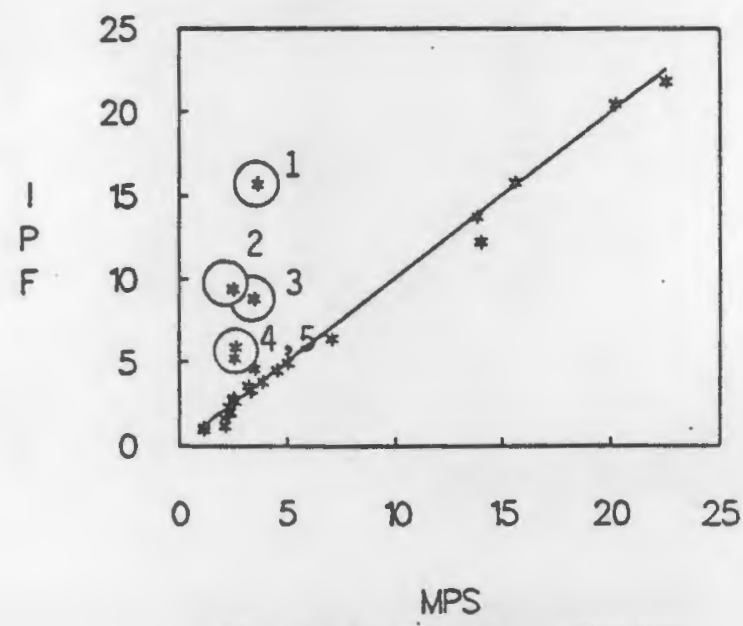

FIG 39. MA SAMPLE WEIGHTS

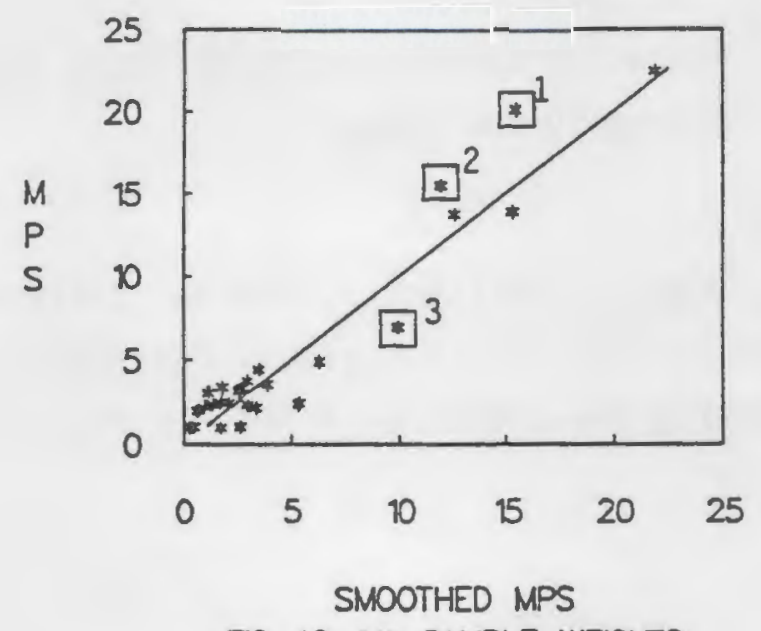

FIG 40. MA SAMPLE WEIGHTS 


\section{TABLE 9. Georgia Frame}

WHOLESALE RESIDUAL STRATUM $=1$, QUOTA $=4$ RETAIL RESIDUAL STRATA

$\begin{array}{lr}\text { N0. } 2 & 1 \\ \text { DISTILLATE } & 8 \\ \text { STRATA } & 9 \\ & 10 \\ & 13 \\ & 14 \\ 15 \\ 18 \\ 19 \\ 20 \\ 23 \\ 24 \\ 25\end{array}$

TOTAL

QUOTA

1
8
9
10
13
14
15
18
19
20
23
24
25

1223 TOTAL QUOTA

$\begin{array}{lllll}106 & 0 & 0 & 106 & 10\end{array}$

$\begin{array}{rrrrr}0 & 0 & 0 & 0 & 5 \\ 0 & 0 & 0 & 0 & 5\end{array}$

$\begin{array}{rrrrr}0 & 0 & 0 & 0 & 5 \\ 0 & 0 & 0 & 0 & 17\end{array}$

$\begin{array}{lllll}0 & 0 & 0 & 0 & 4\end{array}$

$\begin{array}{lllll}0 & 0 & 0 & 0 & 5\end{array}$

$\begin{array}{lllll}0 & 0 & 0 & 0 & 6\end{array}$

$\begin{array}{lllll}0 & 0 & 0 & 0 & 6\end{array}$

$\begin{array}{lllll}0 & 0 & 0 & 0 & 4\end{array}$

$\begin{array}{lllll}0 & 0 & 0 & 0 & 6\end{array}$

$\begin{array}{llll}0 & 0 & 0 & 0\end{array}$

$\begin{array}{rrrrr}0 & 0 & 0 & 0 & 4 \\ 0 & 0 & 0 & 0 & 10\end{array}$

$\begin{array}{rrrr}106 & 0 & 0 & 106 \\ 4 & 4 & 8 & \end{array}$

WHOLESALE RESIDUAL STRATUM $=2$, QUOTA $=4$ RETAIL RESIDUAL STRATA

$\begin{array}{llll}1 & 2 & 3 & \text { TOTAL QUOTA }\end{array}$

$\begin{array}{ll} & 1 \\ \text { DISTILLATE } & 8 \\ \text { STRATA } & 9\end{array}$

10

13

25

$\begin{array}{rrrrr}0 & 0 & 0 & 0 & 10 \\ 0 & 129 & 3 & 131 & 5 \\ 0 & 49 & 1 & 50 & 5 \\ 0 & 27 & 2 & 29 & 17 \\ 0 & 52 & 3 & 55 & 4 \\ 0 & 53 & 1 & 54 & 5 \\ 0 & 17 & 0 & 17 & 6 \\ 0 & 27 & 0 & 27 & 6 \\ 0 & 14 & 8 & 14 & 4 \\ 0 & 13 & 1 & 14 & 6 \\ 0 & 8 & 0 & 8 & 5 \\ 0 & 9 & 8 & 9 & 4 \\ 0 & 9 & \mathbb{1} & 10 & 10\end{array}$

TOTAL

$\begin{array}{rrrr}106 & 0 & 0 & 106 \\ 4 & 4 & 8 & \end{array}$


$\begin{array}{lr}\text { No. } 2 & 1 \\ \text { DISTILLATE } & 8 \\ \text { STRATA } & 9 \\ & 10 \\ & 13 \\ & 14 \\ 15 \\ 18 \\ 19 \\ 20 \\ 23 \\ 24 \\ 25\end{array}$

TOTAL

QUOTA

IABLE 9. Georgia Frame (Cont.)

WHOLESALE RESIDUAL STRATUM $=3$, QUOTA $=2$ RETAIL RESIDUAL STRATA

$\begin{array}{llll}1 & 2 & 3 & \text { TOTAL QUOTA }\end{array}$

$\begin{array}{lllll}0 & 0 & 0 & 0 & 10\end{array}$

$\begin{array}{lllll}0 & 0 & 0 & 0 & 5\end{array}$

$\begin{array}{lllll}0 & 0 & 0 & 0 & 5\end{array}$

$\begin{array}{lllll}0 & 0 & 0 & 0 & 17\end{array}$

$\begin{array}{lllll}0 & 0 & 1 & 1 & 4\end{array}$

$\begin{array}{lllll}0 & 0 & 0 & 0 & 5\end{array}$

150000006

000

$\begin{array}{llll}0 & 0 & 0 & 0\end{array}$

$\begin{array}{llll}0 & 0 & 0 & 0\end{array}$

$\begin{array}{lllll}0 & 0 & \frac{0}{2} & 0 & 5 \\ 0 & 0 & \frac{1}{0} & 1 & 4 \\ 0 & 0 & 0 & 10\end{array}$

$\begin{array}{rlll}106 & 0 & 2 & 2 \\ 4 & 4 & 8 & \end{array}$

WHOLESALE RESIDUAL STRATUM $=4$, QUOTA $=1$ RETAIL RESIDUAL STRATA

$\begin{array}{llll}1 & 2 & 3 & \text { TOTAL QUOTA }\end{array}$

DISTILLATE 8

STRATA 9

10

13

14

15

18

19

20

23

24

25

TOTAL

QUOTA

$\begin{array}{llllr}0 & 0 & 0 & 0 & 10 \\ 0 & 0 & 0 & 0 & 5 \\ 0 & 0 & 0 & 0 & 5 \\ 0 & 1 & 0 & 1 & 17 \\ 0 & 0 & 0 & 0 & 4 \\ 0 & 0 & 0 & 0 & 5 \\ 0 & 0 & 0 & 0 & 6 \\ 0 & 0 & 0 & 0 & 6 \\ 0 & 0 & 0 & 0 & 4 \\ 0 & 0 & 0 & 0 & 6 \\ 0 & 0 & 0 & 0 & 5 \\ 0 & 0 & 0 & 0 & 4 \\ 0 & 0 & 0 & 0 & 10\end{array}$

$\begin{array}{llll}0 & 1 & 0 & 1 \\ 4 & 4 & 8 & \end{array}$


Three Variable Analys is

In the three variable analysis for the State of Georgia, the first two applications of IPF generated expected cell sample sizes which sometimes exceeded their corresponding frame counts. In each case, the cells were removed, the marginal totals adjusted, and IPF reapplied. The third application resulted in an expected sample table with cell entries less than or equal to their corresponding frame counts. Comparisons of the resulting expected sample sizes and sample weights for all three methods are given in Figures 41-45.

\section{Two Variable Analys is}

The sampling problem for the Georgia data was reduced to two dimensions by separate sampling of the 10 company quota for the nonrespondent cell and certainty sampling of the third and fourth strata of the wholesale residual variable. Removing these components (plus stratum 25 of the no. 2 distillate variable which has quota equal to its population count) from the population table results in a reduced bivariate population shown in Table 10 .

TABLE 10. Reduced GA Frame

WHOLESALE RESIDUAL STRATUM $=4$, QUOTA $=1$ RETAIL RESIDUAL STRATA

NO. 2

DISTILLATE STRATA

8
9
10
13
14
15
18
19
20
23
24

TOTAL QUOTA

PREVIOUSLY FILLED

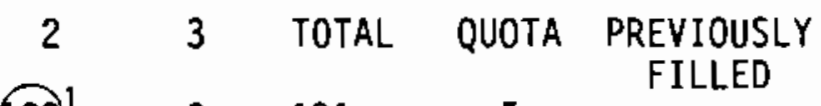

$\begin{array}{rrr}1281 & 3 & 131 \\ 49 & 1 & 50 \\ 27 & 8 & 29 \\ 52 & 3 & 55 \\ 53 & 1 & 54 \\ 17 & 0 & 17 \\ 27 & 0 & 27 \\ 14 & 8 & 14 \\ 13 & 8 & 14 \\ 8 & 0 & 8 \\ 9 & 0 & 9\end{array}$

5

5 17 4 5 6 6 


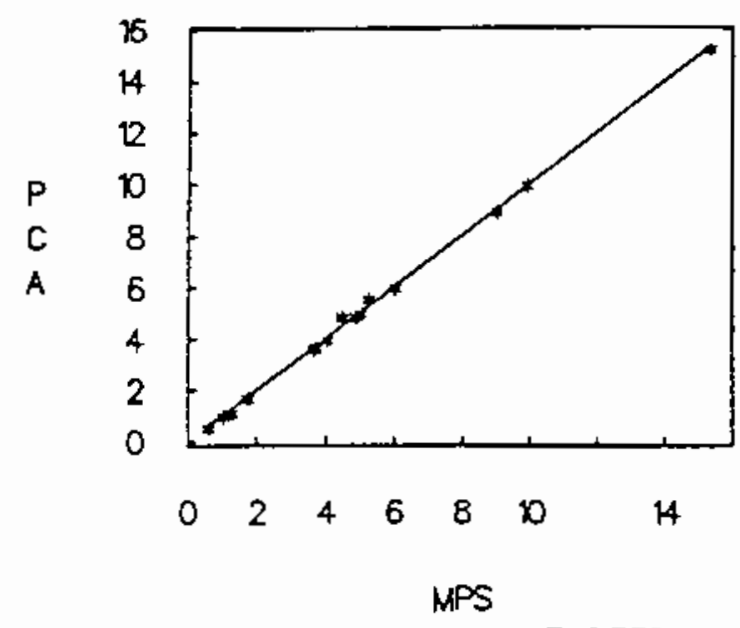

FIG 42 GA SAMPLE SIZES

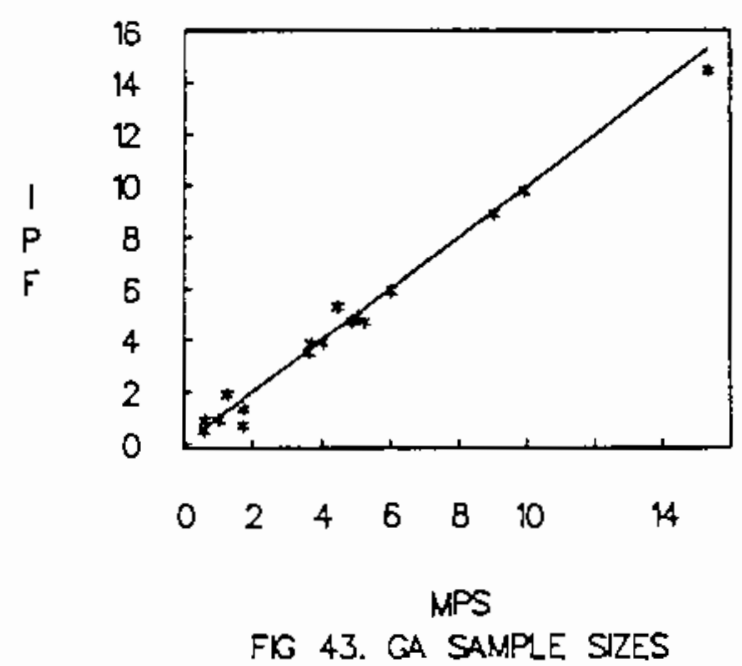

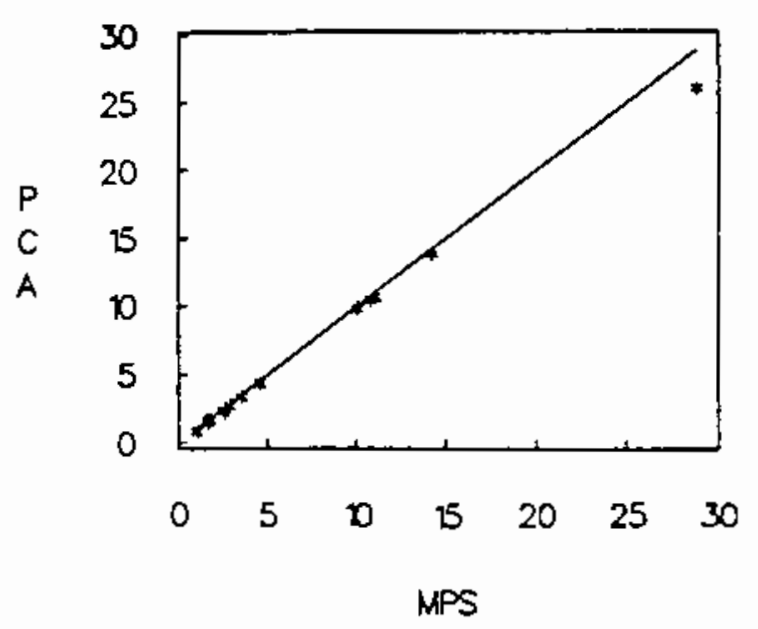

FIG 42. GA SAMPLE WEIGHTS

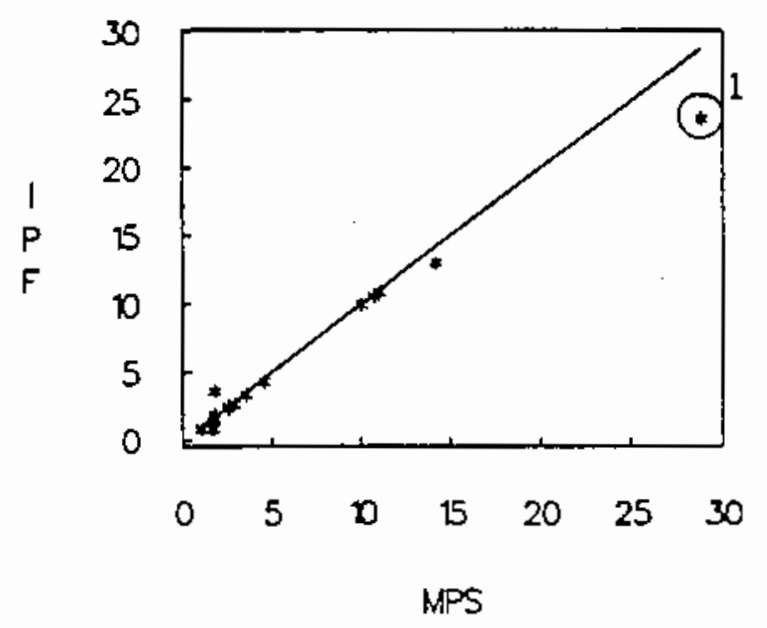

FIG 44. GA SAMPLE WEIGHTS

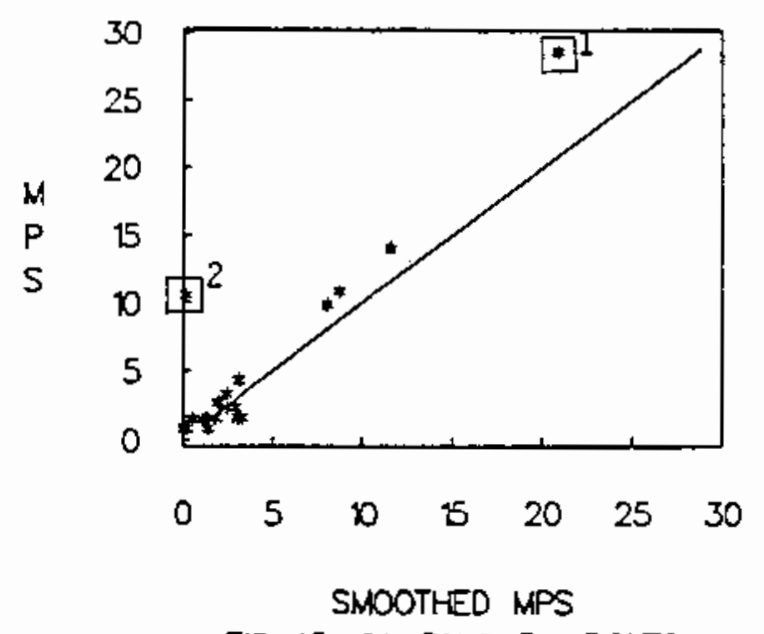

FIG 45. GA SAMPLE WEKHTS 
IPF was applied twice before yielding a table with all sample quotas less than or equal to their corresponding frame entries. Expected cell sample sizes and sample weights for the three methods were compared exactly as in the three variable analysis. Examination of figures 46-50 shows that the conclusions of these comparisons are generally the same. 


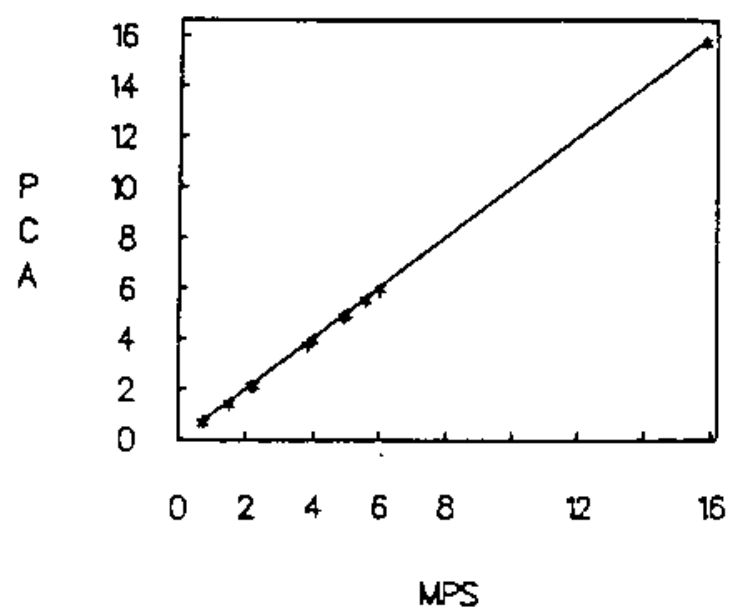

FK 46. GA SAMPLE SZES

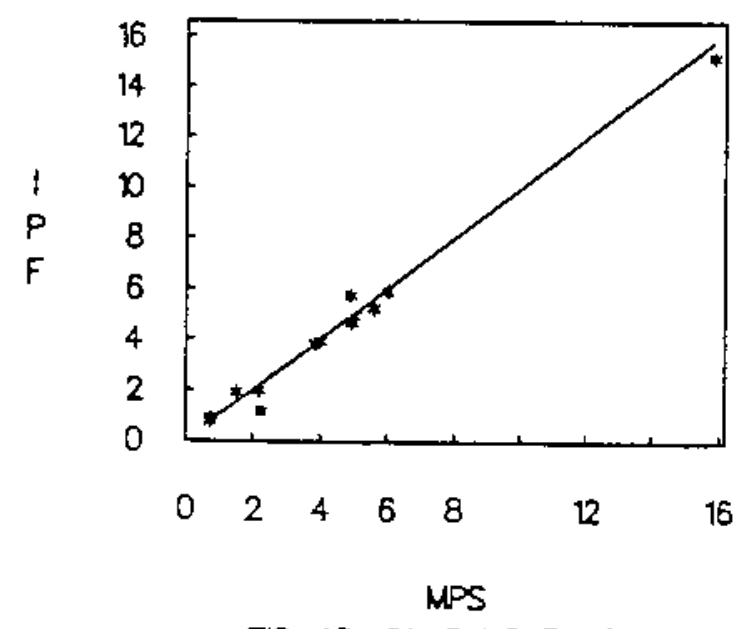

FK 48. GA SAMPLE SIZES

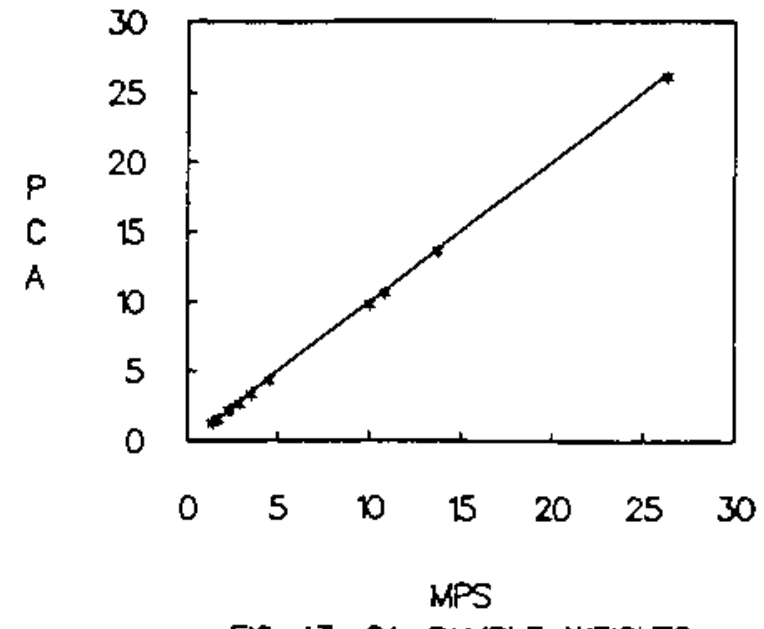

FK 47. GA SAMPLE WEIGHTS

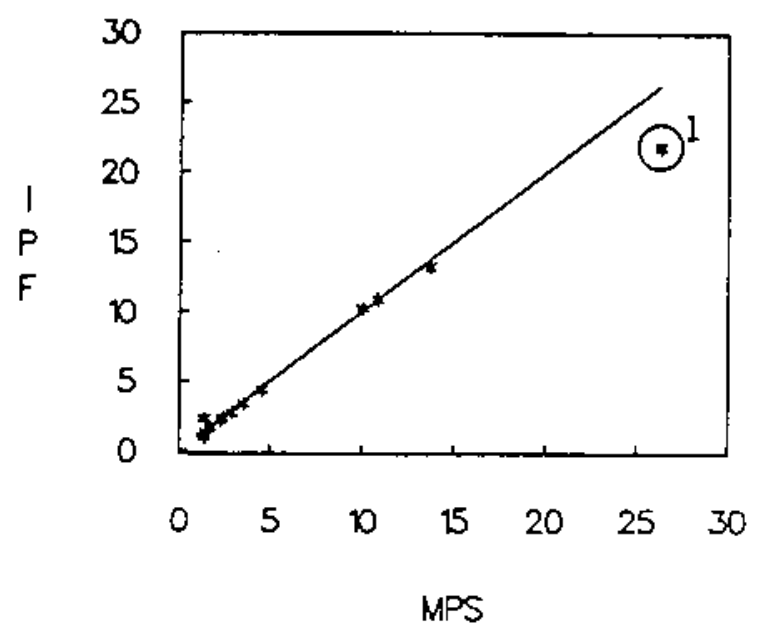

FIG 49. GA SAMPLE WEXGTS

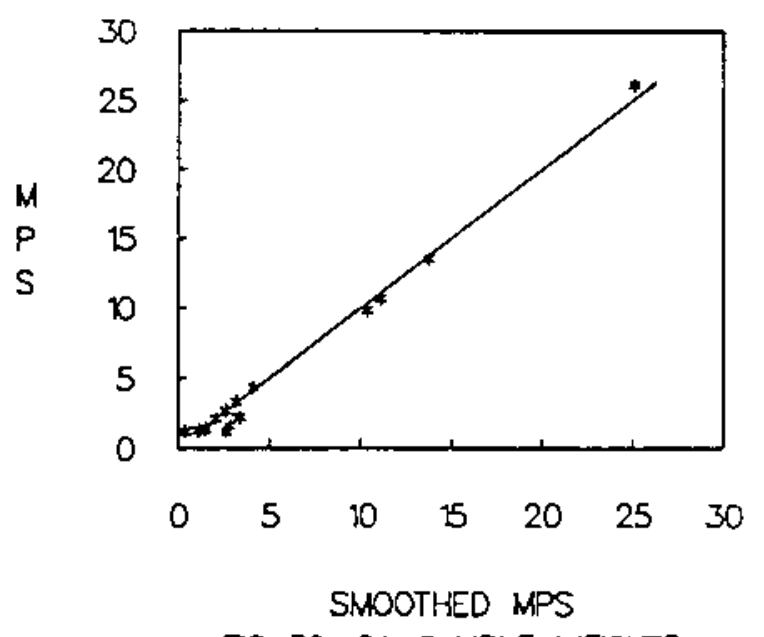

FIC 50. GA SAMPLE WEKHTS 


\subsection{CONCLUSIONS}

\subsection{SUMMARY}

In this paper we have considered three methods for multivariate sample design: the multiproduct sampling (MPS), proportional cell allotment (PCA), and iterative proportional fitting (IPF) techniques. Each method has its own particular strengths and weaknesses; however, at the current stage of development, the major differences among the three methods are related to ease of implementation and the ability to describe the statistical properties of associated estimators. In a bivariate application, PCA or IPF sampling appear to be preferable over the MPS technique, since exact sample weights are more easily determined, implementation is facilitated by the cox algorithm, and a smaller overall sample size may be possible. For more than two variables, the lack of a suitable rounding procedure limits the use of the PCA and MPS techniques; thus, MPS sampling is preferred, despite the need to result to Monte Carlo techniques in order to estimate the sample weights. The bounds established in Section 3.1 .3 can be used to determine an appropriate number $M$ of Monte Carlo trials as described in Section 3.3.2. In addition, empirical evidence (Section 7) suggests that the easily computed PCA weights may provide reasonable approximations for their MPS counterparts. Yet to be determined are the relative precisions of estimators for the three techniques.

In addition to the three basic estimators, a sampling technique called PCA Reduction (Section 4.2) was also described. The primary advantage of PCA Reduction appears to be its potential for reducing the overall sample size required in $P C A$ sampling. Further study is required to determine how the reduction procedure impacts the precision of estimation.

A further complication in implementing IPF sampling is the need for an adjustment of the initial univariate quotas prior to the initial application of IPF. Several potential methods were described in Sections 5.2.1 - 5.2.4. Additional study is required in order to determine the circumstances favoring each technique. The MPS adjustment technique of Section 5.2.3 was used exclusively in the analyses described in Section 7.0. This choice was made primarily to facilitate the comparison of sample weights for the three sampling 
methods, and appeared to be satisfactory in most cases. In practice, one would not typically use MPS adjustment, since Monte Carlo techniques must be used to determine the expected MPS margins. Given the similarity between MPS margins and their easily computed PCA counterparts, one would expect PCA adjustment (Section 5.2.2) to perform similarly.

Analyses of the 1989 EIA-821 frame data for selected states (Section 7) suggest that the three-way stratification procedure used tends to over-stratify the company populations. Use of the pre-1989 five-way stratification can only be expected to increase this over-stratification. Under the 1989 procedure, however, the sampling problem was easily reduced to two dimensions by removal of the nonrespondent stratum and certainty sampling of a small number of companies. This bivariate reduction makes application of any of the three techniques possible. Consideration of alternative stratifications of the frame data seems warranted.

Analyses of the 1989 frame data also pointed out a striking similarity among the sampling weights obtained under MPS, PCA, and IPF sampling. Where the weights differed greatly, further study is needed to determine the exact cause. Since these differences typically occurred when comparing MPS weights with their IPF counterparts, it would be of interest to determine which method produced the best weights, and in what sense they were "best."

Since many of the expected cell sample sizes are small under any of the three sampling schemes, imputation for cell nonresponse is an important issue. Because imputation techniques were only briefly discussed in this document (Section 6), further study is needed in this area as well.

\subsection{TOPICS FOR FUTURE STUDY}

Based on the discussion of Section 8.1, general topics appropriate for further investigation include the following:

- What are the properties of the MPS estimator $V^{\star}$ ? What is the variance of the estimator $\mathrm{VHT}^{*}$ ? How do the estimators compare in mean square error?

- Can a rounding technique be devised which will allow extension of the IPF and PCA techniques beyond the bivariate case? 
- What are the relative precisions of estimators bases on the MPS, PCA, PCA Reduction, and IPF techniques? A simulation study based on frame data would be helpful in answering this question.

- How do the various a priori adjustment techniques for use with IPF sampling perform? Under what conditions is one to be preferred over another?

- Under what conditions will IPF weights more closely approximate MPS weights?

Topics for further study which pertain specifically to the EIA-821 application include the following:

- How many Monte Carlo trials should be used in estimating the MPS sample weights?

- How can the stratification of the sample frames be improved?

- Can the efficiency of the algorithm for computing exact MPS weights be improved in order to extend its usefulness for bivariate tables? Can the algorithm then be extended to multiway tables? Can any limiting results be obtained? 
, 


\subsection{REFERENCES}

Bishop, Y.M.M., S.E. Fienberg, and P.W. Holland. 1975. Discrete Multivariate Analysis: Theory and Practice. MIT Press, Cambridge, Massachusetts.

Bryant, E.C., H.0. Hartley, and R.J. Jessen. 1960. "Design and Estimation in Two-Way Stratification." Journal of the American Statistical Association $55: 105-124$.

Causey, B.D., L.H. Cox, and L.R. Ernst. 1985. "Applications of Transportation Theory to Statistical Problems." Journal of the American Statistical Association 80:903-909.

Chapman, D.W. 1976. "A Survey of Non-Response Imputation Procedures." Proceedings of the American Statistical Association, Survey Research Methods Section, 245-251.

Cochran, W.G. 1977. Sampling Techniques. Wiley, New York.

Cox, B.G. 1989. "Weighting Survey Data." American Statistical Association Continuing Education Program Presentation, 1989 Joint Statistical Meetings.

Cox, L.H. 1987. "A Constructive Procedure for Unbiased Controlled Rounding." Journal of the American Statistical Association 82:520-524.

Cox, L. and L. Ernst. 1982. "Controlled Rounding." INFOR 20:423-432.

Dalenius, T. and J.L. Hodges, Jr. 1959. "Minimum Variance Stratification." Journal of the American Statistical Association 54:88-101.

Deming, W.E. and F.F. Stephan. 1940. "On a Least Squares Adjustment of a Sampled Frequency Table when the Expected Marginal Totals are Known." Annals of Mathematical Statistics, 11:427-444.

Dykstra, R. 1985a. "An Iterative Procedure for 0btaining I-Projections onto the Intersection of Convex Sets." Annals of Probability, 13:975-984.

Dykstra, R. 1985b. "Computational Aspects of I-Projections." Journal Statistical Computing Simulation 21k:265-274.

Dykstra, R.L. 1986. Independent Expert Review of: On Dykstra's Iterative Fitting Procedure. EIA Technical Report.

Goodman, R. and L. Kish. 1950. "Controlled Selection - A Technique in Probability Sampling." Journal of the American Statistical Association 45:350372.

Ireland, C.T. and S. Kullback. 1968. "Contingency Tables with Given Marginals." Biometrika 55:179-188. 
Jessen, R.J. 1970. "Probability Sampling with Marginal Constraints." Journal of the American Statistical Association 65:776-795.

Kish, L. 1965. Survey Sampling. Wiley, New York.

Kokan, A.R. 1963. "Optimum Allocation in Multivariate Surveys." Journal of the Royal Statistical Society A 126:557-565.

Kokan, A.R. and S. Kahn. 1967. "Optimum Allocation in Multivariate Surveys: an Analytic Solution." Journal of the Royal Statistical Society B 29:115-125.

Kullback, S. 1959. Information Theory and Statistics. Wiley, New York.

Neyman, J. 1934. "On the Two Different Aspects of the Representative Method: The Method of Stratified Sampling and the Method of Purposive Selection." Journal of the Royal Statistical Society 97:558-606.

Rao, J.N.K. 1975. "Unbiased Variance Estimation for Multistage Designs." Sankhya-C 37:133-139.

Tepping, B.J., W.N. Hurwitz, W.N., and W.E. Deming. 1943. "On the Efficiency of Deep Stratification in Block Sampling." Journal of the American Statistical Association 45:93-100.

Winkler, W.E. 1986. On Dykstra's Iterative Fitting Procedure. EIA Technical Report.

Winkler, W.E. 1987a. Multi-Purpose Survey Sampling. EIA Technical Report.

Winkler, W.E. 1987b. Multi-Purpose Survey Sampling. EIA Working Document;

Agenda Item 4, American Statistical Association Committee on Energy Statistics. 


\subsection{CITED EIA SOURCES}

Annual Fuel $0 \mathrm{il}$ and Kerosene Sales Report, Form EIA-821. Petroleum Marketing Annual, DOE/EIA-0487, 1989. Petroleum Product Sales Identification Survey, Form EIA-863. Request for OMB Review of the Petroleum Marketing Program, 1987. 
PNL -7338

UC -950

\section{DISTRIBUTION}

No. of

Copies

OFFSITE

M. Welch

Energy Information

Administration

1000 Independence Ave. SW

Washington, DC 20585

2 DOE Office of Scientific and

Technical Information

Y. Bishop

Energy Information

Administration

1000 Independence Ave., SW

Washington, DC 20585

S. Freedman

Energy Information

Administration

1000 Independence Ave., SW

Washington, DC 20585

D. Hale

Energy Information

Administration

1000 Independence Ave., SW

Washington, DC 20585

N. Kirkendall

Energy Information

Administration

1000 Independence Ave., SW

Washington, DC 20585
No. of

Copies

ONSITE

16 Pacific Northwest Laboratory

R. L. Cheatham

A. R. Olsen

R. G. Pratt

T. J. Secrest

W. G. Stillwell

M. A. Williamson (5)

Publishing Coordination

Technical Report Files (5) 


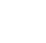

. 